\title{
Punishment and Crime: The Impact of Felony Conviction on Criminal Activity
}

\author{
Osborne Jackson
}

\begin{abstract}
:
This paper uses increases in felony larceny thresholds as a negative shock to felony conviction probability to examine the impact of punishment severity on criminal behavior. In the theft value distribution between old and new larceny thresholds ("response region"), higher thresholds cause a 2 percent increase in the average larceny value within 120 days of enactment. However, within five years of enactment, response region average larceny values and rates decline 2 percent and 13 percent, respectively, in low-wage areas. Thus, under certain market conditions, smaller expected penalties may reduce incentives and deter crime in the long run.
\end{abstract}

JEL Classifications: K14, K42, J22

Keywords: felony conviction, larceny thresholds, crime, theft, labor supply

Osborne Jackson is a senior economist in the research department of the Federal Reserve Bank of Boston; his email is Osborne.Jackson@bos.frb.org.

The author thanks William Brownsberger and Anne Johnson Landry at the Office of Massachusetts State Senator Brownsberger, Colin Clark at the Office of Louisiana Attorney General Jeff Landry, Drema Fouch and Loretta Simmons at the Criminal Justice Information Services Division of the Federal Bureau of Investigation, Rebecca Leonard at the Crime Analysis Unit of the Cambridge Police Department, and numerous additional state and local officials for providing helpful background information regarding legislation, legal practice, or crime data. The author thanks Kevin Behan for initial exploration of National Incident-Based Reporting System data, personnel at the University of Michigan Inter-university Consortium for Political and Social Research and the Western Institutional Review Board for application review allowing for acquisition of National Corrections Reporting Program (NCRP) data, and Randi Cavanaugh, Jones George, Chris Guarente, Teresa Huie, Martha Morrone, Delia Sawhney, Kevin Shruhan, and Henry Szeto for help obtaining and securing NCRP data. The author also appreciates the helpful feedback from María Luengo-Prado, Jeff Thompson, and seminar participants at the Federal Reserve Bank of Boston and the New England Public Policy Center Advisory Board Annual Meeting, as well as beneficial edits from Lawrence Bean. Outstanding research assistance was provided by Thu Tran.

This paper presents preliminary analysis and results intended to stimulate discussion and critical comment. The views expressed herein are those of the author and do not indicate concurrence by the Federal Reserve Bank of Boston, the principals of the Board of Governors, or the Federal Reserve System.

This paper, which may be revised, is available on the website of the Federal Reserve Bank of Boston at https://www.bostonfed.org/publications/research-department-working-paper.aspx.

This version: October 2019

https://doi.org/10.29412/res.wp.2020.01 


\section{Introduction}

Determining the impact of punishment severity on criminal activity is a central question in the area of criminal justice for academics, policymakers, and society. Increases in severity may reduce, escalate, or have no impact whatsoever on crime. Which of those possibilities most closely reflects reality has important implications for determining the optimal structure of punishment in order to maximize welfare. While penalties for a crime committed can take many forms, felony conviction is a major lever at a court's disposal, both in terms of the size of the affected population and the possibility for incarceration.

In the United States, approximately 8 percent of the adult population has a felony conviction and 3 percent of adults have been imprisoned (Shannon et al. 2017). Evidence shows that irrespective of incarceration, a felony record can be a substantial barrier to employment and prompt recidivism (Agan and Starr 2018; Doleac and Hansen forthcoming; Holzer, Raphael, and Stoll 2006; Jackson and Zhao 2016; Pager 2003). Larcenies, in particular, comprise a sizable 11 percent of felony convictions and, similar to crimes in general, may result in incarceration (Rosenmerkel, Durose, and Farole Jr. 2009). ${ }^{1}$ Thus, larceny felony convictions are a key component of total felony convictions, and such penalties can play an important role in the outcomes of offenders and non-offenders in society.

This paper examines the impact of felony conviction on crime using increases in felony larceny thresholds as an exogenous, negative shock to felony conviction probability. Felony larceny thresholds determine the dollar value of stolen property at or above which a larceny offense may be charged in court as a felony rather than a misdemeanor. Since 2000, the majority of US states have changed their felony larceny thresholds, typically raising them (Pew Charitable Trusts 2017). As a result, felony larceny threshold policy actively helps states govern felony convictions, thereby regulating punishment severity.

Due to insufficient data on felony convictions, I focus on estimation of the reduced form

\footnotetext{
${ }^{1}$ For motor vehicle theft in 2000, 73 percent of felony convictions led to incarceration, with 41 percent of felony convictions resulting in prison (Durose and Langan 2003).
} 
impact of felony larceny threshold increases on criminal activity using 2000-2015 incidentlevel data on crimes from the National Incident-Based Reporting System (National Archive of Criminal Justice Data 2018). I use this reduced form result to identify the sign of the second stage effect of felony conviction on crime, thus informing whether increases in punishment severity reduce, escalate, or have zero effect on criminal activity. I cannot determine the magnitude of punishment severity's impact on crime, since data limitations prevent estimation of a first stage effect of felony larceny threshold increases on felony conviction probability. Nevertheless, sign determination of the second stage effect has particular value in this topic area, given mixed findings in the literature. Such findings differ depending on various factors, including the identification strategy, how punishment severity is measured, the type of crime examined, the time horizon and associated impact channels, and offender characteristics (Abrams 2012; Chen and Shapiro 2007; Hansen 2015; Levitt 2004).

To estimate the effect of felony larceny threshold increases on crime, I employ a regression discontinuity (RD) design as well as a difference-in-differences (DD) approach. The RD strategy leverages a discontinuous increase in the larceny threshold value that occurs from one day to the next given policy enactment, assuming other determinants of crime evolve smoothly over the same time period. This research design therefore solely identifies short-run effects. At the cost of potentially stronger assumptions, the DD strategy can additionally identify long-run effects by exploiting differential patterns in larceny activity compared with non-larceny theft activity. Conditional on parallel trends between those two types of crime absent policy enactment, observed deviations from such counterfactual trends following enactment can be attributed to the larceny threshold increase. Additionally, both the RD and DD strategies focus on the theft value distribution between old and new larceny thresholds. This "response region" is where the incentives following enactment to commit larceny of a given stolen value amount are theorized to increase the most, since larceny theft in this region switches from being generally felony-eligible to generally felony-ineligible (that is, typically a misdemeanor). Other parts of the theft value distribution remain either felony-eligible or 
generally felony-ineligible when enactment occurs.

The RD results show that in the short run, within 120 days of enactment, higher felony larceny thresholds cause a small, 2 percent increase $(\$ 20)$ in the response-region average larceny stolen value per incident. This result is robust to several changes in specification and sample, in addition to being absent when I use placebo enactment dates. I find no effects on the average daily jurisdiction larceny rate or probability of larceny occurrence, as well as no effects on larceny stolen values when considering the entire stolen value distribution rather than only the response region. Assuming symmetric but opposite effects of lowering larceny thresholds, the stolen value finding suggests that increasing punishment severity through a higher probability of felony conviction decreases larceny crime in the short run. Also, if "strategically escalating" offenders increase larceny stolen values by the full amount of a threshold increase, these findings imply that 4 percent of response-region offenders increase larceny values in response to higher thresholds in areas experiencing the modal $\$ 500$ threshold increase.

The DD findings indicate that in the long run, within five years of enactment, increases in felony larceny thresholds lead to a 1 percent decrease $(\$ 8)$ in the response-region average larceny stolen value per incident. Additionally, larceny threshold increases cause a 10 percent increase (0.2 incidents per 1 million residents) in the response-region average daily jurisdiction larceny rate and have no impact on the daily jurisdiction larceny probability. In further analysis, I find that these aggregate long-run results mask differential effects by labor market pre-enactment wages, where such wages indicate the scope for offender postenactment labor market improvement. In low-wage areas with high scope, a higher larceny threshold causes a significant decline in larceny stolen values (2 percent) and larceny rates (13 percent). Conversely, in high-wage areas with low scope, a higher larceny threshold leads to a significant increase in larceny rates (19 percent) but has no significant effect on larceny stolen values. The estimated decrease in crime following enactment in low-wage areas is theorized to operate through a higher opportunity cost of legal consumption, which 
itself would result from a post-enactment increase in an offender's legal wage offer given a less severe criminal history. Assuming symmetric but opposite effects of lowering larceny thresholds once again, these results suggest that increasing punishment severity through a higher probability of felony conviction decreases larceny crime in the long run in high-wage labor markets, but it actually increases larceny crime in the long run in low-wage labor markets. Thus, this paper's findings indicate that the impact of punishment severity on criminal activity may vary by time horizon and area.

To further interpret the main findings, I also utilize 2000-2015 offender-level data on prison admissions and releases from the National Corrections Reporting Program (United States Department of Justice 2017). These data allow me to construct incarceration-related measures specific to larceny crime. I generate proxies for criminal justice system "severity" that reflect the probability of prison admission conditional on an incident and average time served conditional on an incident, as well as create a measure of the stock of persons incarcerated. I then examine how changes in the prison stock, as well as justice system severity, vary across enactment in the short run and long run.

Descriptive evidence suggests that justice system severity and persons incarcerated decline in both the short run and long run across enactment. Race-specific results show that pre-enactment larceny admission probability is 2.5 times higher for non-white offenders than white offenders. Across enactment, short-run declines in justice system severity and persons incarcerated are disproportionately larger for non-white offenders, suggesting that diminished larceny punishment benefits this group relatively more. However, long-run declines in the admission probability and incarceration are larger for white offenders, and a long-run increase in the average time served is smaller for that group. Thus, short-run reductions in racial disparities for incarceration-related outcomes associated with reduced punishment severity via larceny threshold increases do not appear to persist in the long run.

In its approach to examining criminal behavior, this study aligns with one by Doleac and Sanders (2015), who explore the impact of the probability of arrest on criminal activity 
by examining daylight-saving-time-induced changes in ambient light. Using RD and DD approaches, they find that the shift to daylight saving time and resulting increase in daylight during certain hours leads to a decrease in robberies. Both the Doleac and Sanders (2015) paper and this paper thus use exogenous policy variation to examine a parameter of a rational offender's utility maximization problem-namely, punishment probability and punishment severity, respectively - and both studies find evidence that the parameter in question affects offender behavior. The incarceration-related analysis in this paper partly aligns with the approach taken by Neal and Rick (2016), who use the same data source to quantify changes in the severity of corrections policies from 1985 through 2005 and how such policy changes differed for blacks compared with whites. Lastly, this study also informs limited existing analysis of felony larceny thresholds and how they relate to larceny and theft rates in US states (Pew Charitable Trusts 2017) as well as theft values, prison admission rates, and sentence duration in North Carolina (Pew Charitable Trusts 2018).

The remainder of the paper is organized as follows. Section 2 provides background on felony larceny threshold policy in the United States and how it relates to felony conviction. Section 3 discusses the conceptual framework regarding the effect on criminal behavior of a change in punishment severity via larceny threshold adjustment. Section 4 describes the data on criminal activity and incarceration. Section 5 outlines the identification strategy for estimating the impact on criminal behavior of reducing felony conviction probability by raising larceny thresholds. Section 6 presents the main findings on criminal activity, and section 7 discusses additional results on incarceration. Lastly, section 8 concludes.

\section{Larceny Thresholds and Felony Conviction}

As mentioned, the dollar value at which the felony larceny threshold is set in a state is directly related to the probability of felony conviction for larceny crimes. Larceny thresholds help determine whether larcenies are charged as felonies and, thus, whether such crimes are 
eligible for felony conviction. As a "direct" penalty, felony conviction may influence the probability of an offender being incarcerated as well as the average time served. Felony offenses typically carry a penalty of at least a year in state prison, whereas misdemeanors usually result in less than a year in a local jail or probation. Additionally, regardless of incarceration, felony conviction may result in various "indirect" penalties for an offender. These penalties may include state-mandated civil "collateral consequences" - for instance, the loss of a professional work license or the loss of voting rights - or other non-mandated consequences, such as barriers to employment due to employer access to criminal records, or social stigma due to general public access to such records. Thus, public policy governing felony larceny thresholds helps determine the number of felony conviction records in a state, thereby contributing to the structure of punishment severity in the criminal justice system.

In the United States, felony larceny thresholds differ across states as well as over time for a given state. ${ }^{2}$ The majority of states adjusted their felony larceny thresholds between 2000 and 2018; only one reform in that period was a downward revision (Jackson and Sullivan forthcoming; Pew Charitable Trusts 2017). ${ }^{3}$ These increases in felony larceny thresholds typify a broader recent trend in states across the country to reform the local criminal justice system in order to address a precipitous rise in mass incarceration and criminalization dating to the 1980s (Neal and Rick 2016). ${ }^{4}$

Policymakers have instituted these higher felony larceny thresholds, in part, to prioritize costly prison space for more serious offenders. Legislators and other advocates also argue that threshold increases ensure that such nominal-value-based penalties account for inflation.

\footnotetext{
${ }^{2}$ For instance, Florida has had a larceny threshold of $\$ 300$ since 1986, raised from $\$ 100$. Florida ranks second only to New Jersey, where the larceny threshold is $\$ 200$, for the lowest threshold in the country as of 2019. In contrast, Texas has a larceny threshold of $\$ 2,500$-more than eight times as high as Florida's threshold - and is tied with Wisconsin for the highest threshold in the nation as of 2019. Texas' relatively high threshold is due to a recent reform in 2015 that raised the threshold from $\$ 1,500$ (Jackson and Sullivan forthcoming; Pew Charitable Trusts 2017).

${ }^{3}$ Maine lowered its threshold from $\$ 2,000$ to $\$ 1,000$ in 2001 .

${ }^{4}$ For example, Massachusetts enacted a comprehensive criminal justice reform in 2018 that includes the first increase in the state's felony larceny threshold since 1987, raising it from $\$ 250$ to $\$ 1,200$ (see Paul C. Dawley, "New Criminal Justice Reform Laws," Trial Court of the Commonwealth District Court Department 2018 Memorandum No. 1229).
} 
These inflation adjustments, they contend, help preserve the relationship over time between crime severity and associated punishment, thus preventing increasingly minor offenses from becoming eligible for a felony conviction record and possible prison time. ${ }^{5}$ For example, Florida has had a larceny threshold of $\$ 300$ since 1986. Adjusted for inflation, a nominal threshold of $\$ 300$ from 1986 would have been equivalent to a nominal threshold of roughly $\$ 680$ in 2018. ${ }^{6}$ Opponents of raising larceny thresholds worry that such policies might worsen crime, particularly larceny crime. ${ }^{7}$ Such concern speaks more broadly to the question of if and how punishment severity - here, operating via felony conviction probability, as affected by larceny threshold policy - alters criminal behavior, which will be discussed further in section 3 .

While felony larceny threshold legislation helps states manage felony convictions, importantly, there are exceptions to felony larceny threshold eligibility. Such exceptions imply that the probability of being charged with a felony - conditional on being arrested for a larceny incident with a sufficiently large stolen value - is neither 0 below the threshold nor 1 at or above the threshold. Such exemption from threshold eligibility may result from at least one of several factors, including characteristics of the larceny offender, victim, stolen property, or incident. ${ }^{8}$ Additionally, differences across states in the severity of the criminal justice system, as reflected in court decisions by judges or prosecutors, may result in a felony-eligible larceny charge being reduced to a misdemeanor, or a generally felony-ineligible misdemeanor charge

\footnotetext{
${ }^{5}$ See Greater Boston Legal Services, "Increase the Felony-Larceny Threshold to $\$ 1,500$ or More," from Massachusetts Legal Aid website, and see Krisai (2017).

${ }^{6}$ Specifically, $\$ 682.08$, according to the Consumer Price Index (CPI) inflation calculator from the Bureau of Labor Statistics, available at https://www.bls.gov/data/inflation_calculator.htm. This calculator uses the CPI for All Urban Consumers (CPI-U) US city average series for all items, not seasonally adjusted. Values listed in the text correspond to December 1986 and December 2018.

${ }^{7}$ See Nick Aresco, "Bill Would Raise Dollar Threshold for Felony Larceny to $\$ 1,200$," from $W W L P$ website; and see Ryan Kearney, "Increasing Felony Threshold for Larceny Represents a Dramatic Raise for Thieves," from Retailers Association of Massachusetts website.

${ }^{8}$ For instance, in New Hampshire, a larceny constitutes a felony irrespective of the stolen property's value if the property stolen is a firearm (class A felony), or if the offender has two prior convictions for "theft of property or services, as a felony or class A misdemeanor" (see New Hampshire 2010 S.B. 205, Regular Session). In Connecticut, a larceny constitutes a felony (class C) regardless of the stolen property's value if "the victim of such larceny is sixty years of age or older or is blind or physically disabled" (see Connecticut 2009 H.B. 6576, Public Act No. 09-138).
} 
being elevated to a felony due to, for example, offender criminal history. ${ }^{9}$ I will exclude legislative exemptions from larceny threshold policy in the preferred estimation sample and then examine sensitivity of the results to such exclusion. I will also explore the role that justice system severity plays in the findings.

\section{Conceptual Framework}

The seminal Becker (1968) model predicts that a rational offender will commit a crime if the expected benefit of doing so exceeds the expected cost. Such a decision thus has implications for the crime rate in an area, or the probability of at least some crime in an area. I additionally focus on an offender's optimal dollar value of stolen property to maximize utility when committing a property crime, which thus has implications for the stolen value per crime incident.

Increasing punishment severity may reduce either the dollar value or amount of criminal activity due to incapacitation and deterrence effects. The incapacitation effect arises from an offender becoming incarcerated and thereby prevented from committing crimes while serving a sentence. The deterrence effect arises from criminal activity becoming less attractive to a forward-looking potential offender due to a fall in the expected net benefit of crime. If increases in penalty severity at least partly reflect increased incarceration, empirical estimates regarding the impact of punishment severity on crime will capture both the incapacitation and deterrence channels (Levitt 2004).

Regarding the deterrence channel, despite this mechanism being theoretically possible, such an effect may not occur in practice, depending on realized values of model parameters. For instance, Lee and McCrary (2017) discuss how large offender discount rates may mitigate the magnitude of deterrence effects. They find evidence in support of this hypothesis, estimating at most a small reduction in criminal behavior when offenders turn 18 and face

\footnotetext{
${ }^{9}$ For instance, regarding Virginia, see Alanna Durkin Richer, "Virginia Is for Felonies? Petty Theft Law from 1980s Sticks," from Associated Press website. Alternatively, for Florida, see Krisai (2017).
} 
harsher penalties upon becoming legal adults. Nevertheless, multiple studies find some evidence of a deterrence effect from an increased probability of offender incarceration, often exploiting sentencing enhancements to identify the effect (Abrams 2012; Drago, Galbiati, and Vertova 2009; Hansen 2015; Helland and Tabarrok 2007; Kessler and Levitt 1999). Moreover, some research finds that greater punishment severity through harsher prison conditions may actually increase crime (recidivism) rather than reduce it (Chen and Shapiro 2007; Drago, Galbiati, and Vertova 2011).

I use a streamlined theoretical framework to guide my analysis of how felony conviction probability governed partly by larceny thresholds may influence criminal activity (see Appendix section A.1). The conceptual framework highlights that it is possible to observe a positive, negative, or nonexistent response of criminal activity - in both stolen property values and the number of incidents - to decreases in punishment severity experienced through increases in felony larceny thresholds. The model shows that, over a long time horizon, a higher opportunity cost of legal consumption when the larceny threshold is raised might sufficiently lower the incentive to commit larceny crime. This higher opportunity cost of legal consumption operates through the decrease in punishment severity (and associated changes in offender criminal history) ultimately increasing legal wage offers. As a result, in the long run, lower punishment severity could deter crime rather than escalate it, analogous to Chen and Shapiro (2007) and Drago, Galbiati, and Vertova (2011). Thus, it remains an empirical question to examine how an increase in the felony larceny threshold will affect outcomes of interest: the stolen value per larceny incident, the larceny incident rate in an area, and the probability of a larceny incident in an area. 


\section{Data on Criminal Activity and Incarceration}

\subsection{NIBRS Crime Data}

Data on US crime incidents come from the National Incident-Based Reporting System (NIBRS) from 2000 through 2015 (National Archive of Criminal Justice Data 2018). ${ }^{10}$ NIBRS data are administered by the Federal Bureau of Investigation (FBI) and contain detailed incident-level data on crimes reported to law enforcement agencies, henceforth "jurisdictions." 11 Jurisdictions can vary in size and level of government, sometimes corresponding to cities, counties, or other governing bodies.

I restrict the sample to jurisdiction-enactment events (Colorado and Louisiana, and jurisdictions therein, each experience two threshold changes during the sample period) that likely correspond to the same geographic area over time and that also meet other desirable criteria, such as having crime reports that span the pre-enactment and post-enactment periods (to allow for within-jurisdiction estimation). ${ }^{12}$ These jurisdiction restrictions, combined with larceny threshold legislation, result in a sample of 22 states and 24 state-enactment events, as indicated in Appendix Table A1. Additionally, regarding theft-related restrictions, the sample excludes incidents with a theft where the theft value is unknown (for instance, credit card

\footnotetext{
${ }^{10}$ The initial year, 2000, aligns with a Pew study documenting felony larceny threshold changes (Pew Charitable Trusts 2017). The final year, 2015, was the last available year of NIBRS data at the start of the project.

${ }^{11}$ Regarding NIBRS, the FBI Uniform Crime Reporting (UCR) Program defines an incident as "one or more offenses committed by the same offender, or group of offenders acting in concert, at the same time and place" (United States Department of Justice 2013). However, the terms "acting in concert" and "same time and place" should be interpreted on a case-by-case basis and thus may differ across cases. For instance, a computer programmer manipulating a bank's computer and embezzling $\$ 70,000$ over an 18 -month period is recommended to be recorded as a single embezzlement incident (United States Department of Justice 2013).

${ }^{12}$ Specifically, within the "time window" relative to enactment that is determined for a given approach to identification (that is, regression discontinuity or difference-in-differences, discussed further in section 5), I exclude jurisdiction-enactment events that meet any of the following criteria: (a) "covers" (reports for) another jurisdiction-enactment event during the sample period, (b) "covered by" (reported for) another jurisdiction-enactment event during the sample period, (c) exhibits any year-to-year absolute population deviations greater than 10 percent, (d) does not report for all months, (e) contains a missing or zero population value, and (f) does not report in both the pre-enactment and post-enactment period. Criteria (a) through (c) determine jurisdiction-enactment events with potentially inconsistent geographic areas over time. I retain jurisdiction-enactment events that, conditional on meeting non-reporting criteria (d), have zero crimes reported throughout.
} 
theft), incidents with a theft where the stolen property is unidentified (since the property may, for instance, have unknown theft value or be exempt from larceny threshold policy), and incidents with multiple types of theft (since theft value is provided only in total, not disaggregated by each type of theft). ${ }^{13}$

Lastly, I impose several sample restrictions motivated by larceny threshold policy, all of which are relaxed during robustness checks in order to examine result sensitivity. First, for incidents involving thefts (larceny or non-larceny), I focus analysis on the theft value distribution between old and new larceny thresholds. The first motivation for this restriction is conceptual. This "response region" is where the incentives to commit larceny of some stolen value amount are theorized to increase the most following enactment, since larcenies in this region switch from being generally felony-eligible to generally felony-ineligible. The second reason for this restriction is empirical. Changes in other larceny penalty thresholds outside of the response region - that is, "within-misdemeanor" or "within-felony" thresholds - often occur simultaneously with changes in the felony larceny threshold and thus may also influence criminal activity. Therefore, focusing on the response region provides the cleanest test of how changes in felony conviction probability via changes in felony larceny thresholds affect offender behavior. In primary analysis, the response region is widened by a $\$ 1$ buffer-from $\$ 1$ below the old felony larceny threshold to $\$ 1$ above the new felony larceny threshold-to allow for minimal offender miscalculation as well as larceny threshold definitional heterogeneity across states. ${ }^{14}$

Additionally, to isolate larceny incidents that are most likely eligible to be affected by felony larceny threshold changes, I exclude larceny incidents that reflect multiple charges, multiple property types, attempted offenses (as opposed to completed offenses), and the listed date as the report date (as opposed to the incident date). ${ }^{15}$ Likewise, to the extent possible,

\footnotetext{
${ }^{13}$ Although it does not result in any sample restrictions, I also exclude seized property values from the calculation of theft values, and re-categorize theft incidents with zero theft values as non-theft incidents.

${ }^{14}$ In some states, the listed felony larceny threshold corresponds to the smallest stolen property value generally eligible for a felony charge, whereas in other states, the listed threshold refers to the largest stolen property value generally eligible for a misdemeanor charge.

${ }^{15}$ These restrictions are also applied to non-larceny thefts in difference-in-difference analysis, since they
} 
given available NIBRS information and as discussed in section 2, I exclude larceny incidents in each state that are exempt from larceny threshold policy due to characteristics of the larceny offender, victim, stolen property, or incident. ${ }^{16}$ Imposing all of the aforementioned sample restrictions except for the "response region" (which will be imposed for estimation), and focusing on larceny incidents that occur in the "short run" (within 120 days before and after enactment), results in 2,193 jurisdictions. ${ }^{17}$ Figure 1 maps coverage of these jurisdictions at the county level. While there are more states in the sample from the western part of the country, states included from the East tend to have a large number of jurisdictions. ${ }^{18}$ Additionally, Figure 2 illustrates how the distribution of felony larceny thresholds changed between 2000 and 2015 for the 22 states in the sample. Over that period, threshold values tended to increase by more than inflation, with the modal state doubling its threshold value from $\$ 500$ to $\$ 1,000$ (see Appendix Table A1).

\subsection{NCRP Incarceration Data}

Data on US prison admissions and releases come from the restricted-access National Corrections Reporting Program (NCRP) from 2000 through 2015 (United States Department of

serve as the control group, to be discussed in section 5. Additionally, regarding multiple charges and property types, I focus on incidents with three or fewer charges and three or fewer property types, as NIBRS has detailed information only for the first three instances of both categories. However, this accounts for nearly all incidents (for instance, roughly 99 percent of incidents have three or fewer charges).

${ }^{16}$ For each state, exemptions from the most recent state-enactment event in the 2000-2015 period are assumed to apply throughout the entire period. I also drop two outlier incidents with extremely large stolen values that could not be verified upon contacting the relevant local law enforcement agencies or through internet search. One case is a 2001 shoplifting incident of $\$ 700$ million in Charleston County, South Carolina, and the other case is a 2011 incident involving $\$ 67,558,237$ in Evangeline Parish, Louisiana. Findings with or without these observations are similar, however, because the response region sample excludes such large stolen values by construction.

${ }^{17}$ Appendix Table A2 shows that restricting the sample to a 120-day bandwidth around enactment has minimal effect on measured criminal activity, while the "response region" restriction expectedly does affect such activity.

${ }^{18}$ Estimation (described in section 5 ) leads to further loss in jurisdiction coverage due to control variables. Following Doleac and Sanders (2015), I use the Law Enforcement Identifiers Crosswalk in 2012 (the latest year available in my 2000-2015 estimation period) to map jurisdictions to counties. Examining the jurisdictions that are in both the 2012 Crosswalk and the 2012 NIBRS data, I find that 96 percent correspond to a single county. Of the remaining jurisdictions spanning multiple counties (4 percent), nearly all of them (95 percent) are mapped to the county with the plurality of the jurisdiction population. Additionally, jurisdictions with "no data" in the map either have no NIBRS data that meet sample inclusion criteria, have no felony larceny threshold change during the estimation period, or both. 
Justice 2017), a period that aligns with the NIBRS data period. NCRP data are administered by the US Bureau of Justice Statistics (BJS) and contain detailed offender-level data on incarceration in state prison facilities collected by state departments of correction. The US Census Bureau served as the data collection agent for the BJS until October 2010, at which point Abt Associates assumed that role (United States Department of Justice 2016).

In recent years, Abt and the BJS have transformed the NCRP from an annual account of prison admissions, releases, and prison stocks into offender prison term records. For offenders with multiple prison terms, their records are linked chronologically to construct term histories. ${ }^{19}$ To build these term histories and attain data consistency, Abt implements various data cleaning procedures - for instance, adjustments for overlapping records - detailed in a series of methodological papers (for example, Rhodes et al. 2012). As a result of these procedures, only a subset of records from the full annual admission, release, and prison stock files are retained to build term histories. ${ }^{20}$ I leverage Abt's data-quality adjustments and use the NCRP term history file from 2000 through 2015 for incarceration-related analysis.

To generate proxies for criminal justice system "severity" that reflect the probability of prison admission per incident and average time served per incident (an incident approximates an offender, the relevant person-level denominator), I restrict NCRP data to align the timing of NIBRS incidents with NCRP admissions. ${ }^{21}$ To do so, I first create a revised NIBRS sample of incidents. In this revised sample, I relax several sample restrictions that are imposed for the main NIBRS analysis but cannot be applied to NIBRS-NCRP analysis, since the necessary information is not available in the NCRP data (see Appendix section A.5). Note that in place of a response region restriction, larceny and non-larceny theft incidents are limited to stolen values above the pre-enactment felony larceny threshold.

\footnotetext{
${ }^{19}$ See the National Archive of Criminal Justice (NACJD), "Resource Guide: National Corrections Reporting Program," from the NACJD website.

${ }^{20}$ In the 2000-2015 period, there are 11,706,501 retained offender records, while 6,373,44 offender records are unused - that is, 65 percent of all 18,079,945 records are retained.

${ }^{21}$ The distribution of offenders per larceny incident in the NIBRS-NCRP joint sample is 1 at the 90th percentile, with a mean of 1.1. One could further assume that prison admission decisions are perfectly correlated among offenders involved in a given incident. However, this stronger assumption is not necessary.
} 
Additionally for the NIBRS-NCRP analysis, I specify observation "cell" dimensions to allow alignment of the NIBRS and NCRP data by offense type, area, time period, and offender demographic group (see Appendix section A.5). The NCRP sample restrictions thus impose the aforementioned revised NIBRS sample restrictions, with proxy measures for justice system severity and the stock of persons incarcerated generated according to the specified cell dimensions. Of the 22 states and 24 state-enactment events in the NIBRS primary analysis sample, 21 states and 23 state-enactment events are in the NIBRS-NCRP analysis sample (no Vermont). Due to NCRP confidentiality obligations, all cell-level data used for analysis reflect counts of at least 11 persons or else are replaced with missing values, along with corresponding values of average time served. ${ }^{22}$

\section{Identifying the Impact of Felony Conviction on Crime}

\subsection{Structural Relationship}

The goal is to understand the impact of some measure of punishment severity, $S$, on various measures of criminal activity, $Y$. When $Y$ is the stolen value per incident, for instance, estimation is at the incident-jurisdiction-day level. Alternatively, when $Y$ is the daily jurisdiction crime rate (the count of incidents on a given day per 1 million residents in a jurisdiction) or daily jurisdiction crime occurrence (a binary indicator of at least one incident existing on a given day in a jurisdiction), then estimation is at the jurisdiction-day level. The measure of punishment severity, $S$, is the probability of felony conviction given an arrest.

When estimation is at the incident-jurisdiction-day level, the felony conviction measure is binary, where $S$ equals 1 if the incident later leads to an arrest that in turn results in a felony conviction, and $S$ equals 0 if the incident later leads to an arrest but does not result in a felony conviction. When estimation is at the jurisdiction-day level, the felony conviction

\footnotetext{
${ }^{22}$ An alternative approach that uses bottom coding to retain such NCRP missing values generally yields similar conclusions in NIBRS-NCRP analysis.
} 
measure is continuous, and $S$ is the daily felony conviction rate (that is, of the incidents occurring on a given day that later lead to arrests, the share of such incidents that result in felony convictions). Thus, for incident $i$ in jurisdiction $j$ on day $t$ :

$$
Y_{i j t}=\xi+\beta S_{i j t}+\mathbf{X}_{j t}^{\prime} \theta+\varepsilon_{i j t}
$$

where $\mathbf{X}$ is a vector of control variables (to be described) that vary across jurisdiction-days but do not vary across incidents within a jurisdiction-day, and $\varepsilon$ is an error term. A similar equation holds at the jurisdiction-day level for crime rate and probability outcomes. ${ }^{23}$ The parameter of interest is $\beta$, which indicates the impact of increased punishment severity on criminal activity - here, the impact of future or expected felony conviction on the current value of property stolen. Given the mixed literature previously discussed, it is of interest to determine the sign of $\beta$, as it could be negative (indicating deterrence), zero (indicating no effect), or positive (indicating escalation).

Because greater criminal activity likely increases the probability of felony conviction, reverse causality will bias ordinary least squares (OLS) estimates of $\beta$. Additionally, comprehensive data are not available across jurisdictions and over time regarding felony convictions, let alone specific to particular incidents that resulted in arrests. ${ }^{24}$ This paper instead utilizes changes in felony larceny thresholds as an exogenous shock to felony conviction probability to help inform parameter $\beta$.

\footnotetext{
${ }^{23}$ The jurisdiction-day analog of equation (1) is $Y_{j t}=\xi+\beta S_{j t}+\mathbf{X}_{j t}^{\prime} \theta+\varepsilon_{j t}$.

${ }^{24}$ The National Judicial Reporting Program is the data source most closely suited to the given estimation needs. Conducted biennially from 1986 through 2006 by the Bureau of Justice Statistics, it is a nationally representative survey with detailed information on the sentences and characteristics of felons convicted in state courts. Unfortunately, the survey's biennial frequency, reporting period, and state-level coverage do not allow it to sufficiently capture the ideal felony conviction measures in this study (Rosenmerkel, Durose, and Farole Jr. 2009).
} 


\subsection{Reduced Form: Regression Discontinuity}

As in Doleac and Sanders (2015), the primary identification approach in this paper is a regression discontinuity $(\mathrm{RD})$ design, where the running variable is days before and after larceny threshold enactment, scaled so that the running variable equals 0 on the day of enactment. I implement various procedures to assess the optimal bandwidth and choice of running variable polynomial order (see Appendix section A.3). I opt for local linear estimation close to the enactment cutoff with a preferred bandwidth of 120 days. This approach also mitigates concerns that global estimation further from the cutoff, even with a flexible, high-order polynomial for the running variable, may lead to biased estimation and inference with poor properties (Gelman and Imbens 2019). I examine sensitivity of the results to alternative bandwidths in later robustness checks. Given such exploration of different bandwidths, I use a uniform (rectangular) kernel throughout all analysis for simplicity and ease of interpretation (Lee and Lemieux 2010).

Ideally, for incident $i$ in jurisdiction $j$ on day $t$, I would estimate the following first stage equation for the felony conviction probability:

$$
S_{i j t}=\omega+\gamma E N A C T_{j t}+\tau_{1} d a y_{j t}+\tau_{2}\left(E N A C T_{j t} \times d a y_{j t}\right)+\mathbf{X}_{j t}^{\prime} \psi+\kappa_{i j t},
$$

where $E N A C T$ is a binary indicator equal to 1 for all days in a jurisdiction on or after enactment, and day is the number of days relative to enactment, as described. ${ }^{25}$ Unfortunately, as mentioned, data limitations prohibit sufficient measurement of felony conviction, $S$. Instead, I estimate via OLS the reduced form impact of larceny threshold enactment on criminal activity:

$$
Y_{i j t}=\alpha+\pi E N A C T_{j t}+\phi_{1} d a y_{j t}+\phi_{2}\left(E N A C T_{j t} \times d a y_{j t}\right)+\mathbf{X}_{j t}^{\prime} \delta+\mu_{i j t} .
$$

\footnotetext{
${ }^{25}$ As noted in Appendix Table A1, Colorado and Louisiana each have two enactment dates during the estimation period. For these states, each state-enactment event is a separate treatment. Also, analogous jurisdiction-day level estimation would predict the daily felony conviction rate using the same regressors in equation (2).
} 
The parameter of interest is $\pi$, which indicates the impact of raising the state larceny threshold on area criminal activity within 120 days of enactment, or roughly four months. In the $\mathrm{RD}$ design, assuming unobservables vary smoothly across the enactment cutoff, $\widehat{\pi}_{R D}$ will consistently estimate $\pi$ over the designated time horizon. This treatment effect not only has direct policy relevance, but it also can provide information on the structural parameter $\beta$, since equations (2) and (3) imply a reduced form model of equation (1), where $\pi / \gamma=\beta$. The magnitude of $\beta$ cannot be determined, since aforementioned data constraints prevent me from estimating $\gamma$. However, it is reasonable to assume that raising a larceny threshold (which $E N A C T=1$ reflects in the estimation sample) lowers the probability of felony conviction for at least some offenders committing incidents that result in arrests, such that $\gamma<0$. Therefore, $\operatorname{sign}(\pi)=-\operatorname{sign}(\beta)$, and symmetric but opposite effects of lowering the state larceny threshold are assumed. Determining the sign of $\beta$ is important, given the mixed evidence in the literature and notably different policy implications regarding how punishment severity affects crime.

As in Doleac and Sanders (2015), the use of time as the running variable here might cause concern that some assumptions of the RD design do not hold, even given discontinuous larceny threshold enactment. The controls in $\mathbf{X}$ are included in estimation to address such concerns, thus mitigating potential bias if correlated with enactment or attempting to improve precision by explaining some residual variation in criminal activity. Because crime patterns might differ on holidays or weekends, compared with weekdays, due to changes in offender or victim behavior, I include controls for major holiday indicators and day-of-week indicators. ${ }^{26}$ I also control for first-of-month indicators, since larceny threshold enactment often falls on the first of the month due to state legislative cycles, which might coincide with factors that affect crime (for instance, income). Lastly, I control for jurisdiction-byyear-by-quarter indicators to allow for mean differences in crime across jurisdictions at a

\footnotetext{
${ }^{26}$ Major holidays are defined as New Year's Day, Easter Sunday, Memorial Day, Fourth of July, Labor Day, Thanksgiving, and Christmas Day.
} 
relatively narrow time frequency. ${ }^{27}$ These fixed effects also help account for inflation increasing nominal stolen values even absent changes in offender behavior, as well as potential jurisdiction-level changes in the criminal justice system-for instance, changes in law enforcement funding that could alter policing and cause variation in arrests per incident before and after enactment. ${ }^{28}$ Like Doleac and Sanders (2015), I do not control for population, since jurisdiction-by-year-by-quarter fixed effects account for such demographic change. However, I do weight jurisdiction-day-level analysis by the annual jurisdiction population relevant to a jurisdiction-day in a given calendar year. ${ }^{29}$ In both incident-jurisdiction-day estimation and jurisdiction-day estimation, I cluster standard errors at the jurisdiction level to allow for within-jurisdiction correlation over time in the error term. I examine tests regarding whether covariates in $\mathbf{X}$ are balanced across enactment, as well as whether running variable density is smooth across enactment (see Appendix section A.3). Both tests are intended to inform whether the identifying assumption of "smooth unobservables" is reasonable and, ultimately, to support the validity of the RD design here (Lee and Lemieux 2010). ${ }^{30}$

\footnotetext{
${ }^{27}$ Given the large number of fixed effects to estimate, to improve computational speed I rely on the Stata command reghdfe, which implements an estimator described in Correia (2016).

${ }^{28}$ Consider $F=R S$, where $R$ is the probability of arrest given an incident (as in Appendix section A.1), $F$ is the probability of felony conviction given an incident, and both $F$ and $R$ are measured at the incident level. In this expression, $S$ is defined only for incidents where an arrest is made, while $F$ is defined for all incidents and can be 0 either due to no arrest or no felony conviction given an arrest. Thus, it is important to control for any variation in arrest behavior across enactment in order to interpret the results as informative of punishment severity alone and not also punishment probability (as reflected by arrest probability). I do not attempt to control for arrests per incident directly, because although some incidents in NIBRS contain arrest status, such information is not always available, which may be due to an arrest never occurring or the absence of a NIBRS incident update by law enforcement.

${ }^{29}$ Such weighting is intended to correct for heteroskedasticity, assuming that more populous jurisdictions tend to have more incidents, all else being equal, and that the group (jurisdiction-day) component of the composite error term is relatively small (Solon, Haider, and Wooldridge 2015). Accordingly, incidentjurisdiction-day-level regressions do not require such weighting.

${ }^{30} \mathrm{An}$ alternative identification approach might be an RD design that compares the amounts of criminal activity above and below the level of the felony larceny threshold (similar to Hansen 2015). However, larceny stolen values are manipulable if offenders are strategic, thus invalidating such an RD design. Even if a "bunching" approach were pursued instead given such manipulability, forming credible counterfactual densities for larceny stolen values might be challenging, especially if cross state variation were utilized in the absence of jurisdiction fixed effects (only Colorado and Louisiana have multiple enactments within the 20002015 estimation period). Lastly, the implied policy question from such an approach - namely, the impact on crime of the existence of a felony larceny threshold rather than a change in the threshold - is also of less interest since every US state already has a felony larceny threshold in effect. Current debate surrounds the questions of if and how to adjust such thresholds, not whether to create or remove them.
} 
Using an RD design as the primary approach has the advantage of credible quasiexperimental identification (Lee and Lemieux 2010). However, because the running variable is in "event time" with the event being enactment, even with controls included, such an approach identifies only short-run effects near the enactment cutoff. If the short-run and long-run effects of raising the state felony larceny threshold differ, perhaps due to changes over time in offender policy knowledge or employer access to offender criminal records, then RD estimates of short-run effects cannot be extrapolated to the long run. To examine longrun effects, I turn to a difference-in-differences approach.

\subsection{Reduced Form: Difference-in-Differences}

The secondary identification approach is difference-in-differences (DD). I focus on estimation with a window of 1,800 days (or approximately five years) before and after larceny threshold enactment. Non-larceny theft incidents - that is, burglary, robbery, and other theft- serve as the control group for larceny incidents. ${ }^{31}$

As in the RD design, because felony conviction probability is unobserved, I once again focus on OLS estimation of the reduced form impact of larceny threshold enactment on criminal activity. For incident $i$ in jurisdiction $j$ on day $t$ :

$$
Y_{i j t}=\zeta+\eta E N A C T_{j t}+\lambda L A R C E N Y_{i j t}+\pi\left(E N A C T_{j t} \times L A R C E N Y_{i j t}\right)+\mathbf{X}_{j t}^{\prime} \omega+\nu_{i j t},
$$

where $E N A C T$ has the same definition as in the RD approach but now indicates the DD post period, $L A R C E N Y$ is a binary indicator equal to 1 for observations reflecting larceny outcomes (the DD treatment group) rather than non-larceny theft outcomes (the DD control group), and other variables are as defined before. ${ }^{32}$ Once again, jurisdiction-day estimation

\footnotetext{
${ }^{31}$ The following types of crimes are included in "other theft," since they all have a stolen value available in the NIBRS data: counterfeiting/forgery, embezzlement, extortion/blackmail, fraud, kidnapping/abduction, stolen property offenses, and bribery (with the caveat that bribery could reflect a voluntary monetary exchange).

${ }^{32}$ Because Colorado and Louisiana each have two enactment dates during the estimation period, further details are needed to define the pre-period and post-period in each case. The pre-period of the first legislation
} 
(with both larceny and non-larceny theft observations) is defined analogously, and in both incident-jurisdiction-day and jurisdiction-day estimation, I again cluster standard errors at the jurisdiction level.

In addition to following the sample restrictions discussed in section 4, I further restrict non-larceny thefts in order to improve comparability with larceny thefts. Specifically, I exclude non-larceny thefts that reflect multiple charges, multiple property types, attempted offenses, and the listed date as the report date. Additionally, to further mitigate concerns regarding non-random selection of larceny incidents in the treatment group, I use inverse probability weighting to weight larceny and non-larceny theft incidents by the inverse probability of an observation being in the treatment or control group, respectively, based on observable characteristics (see Appendix section A.4). ${ }^{33}$

The parameter of interest is once again $\pi$, which now indicates the impact of raising the state larceny threshold on area criminal activity within 1,800 days of enactment. In the DD design, assuming that average outcomes of larceny and non-larceny theft follow similar, parallel counterfactual trends in the absence of treatment, $\widehat{\pi}_{D D}$ will consistently estimate $\pi$ over the given time horizon. I examine a test of whether the "parallel trends" assumption, which focuses on comparing pre-enactment average outcomes of larceny and non-larceny theft, seems likely to hold (see Appendix Figure A5). The results of this test support the validity of the DD design here. That said, because the "parallel trends" assumption for DD may be stronger than the "smooth unobservables" assumption for RD, the latter approach is preferable for identifying short-run treatment effects, despite DD being capable, in theory, of identifying both short-run and long-run effects. ${ }^{34}$

occurs for all days in the sample period prior to enactment, while the post-period of the first legislation begins on the day of enactment and ends the day prior to enactment of the second legislation. The pre-period of the second legislation is the same as the post-period of the first legislation, while the post-period of the second legislation occurs for all days in the sample period on or after enactment.

${ }^{33}$ In jurisdiction-day estimation, the incident-level inverse probability weights are used to rescale incidents and then aggregate these weighted incidents up to the jurisdiction-day level. Analysis is then once again weighted by the annual jurisdiction population relevant to each jurisdiction-day.

${ }^{34}$ Identification of short-run treatment effects via RD relies on larceny crime counterfactually evolving smoothly across enactment in the absence of treatment. In contrast, identifying short-run treatment effects via DD relies on larceny crime counterfactually evolving similarly (but not necessarily smoothly) to non- 


\section{Main Results on Criminal Activity}

\subsection{Regression Discontinuity}

To give a broad illustration of the RD approach, Figure 3 displays the stolen value distribution for larceny incidents occurring within 120 days of enactment (roughly four months) for two treatment states, Vermont and Connecticut (with the day of enactment counted as "after enactment"). The figure provides initial, suggestive evidence that the average stolen value per incident in the response region might experience a small, short-run increase following enactment. The figure also demonstrates the empirical benefit of focusing on the response region given potentially confounding, simultaneous changes to other penalty thresholds in some states.

Figure 4 depicts unconditional, local linear estimates for the larceny stolen value per incident, daily jurisdiction rate of larcenies per 1 million residents, and daily jurisdiction probability of larceny occurrence in the response region (including the default $\$ 1$ buffer). ${ }^{35}$ There is a discernible increase in the response-region average larceny stolen value within 120 days of enactment, but no such changes in the larceny rate or probability. Table 1 provides analogous local linear regression estimation of RD equation (3), both without and with controls. The table shows that the unconditional short-run increase in the responseregion average larceny stolen value in Figure 4 is about $\$ 14$, whereas the corresponding increase conditional on controls is similar but somewhat larger at $\$ 20$ (2 percent of the preenactment mean) and is also now statistically significant. Irrespective of controls, there is no detectable effect of enactment on the short-run daily jurisdiction larceny rate or probability. Also, consistent with a valid RD design, coefficients are similar with or without controls,

larceny theft crime across enactment in the absence of treatment. While it is not definitive which assumption is stronger in the short run, the DD assumption requires predictions on non-larceny theft in addition to larceny and thus seems more substantial.

${ }^{35}$ The plots use a bandwidth of 120 days, a uniform kernel, and a bin width of 24 days. Each observation reflects the average outcome value within a bin, with averages for rate and probability outcomes weighted by the applicable annual jurisdiction population. The choice of bin width is guided by informal (ocular) and formal procedures (Lee and Lemieux 2010). However, qualitative conclusions are similar even with an alternative choice of bin width, as Appendix Figure A3 shows. 
although estimate precision is affected. ${ }^{36}$ Additionally, I find that there is no significant effect of raising the larceny threshold on crime for non-larceny theft or non-theft offenses (see Appendix Table A3). ${ }^{37}$

Assuming symmetric but opposite effects of lower larceny thresholds, the estimated 120day modest increase in the response-region average stolen value per incident suggests that increasing punishment severity through a higher probability of felony conviction slightly decreases larceny crime in the short run. For some context to the treatment effect magnitude, consider for example Connecticut, where an increase of $\$ 20$ in the larceny stolen value per incident would equal an average annual cost of $\$ 0.08$ per person and $\$ 264,460$ for the entire state population. ${ }^{38}$ To further interpret the stolen value result, it is helpful to assume that "strategically escalating" offenders increase larceny stolen values by the full amount of a felony larceny threshold increase. Given a modal threshold increase in the estimation sample of $\$ 500$, these findings thus imply that approximately 4 percent of response-region offenders escalate larceny crime in response to lower thresholds, while the remaining 96 percent of offenders do not change their short-run behavior in response to the suggested decrease in felony conviction probability.

\footnotetext{
${ }^{36}$ As discussed earlier, there are also more jurisdictions in the rate and probability specifications because some jurisdictions never have any incidents during the estimation period. However, as expected given an absence of variation in the outcomes, restricting the larceny rate and probability samples to the same jurisdictions present in the larceny stolen value sample results in nearly identical effects of enactment on the larceny rate and probability ( -0.083 and -0.007 , respectively, with controls).

${ }^{37}$ To the extent that larcenies are "complements" with or "substitutes" for certain other types of crime, detecting such effects is constrained to patterns across incidents since the sample is restricted to reflect single-charge incidents for reasons discussed earlier.

${ }^{38}$ I use the Connecticut subset of the 2,477 jurisdictions in the Table 1 rate and probability analysis, which is inclusive of jurisdictions with only non-larceny theft incidents. I retain all of the restrictions imposed for analysis except the "response region" and the 120-day RD bandwidth restrictions, thus allowing me to calculate statistics for a more representative sample of incidents in Connecticut and examine the 2000-2015 period. Using this sample, there is a 2000-2015 average of 0.003679 incidents per resident in Connecticut, resulting in an average annual cost per person of $0.003679 \times \$ 20.364=\$ 0.075$ (with the caveat that such an out-of-sample prediction, from 120 days to one year, assumes a linear treatment effect over time). To obtain a total cost of $\$ 264,460$ for all state residents, I then further multiply $\$ 0.075$ by $3,529,941$ persons, the 2000-2015 average of annual Connecticut population estimates from the US Census Bureau.
} 


\subsection{Robustness Checks}

As the first three specifications of Table 2 show by adjusting bandwidth size, the short-run larceny stolen value effect grows over time somewhat linearly following enactment, although the effect is not significant in the alternative, smaller bandwidths. If the coefficients are taken seriously and once again interpreted as reflecting the share of response-region offenders who escalate criminal activity following enactment, this offender share rises from 1 percent (30 days) to 4 percent (120 days, as discussed). Such dynamics are consistent with offenders learning about the policy over time, further emphasizing the need for the alternative, DD identification approach to estimate long-run effects, since it may be problematic to extrapolate the short-run results to a longer time horizon.

The short-run larceny stolen value finding is also robust to several changes in specification and sample. Table 2 shows that the effect is even slightly larger with a response region buffer of $\$ 10$ rather than $\$ 1$, which may be consistent with offender miscalculation or purposeful deviation given risk preferences or justice system severity. However, when a larger buffer of $\$ 100$ is used or the full, unbounded stolen value distribution is examined, the estimated stolen value effect is not significant, although the "unbounded" results are fairly imprecise. Both results, especially the one involving the full stolen value distribution, may partly or wholly reflect confounded estimates due to simultaneous changes in "within-misdemeanor" or "within-felony" larceny penalties.

Nevertheless, one can take the "unbounded" finding at face value, along with the absence of effects on the larceny rate and probability, and assume minimal effects of "within-severity" larceny threshold changes that occur outside of the response region. Upon doing so, the "unbounded" result suggests that felony larceny threshold increases cause responding offenders to reallocate their labor supply toward alternative larceny stolen values without affecting the average larceny stolen value overall or otherwise altering the amount of larceny crime they commit. ${ }^{39}$ The main stolen value result is also robust to ignoring state-specific exemptions to

\footnotetext{
${ }^{39}$ I attempted to estimate stolen value effects for different definitions of "within-misdemeanor" and "within-
} 
larceny threshold policy, to making different assumptions regarding how such state-specific exemptions should be applied, and to estimation using a "broad" sample of larceny incidents that, similar to legislative exemptions, may not be as affected by larceny threshold policy. Specifically, this "broad" sample includes larceny incidents with multiple charges, multiple property types, attempted offenses, and the listed date as the report date. The last specification in Table 2 reflects a falsification test in which I estimate results for a placebo RD bandwidth that shifts the actual RD bandwidth to 121 days earlier. This shift results in the last day of the placebo bandwidth being one day before the true enactment date in a given jurisdiction. There is no evidence of the main stolen value result being present in this placebo sample. ${ }^{40}$ I also examine heterogeneity of the short-run stolen value result by offender age, race, and gender, but find no notable differential patterns. However, I find limited evidence that larger proportional increases in larceny thresholds drive the stolen value result (see Appendix Table A5).

\subsection{Difference-in-Differences}

To examine long-run crime effects of reductions in felony conviction probability through larceny threshold increases, I turn to the DD approach. ${ }^{41}$ Figure 5 shows unweighted and inverse-probability-weighted 30-day average stolen values in the response region for larceny and non-larceny theft within 1,800 days (roughly five years) of enactment. ${ }^{42}$ The top panel

felony." However, I was unable to detect significant evidence that reallocation of criminal activity was more likely to occur in either "within-severity" region, suggesting perhaps that offenders are equally likely to relocate to the response region from higher or lower stolen values in the distribution.

${ }^{40}$ Complete results for this falsification test in Appendix Table A4 also show that there are no significant effects in the placebo sample on the larceny rate or probability, and that the null placebo effects are not simply an artifact of a difference in the included jurisdiction-enactment events in the placebo sample compared with the Table 1 sample.

${ }^{41}$ Appendix Table A6 shows that a short-run DD stolen value effect is positive, like the analogous RD coefficient, albeit smaller in magnitude and not significant, perhaps reflecting a stronger DD identifying assumption.

${ }^{42}$ Average stolen values trend downward in Figure 5 due to changing composition of state-enactment events over time. When the same plot is examined separately by state, the resulting state-specific figures cease to have a downward trend (for an example, see Appendix Figure A2). Similarly, large declines in average stolen values between $-1,080$ and -720 days from enactment and between 720 and 1,080 days from enactment are due to changes in sample composition. Specifically, the pre-enactment decline is driven by 
of Figure 5 shows that even without the application of inverse probability weights, average stolen values for non-larceny theft closely track the same outcome for larceny preceding enactment. However, using inverse probability weights helps address some pre-enactment divergence in larceny and non-larceny theft. This weighting adjustment permits clearer interpretation of post-enactment patterns showing a decline in larceny stolen values relative to non-larceny theft stolen values (Appendix Figure A5 formally depicts the presence of parallel pre-enactment trends).

Table 3 presents corresponding regression estimation of DD equation (4) with inverse probability weighting and controls. Large p-values for an F-test of pre-enactment 360-day period DD coefficients in a dynamic analog of equation (4) being jointly equal to 0 (relative to the year before enactment) suggests that the DD parallel trends assumption may hold for the larceny stolen value and rate outcomes, but it may be more questionable for the larceny probability outcome. The results in the table are mixed, showing evidence of a long-run significant decrease in larceny stolen values within 1,800 days of enactment, but a significant increase in larceny rates over that time horizon. The response-region average larceny stolen value per incident falls $\$ 8$ (1 percent of the pre-enactment mean), but the response-region average daily jurisdiction larceny rate rises by 0.2 incidents per 1 million residents (10 percent of the pre-enactment mean). There is no detectable effect of enactment on the long-run daily jurisdiction larceny probability.

These estimated 1,800-day changes in the response-region average larceny stolen value and average larceny rate suggest that increasing punishment severity through a higher probability of felony conviction both decreases and increases larceny crime in the long run, varying by the measure of crime. To reconcile these seemingly disparate results, I refer back to

Washington joining the sample in the noted interval (response region average stolen values associated with Washington are low given a felony larceny threshold that changed from $\$ 250$ to $\$ 750$ ), while the postenactment decline is driven by Colorado (2013) leaving the sample in the noted interval (response region average stolen values associated with Colorado [2013] are high given a felony larceny threshold that changed from $\$ 1,000$ to $\$ 2,000$ ). Appendix Figure A1 shows that removing Colorado (2013) and Washington from the sample eliminates the aforementioned large declines in average stolen values. In estimation, the inclusion of jurisdiction-by-year-by-quarter fixed effects mitigates such compositional issues. 
the conceptual framework. I theorize that greater punishment severity could increase crime through a decrease in legal market consumption resulting from diminished wage offers due to a more severe criminal history. Thus, assuming symmetric but opposite effects, a reduction in punishment severity from a higher felony larceny threshold could decrease crime. In such a scenario, offenders with a greater scope for post-enactment wage increases should demonstrate long-run declines in larceny activity. And conversely, offenders with less scope for post-enactment wage increases may exhibit no change in larceny activity or increases in such activity. Thus, the mixed results in Table 3 may be masking differential offender responses that vary by labor market conditions.

Table 4 explores the presence of heterogeneous long-run treatment effects by different measures of labor market "scope." The first set of results examines wages, as discussed, while the second set of results alternatively examines unemployment rates. Both proxies are measured at the county level, matched to jurisdictions, and constructed as indicators for the pre-enactment jurisdiction mean being at or below the median value across jurisdictions (wages), or above the median value across jurisdictions (unemployment rate). ${ }^{43}$ Low wages, and possibly high unemployment rates, should indicate greater scope for post-enactment labor market improvement, thus implying negative sign predictions for the corresponding DD interaction terms.

Regarding response heterogeneity by labor market wages, Figure 6 visually depicts the differential effects of Table 4. As the results show, in low-wage jurisdictions, larceny stolen values and larceny rates both significantly decrease on average, by $\$ 17$ (2 percent of the preenactment mean) and 0.3 incidents per 1 million residents (13 percent of the pre-enactment mean), respectively. Conversely, in high-wage jurisdictions, there is no significant change in average larceny stolen values, and there is a significant increase in average larceny rates of 0.4 incidents per 1 million residents (19 percent of the pre-enactment mean). Thus, while the aggregate findings in Table 3 were mixed across larceny crime outcomes, the findings

\footnotetext{
${ }^{43}$ Focusing on versions of these measures relative to the median is preferable to alternatives if additional spatial and temporal variation is noisy.
} 
disaggregated by wages indicate a consistent pattern across larceny crime outcomes for a given type of labor market. Additionally, the presence of this heterogeneous effect in the long run is consistent with potential changes over time in the visibility to employers of offender punishment severity (using offender criminal records, for instance, as described in Appendix section A.5), with the duration of such visibility likely increasing to some degree as severity increases. ${ }^{44}$ Lastly, Table 4 shows that results are qualitatively similar when unemployment rates instead of wages are used as the measure of labor market scope. However, the findings are generally larger in magnitude and more likely to be significant when examining wage heterogeneity, thus providing support for the conceptual framework's focus on wages as the key mechanism driving labor market heterogeneity. ${ }^{45}$

As with the aggregate small short-run increase in larceny stolen values due to larceny threshold enactment, it is beneficial to contextualize the treatment effect size of the long-run increase in larceny rates that occurs in high-wage areas. Using Connecticut as an example again, an increase in the daily larceny rate of about 0.4 incidents per 1 million residents would equal 142 incidents per 1 million residents over an entire calendar year, an approximate 3.9 percent increase in larceny crime for the entire state. ${ }^{46}$ While such crime escalation is

\footnotetext{
${ }^{44}$ For instance, the "look-back" period for convicted crimes where criminal records are not eligible to be sealed or expunged and are thus more easily accessible by employers is typically a shorter amount of time for misdemeanors than felonies. In Connecticut, for instance, the waiting period to apply for criminal record expungement is three years from the disposition date for a misdemeanor and five years from the disposition date for a felony (see "Is Your Criminal Record Keeping You from Working?" from the CTLawHelp.org website, posted in 2018).

${ }^{45}$ In Appendix Table A7, I also examine both short-run and long-run heterogeneous effects using the NIBRS-NCRP justice system severity proxies discussed in section 4. Such proxies might partly reflect the probability of felony conviction conditional on an arrest, thus capturing the extent to which offenders, before enactment, are likely to face felony convictions given an arrest (that is, indicating how binding the preenactment felony larceny threshold is). However, results for such analysis are largely inconclusive, which may be due in part to the proxies also partly reflecting the probability of arrest given an incident and the probability of admission given felony conviction. Similarly, in Appendix Table A8, when I interact the labor market scope proxies in Table 4 with the justice system severity proxies in Appendix Table A7, I find qualitatively similar but weaker patterns compared to Table 4. Lastly, I also attempt to use educational attainment information from the NCRP data to proxy for offender knowledge of larceny threshold policy and examine heterogeneous effects along this dimension. However, because schooling is a very imperfect measure of larceny policy knowledge, this education proxy yields no insights regarding how offender knowledge affects short-run and long-run responses to enactment.

${ }^{46}$ As before, I use the Connecticut subset of the 2,477 jurisdictions in the Table 1 rate and probability analysis, which is inclusive of jurisdictions with only non-larceny theft incidents. I once again retain all of the restrictions imposed for analysis except the "response region" and the 120-day RD bandwidth restrictions,
} 
not trivial, it is smaller than the 13 percent increase in the larceny rate that is implied when the treatment effect base is the average pre-enactment larceny rate in the response region. Moreover, such larceny crime escalation in high-wage labor markets would need to be considered along with fiscal gains from a potential reduction in incarceration due to higher felony larceny thresholds. ${ }^{47}$ Thus, I turn next to descriptive analysis of the relationship between higher felony larceny thresholds and incarceration.

\section{Additional Results on Incarceration}

Table 5 describes how justice system severity and incarceration change across enactment. Absent controls, I restrict the sample to a balanced panel of 8 (short-run) to 11 (long-run) states (also resulting in the same number of state-enactment events) in order to ensure that changes in sample composition over time have a minimal effect on the descriptive statistics. ${ }^{48}$

thus allowing me to calculate statistics for a more representative sample of incidents in Connecticut and examine the 2000-2015 period. Using this sample, there is a 2000-2015 average of 3,679 incidents per 1 million residents in Connecticut. To obtain the increase in larceny crime implied by the offender response in high-wage labor markets, I multiply 0.390 incidents per 1 million residents by 365 calendar days, resulting in an annual increase of 142 incidents per 1 million residents. I then further divide 142 incidents per 1 million residents by 3,679 incidents per 1 million residents in the state.

${ }^{47}$ Given an estimated reduction in larceny crime from higher felony larceny thresholds in low-wage labor markets, which distinctly benefits both non-offenders and offenders (due to an assumed increase in legal market consumption in the latter case; increased illegal market consumption has no effect on social welfare since it is assumed to have an equal but opposite effect on the welfare of non-offenders), the policy has definitive social welfare gains regardless of any fiscal savings from a potential reduction in incarceration.

${ }^{48}$ With the exception of the "persons in custody" measure, the eight short-run balanced panel stateenactment events are Illinois, Montana, New Hampshire, Ohio, Oregon, South Carolina, Utah, and Washington. For the short-run persons in custody measure and all long-run measures, the 11 balanced panel state-enactment events are the eight typical short-run state-enactment events, plus Colorado (2007), Kentucky, and South Dakota. These states contain admissions (larceny or non-larceny theft) and incidents (larceny or non-larceny theft, in at least one jurisdiction) in every 120-day period (24 total) over the examined +/-1,440-day range of event time. The disparity of three state-enactment events between the typical short-run and long-run samples is due to a combination of small, 120-day period larceny counts surrounding enactment in those areas and data censoring due to NCRP confidentiality obligations. Additionally, due to such obligations, a missing count sometimes occurs for a given cell combination of state-enactment event $\times$ period $\times$ offense type (larceny or non-larceny theft) $\times$ incarceration-related measure. Such missing values cause the underlying balanced panel sample of state-enactment events reflecting a given statistic in Table 5 to deviate sometimes from the previously stated sample counts (that is, $8 \mathrm{SR}$ state-enactment events and 11 LR state-enactment events). Thus, the balanced panel samples in the descriptive analysis mitigate but do not eliminate bias due to compositional changes. However, because missing cell values due to NCRP confidentially restrictions occur only for counts at or below 10 persons, such compositional bias will tend to be small and can be bounded. Additionally, such compositional changes driven by missing values always reduce 
Focusing on the justice system severity measures first: in the short-run, 120-day period preceding enactment, 3.7 percent of larceny incidents (or approximate larceny offenders) are admitted to prison. Within 120 days of enactment, this larceny admission probability falls to 3.3 percent, a reduction of 0.4 percentage point (11.0 percent). Similarly, average time served per larceny incident, roughly 0.04 years in the 120-day period just before enactment, falls about 0.02 years (44.8 percent) in the short run. In the long run (using outcomes for nonlarceny theft in Appendix Table A9 for an approximate difference-in-differences estimate), the larceny admission probability falls more than in the short run-1.0 percentage point net of non-larceny theft trends (26.3 percent, using the long-run pre-enactment larceny mean as the base). Conversely, in the long run, average time served per incident increases roughly 0.02 years (58.6 percent). Turning to incarceration: the stock of larceny offenders in custody is 5,243 persons in the short-run, 120-day period preceding enactment. Following enactment, this offender count declines by 159 persons (3.0 percent) in the short run, and in the long run net of non-larceny counts, it declines by 755 persons (15.4 percent). Appendix section A.5 shows that regression analysis of conditional incarceration outcomes with fixed effects yields qualitative conclusions that are mostly similar to those of the aforementioned descriptive analysis of unconditional outcomes. ${ }^{49}$

Thus, in aggregate, there is descriptive evidence that both justice system severity and incarceration typically decline across enactment. However, while the long-run declines in larceny admission probability and incarceration seem to exceed the analogous short-run declines, the short-run decline in mean time served stands in contrast to the long-run increase in this measure. It is unclear what accounts for this long-run versus short-run disparity, as

the sample count from the previously stated sample counts. For instance, for persons in custody in the short run, the pre-enactment period value is missing for South Dakota. Thus, the SR difference in this measure between the pre-enactment period and post-enactment period is subject to a small amount of composition bias that can be bounded at 10 persons, or roughly 6 percent of the observed short-run difference in Table 5. Finally, I was also able to replicate the main RD and DD results with these respective samples. In the case of the long-run sample, such replication was not feasible when using a sample that was balanced over a $+/-1,800$-day range of event time.

${ }^{49}$ Given these generally similar qualitative findings, as well as estimation limitations that prevent interpretation of the regression analysis with controls as definitively causal (see Appendix section A.5), basic descriptive analysis is preferred. 
well as for the observed results more generally. However, earlier analysis suggests that long-run increases in time served per incident may perhaps be driven by an escalation in larceny activity across enactment in some labor markets. ${ }^{50}$ It is also possible that other factors contribute to the observed pattern in Table 5, such as changes in some stage(s) of the criminal justice system.

I also examine the descriptive statistics in Table 5 for demographic subgroups by race, age, and gender (see Appendix Tables A12 through A17). In the short-run, 120-day period preceding enactment, 2.5 percent of larceny incidents by white offenders result in prison admission, compared with 6.3 percent for non-white offenders. This is the largest disparity in the larceny admission probability among the demographic subgroups. The disparity between offenders aged 0 to 44 and offenders aged 45 and over is 3.2 percent versus 6.9 percent, respectively, while the female-male disparity is 2.0 percent versus 4.5 percent, respectively. For three demographic subgroups these larceny admission probability disparities shrink in the short run - for instance, a relative decline of 22.2 percent for the non-white larceny admission probability compared with the white probability (on a short-run, pre-enactment non-white base) - but such gains are diminished or reversed in the long run. ${ }^{51}$ Similar patterns tend to occur for average time served and incarceration in the demographic subgroups. For instance, net of non-larceny theft trends, non-white offenders experience short-run relative declines in average time served and the number of offenders in custody of 46.9 percent and 2.4 percent, respectively. However, in the long run, those same measures increase for nonwhite offenders relative to white offenders 78.0 percent and 22.3 percent, respectively (on a long-run, pre-enactment mean non-white base). Thus, short-run reductions in incarcerationrelated demographic disparities associated with larceny threshold increases do not appear to persist in the long run. ${ }^{52}$ The long-run reversal in group disparity patterns is sometimes

\footnotetext{
${ }^{50}$ Although, as a caveat, the 1,800-day long-run time horizon in the earlier criminal activity causal results only approximately aligns with the 1,440-day time horizon in the current incarceration descriptive results.

${ }^{51}$ For example, net of non-larceny theft trends, the long-run larceny admission probability increases by 19.0 percent for non-white offenders relative to white offenders.

${ }^{52}$ I also examine these demographic subgroup results while stratifying the short-run and long-run samples of states by state-level wage and unemployment rate labor market "scope" measures similar to those used for
} 
partly driven by worsened incarceration outcomes, relative to the short run, for offenders who are non-white, aged 45 and over, or male. ${ }^{53}$

\section{Conclusion}

This paper uses exogenous increases in felony larceny thresholds to examine how punishment severity via changes in felony conviction probability affects criminal activity and incarceration-related outcomes. I find evidence of effects that differ by time horizon and area. Within 120 days, larceny threshold enactment leads to a small increase in larceny activity, suggesting that greater punishment severity slightly reduces crime in the short run. However, within roughly five years, enactment causes a decline in larceny activity (stolen value and rates) in low-wage areas where there is scope for offender labor market improvement, and an increase in larceny activity (rates) in high-wage areas where there is less scope for such improvement. The findings for low-wage areas indicate that, in some cases, greater punishment severity may increase crime in the long run. The results also suggest a negative short-run and long-run relationship between enactment and justice system severity as well as incarceration, with the sole exception of a positive long-run relationship for average time served per incident. However, short-run reductions in disparities regarding these incarceration-related outcomes across demographic groups do not seem to persist in the long run.

These findings suggest that the impact of punishment severity - namely, felony conviction probability - on criminal activity may differ by time horizon and labor market. Such differential temporal and area effects should thus be taken into account when determining the

heterogeneity analysis in Table 4. I find that the stratified demographic subgroup descriptive findings tend to be larger in magnitude for results in states with pre-enactment average wages at or below the median, as opposed to states with such wages above the median. Findings in each of the unemployment rate strata are more mixed but still generally match the aggregate demographic subgroup patterns.

${ }^{53}$ For instance, regarding race-specific analysis and admissions per incident, the short-run decline is 1.9 percent for white offenders and 23.0 percent for non-white offenders. Meanwhile, the long-run decline in this outcome, net of non-larceny theft patterns, is 59.3 percent for white offenders and 8.6 percent for non-white offenders. 
optimal structure of punishment. How social welfare is affected by short-run versus long-run outcomes, and by a focus on low-wage versus high-wage areas, may influence whether it is welfare-improving to increase or decrease punishment severity. For instance, even for highwage areas that might experience a long-run increase in larceny rates following enactment of a higher felony larceny threshold, a back-of-the-envelope cost-benefit analysis suggests that the average annual cost that would be incurred by a state for such crime escalation $(\$ 0.9$ million) is likely exceeded by the average annual benefit that would accrue to the state from incarceration savings (\$3.1 million). ${ }^{54}$ That said, given the results, further consideration by state governments might also weigh how decreasing punishment severity affects not only the level of social surplus, but also how such surplus is allocated across offenders with differing demographics.

\footnotetext{
${ }^{54}$ To calculate the benefit of a higher larceny threshold that results from incarceration savings, I first obtain an estimate from the Bureau of Justice Statistics of corrections-related expenditures by states in 2015 (from "Justice Expenditure and Employment Extracts, 2015 - Preliminary" [Table 4]). Likewise from the Bureau of Justice Statistics, I obtain an estimate of the total state prison offender count in 2015 (from the National Prisoner Statistics [sum across gender of "total under custody"]). Dividing the expenditure total, $\$ 51,728,476,000$, by the offender count total, $1,162,365$ persons, I obtain an estimate of the average expenditure per offender for a given state of $\$ 44,502.78$. Next, although not causal, from Table 5 of this paper's analysis, I use the long-run, annual average decrease regarding offenders in custody of 754.5 persons, further dividing that number by the 11 states in the long-run NIBRS-NCRP balanced sample, resulting in a state average decrease of 68.59 offenders. Multiplying ( $\$ 44,502.78$ per offender $\times 68.59$ offenders), I obtain an estimate of the average annual incarceration savings for a state implementing a higher larceny threshold, equal to $\$ 3,052,446$. To calculate the cost of a higher larceny threshold that results from a higher larceny rate (in a high-wage labor market), I multiply the estimated coefficient ( 0.390 daily incidents per 1 million residents) by 365 days, obtaining an annual treatment effect of 142 incidents per 1 million residents. Using US Census Bureau data, I obtain the average 2015 population across the 50 states, $6,404,525$ persons. Multiplying the annual treatment effect by the 2015 average state population results in $([142 / 1,000,000] \times$ $6,404,525)=909.44$ incidents per year in an average state. Further multiplying by $\$ 1,042.73$ (this paper's estimate of the long-run average stolen value of a response-region larceny incident in the pre-enactment period, from Table 3; this is the relevant incident value to align with the estimated larceny rate treatment effect) yields an estimate of the average annual dollar increase in larceny crime for a state implementing a higher larceny threshold, equal to $\$ 948,300$.
} 


\section{References}

Abrams, David S. 2012. "Estimating the Deterrent Effect of Incarceration Using Sentencing Enhancements." American Economic Journal: Applied Economics 4(4): 32-56.

Agan, Amanda, and Sonja Starr. 2018. "Ban the Box, Criminal Records, and Racial Discrimination: A Field Experiment." Quarterly Journal of Economics 133(1): 191-235.

Becker, Gary S. 1968. "Crime and Punishment: An Economic Approach." Journal of Political Economy 76(2): 169-217.

Calonico, Sebastian, Matias D. Cattaneo, Max H. Farrell, and Rocio Titiunik. 2017. "Robust Data-Driven Inference in the Regression-Discontinuity Design." Stata Journal 17(2): 372404.

Cattaneo, Matias D., Michael Jansson, and Xinwei Ma. 2018. "Manipulation Testing Based on Density Discontinuity." Stata Journal 18(1): 234-261.

Chen, M. Keith, and Jesse M. Shapiro. 2007. "Do Harsher Prison Conditions Reduce Recidivism? A Discontinuity-based Approach." American Law and Economics Review 9(1): $1-29$.

Correia, Sergio. 2016. "Linear Models with High-Dimensional Fixed Effects: An Efficient and Feasible Estimator." Working Paper. Durham, NC: Duke University.

Doleac, Jennifer L., and Benjamin Hansen. Forthcoming. "The Unintended Consequences of 'Ban the Box': Statistical Discrimination and Employment Outcomes when Criminal Histories are Hidden." Journal of Labor Economics.

Doleac, Jennifer L., and Nicholas J. Sanders. 2015. "Under the Cover of Darkness: How Ambient Light Influences Criminal Activity." Review of Economics and Statistics 97(5): 1093-1103.

Drago, Francesco, Roberto Galbiati, and Pietro Vertova. 2009. "The Deterrent Effects of Prison: Evidence from a Natural Experiment." Journal of Political Economy 117(2): $257-280$.

Drago, Francesco, Roberto Galbiati, and Pietro Vertova. 2011. "Prison Conditions and Recidivism." American Law and Economics Review 13(1): 103-130.

Durose, Matthew R., and Patrick A. Langan. 2003. "Felony Sentences in State Courts, 2000." Bureau of Justice Statistics Bulletin. Washington, DC: Bureau of Justice Statistics.

Gelman, Andrew, and Guido Imbens. 2019. "Why High-order Polynomials Should Not Be Used in Regression Discontinuity Designs." Journal of Business \&6 Economic Statistics 37(3): 447-456.

Hansen, Benjamin. 2015. "Punishment and Deterrence: Evidence from Drunk Driving." American Economic Review 105(4): 1581-1617. 
Helland, Eric, and Alexander Tabarrok. 2007. "Does Three Strikes Deter: A Non-Parametric Investigation." Journal of Human Resources 42(2): 309-330.

Holzer, Harry J., Steven Raphael, and Michael A. Stoll. 2006. "Perceived Criminality, Criminal Background Checks, and the Racial Hiring Practices of Employers." Journal of Law and Economics 49(2): 451-480.

Imbens, Guido, and Karthik Kalyanaraman. 2012. "Optimal Bandwidth Choice for the Regression Discontinuity Estimator." Review of Economic Studies 79(3): 933-959.

Jackson, Osborne, and Riley Sullivan. Forthcoming. "The Impact of Felony Larceny Thresholds on Crime in New England." Research Report. Boston, MA: Federal Reserve Bank of Boston.

Jackson, Osborne, and Bo Zhao. 2016. "The Effect of Changing Employers' Access to Criminal Histories on Ex-offenders' Labor Market Outcomes: Evidence from the 20102012 Massachusetts CORI Reform." Working Paper 16-30. Boston, MA: Federal Reserve Bank of Boston.

Kessler, Daniel P., and Steven D. Levitt. 1999. "Using Sentence Enhancements to Distinguish between Deterrence and Incapacitation." Journal of Law and Economics 42(1): 343-363.

Krisai, Lauren. 2017. "Stuck in the 80s: Time for Reform of Florida's Felony Theft Threshold." The Journal of the James Madison Institute (Spring).

Lee, David S., and Thomas Lemieux. 2010. "Regression Discontinuity Designs in Economics." Journal of Economic Literature 48(2): 281-355.

Lee, David S., and Justin McCrary. 2017. "The Deterrence Effect of Prison: Dynamic Theory and Evidence." In Regression Discontinuity Design: Theory and Applications (Volume 38 in the Advances in Econometrics Series), edited by Mattias D. Cattaneo and Juan Carlos Escanciano, 73-146. Bradford, UK: Emerald Publishing.

Levitt, Steven D. 2004. "Understanding Why Crime Fell in the 1990s: Four Factors that Explain the Decline and Six that Do Not." Journal of Economic Perspectives 18(1): 163-190.

Ludwig, Jens, and Douglas L. Miller. 2007. "Does Head Start Improve Children's Life Chances? Evidence from a Regression Discontinuity Design." Quarterly Journal of Economics 122(1): 159-208.

National Archive of Criminal Justice Data. 2018. "National Incident-Based Reporting System, 2000-2015: Extract Files." Ann Arbor, MI: Inter-university Consortium for Political and Social Research [distributor], 2009-09-14-2018-10-05.

Neal, Derek, and Armin Rick. 2016. "The Prison Boom and Sentencing Policy." Journal of Legal Studies 45(1): 1-41. 
Pager, Devah. 2003. "The Mark of a Criminal Record." American Journal of Sociology 108(5): 937-975.

Pew Charitable Trusts. 2017. "The Effects of Changing Felony Theft Thresholds." Chartbook, April. Philadelphia, PA: The Pew Charitable Trusts.

Pew Charitable Trusts. 2018. "South Carolina Reduced Theft Penalties While Safely Cutting Prison Population." Brief, March. Philadelphia, PA: The Pew Charitable Trusts.

Rhodes, William, Gerald Gaes, Tom Rich, Yuli Almozlino, Mica Astion, Ryan Kling, Jeremy Luallen, Kevin Neary, and Michael Shively. 2012. "National Corrections Reporting Program (NCRP) White Paper Series, White Paper \# 1: Observations on the NCRP." Cambridge, MA: Abt Associates Inc.

Rosenmerkel, Sean, Matthew Durose, and Donald Farole Jr. 2009. "Felony Sentences in State Courts, 2006." Bureau of Justice Statistics Statistical Tables. Washington, DC: Bureau of Justice Statistics.

Shannon, Sarah K.S., Christopher Uggen, Jason Schnittker, Melissa Thompson, Sara Wakefield, and Michael Massoglia. 2017. "The Growth, Scope, and Spatial Distribution of People with Felony Records in the United States, 1948-2010." Demography 54(5): 17951818.

Solon, Gary, Steven J. Haider, and Jeffrey M. Wooldridge. 2015. "What Are We Weighting For?" Journal of Human Resources 50(2): 301-316.

United States Department of Justice. 2013. "National Incident-Based Reporting System (NIBRS) User Manual (Version 1.0)." Washington, DC: Federal Bureau of Investigation.

United States Department of Justice. 2016. "National Corrections Reporting Program, 20002015 Codebook." Ann Arbor, MI: Inter-university Consortium for Political and Social Research.

United States Department of Justice. 2017. "National Corrections Reporting Program, 2000-2015." Office of Justice Programs. Bureau of Justice Statistics. Ann Arbor, MI: Inter-university Consortium for Political and Social Research [distributor], 2017-06-22. https://doi.org/10.3886/ICPSR36746.v1. 


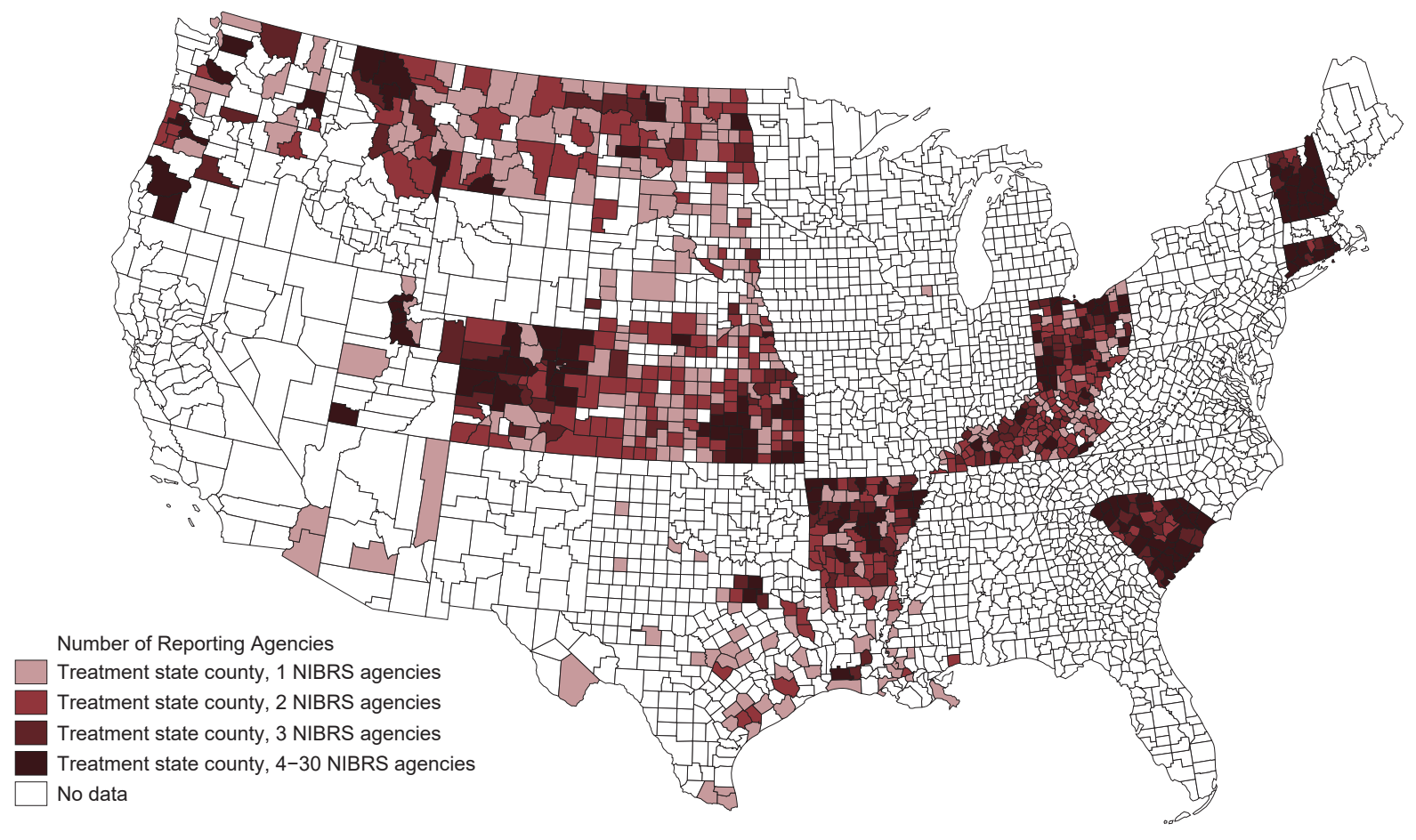

Figure 1: Jurisdictions with Larceny Incidents in Short-Run Sample, 2000-2015 by County Source(s): State legislation, National Incident-Based Reporting System data, and author's calculations. Note(s): "Short-Run Sample" reflects 120 days surrounding the applicable day of enactment for each jurisdiction. The resulting sample of larceny incidents corresponds to 2,193 jurisdictions. 
Distribution of Felony Larceny Thresholds in 2000

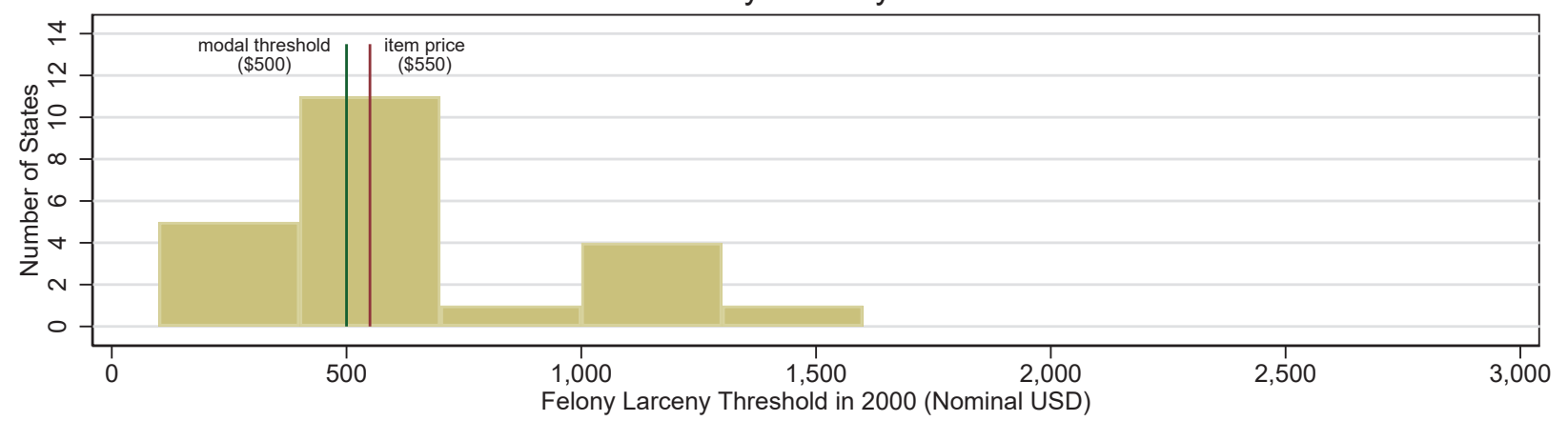

Distribution of Felony Larceny Thresholds in 2015

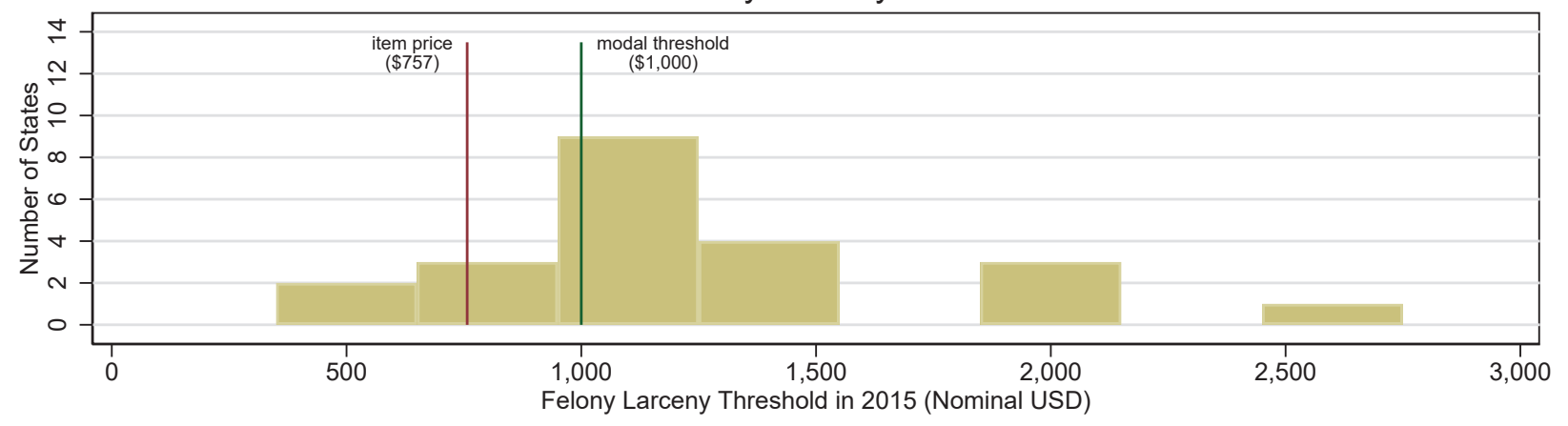

Figure 2: Variation in Larceny Thresholds, 2000 and 2015

Source(s): State legislation, Bureau of Labor Statistics' Consumer Price Index inflation calculator, and author's calculations.

Note(s): "Item price" reflects a hypothetical product with a constant real value over time. 


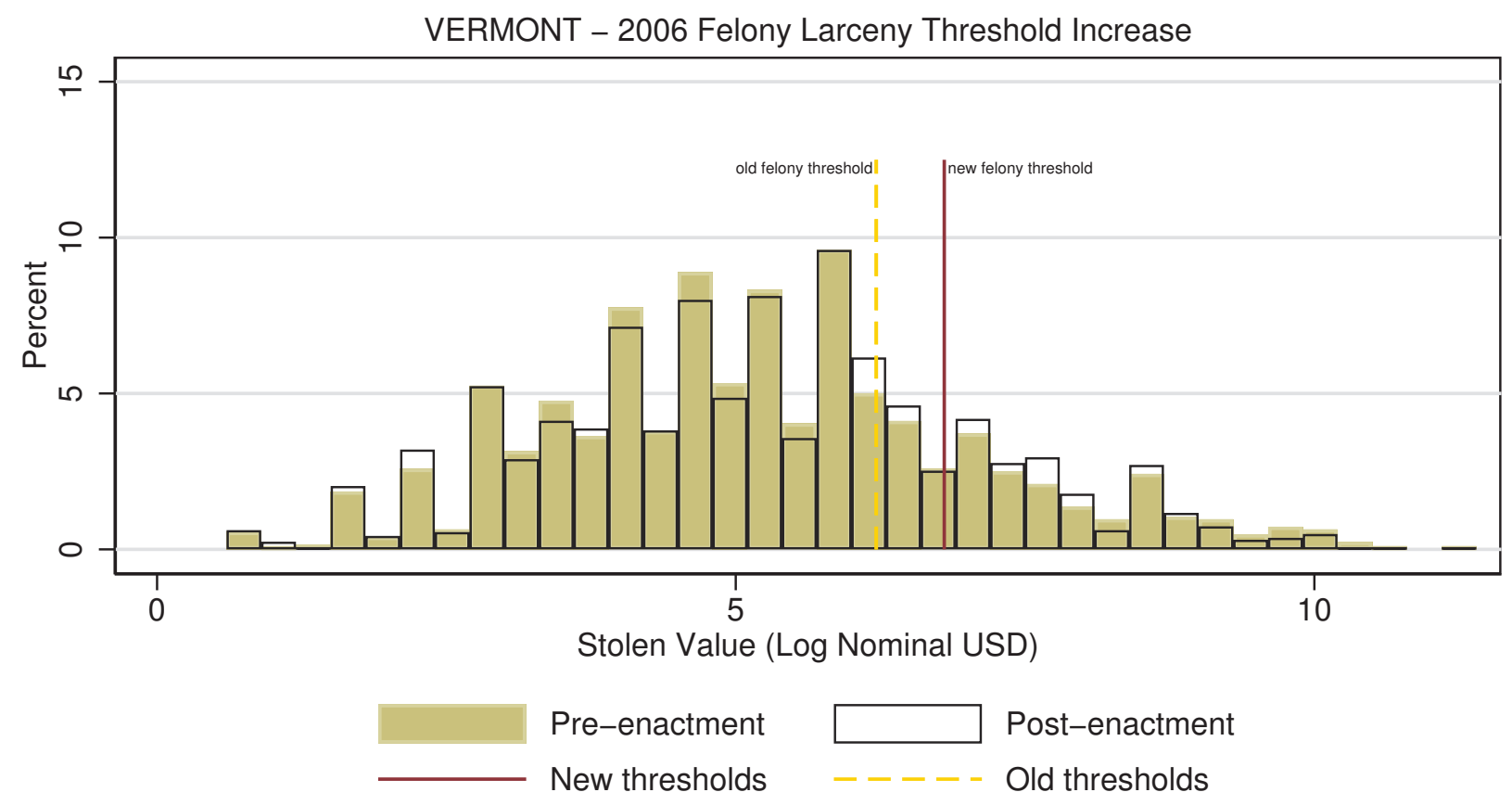

Number of incidents 120 days before enactment: 1,237

Number of incidents 121 days after enactment: 1,624

Total number of incidents: 2,861

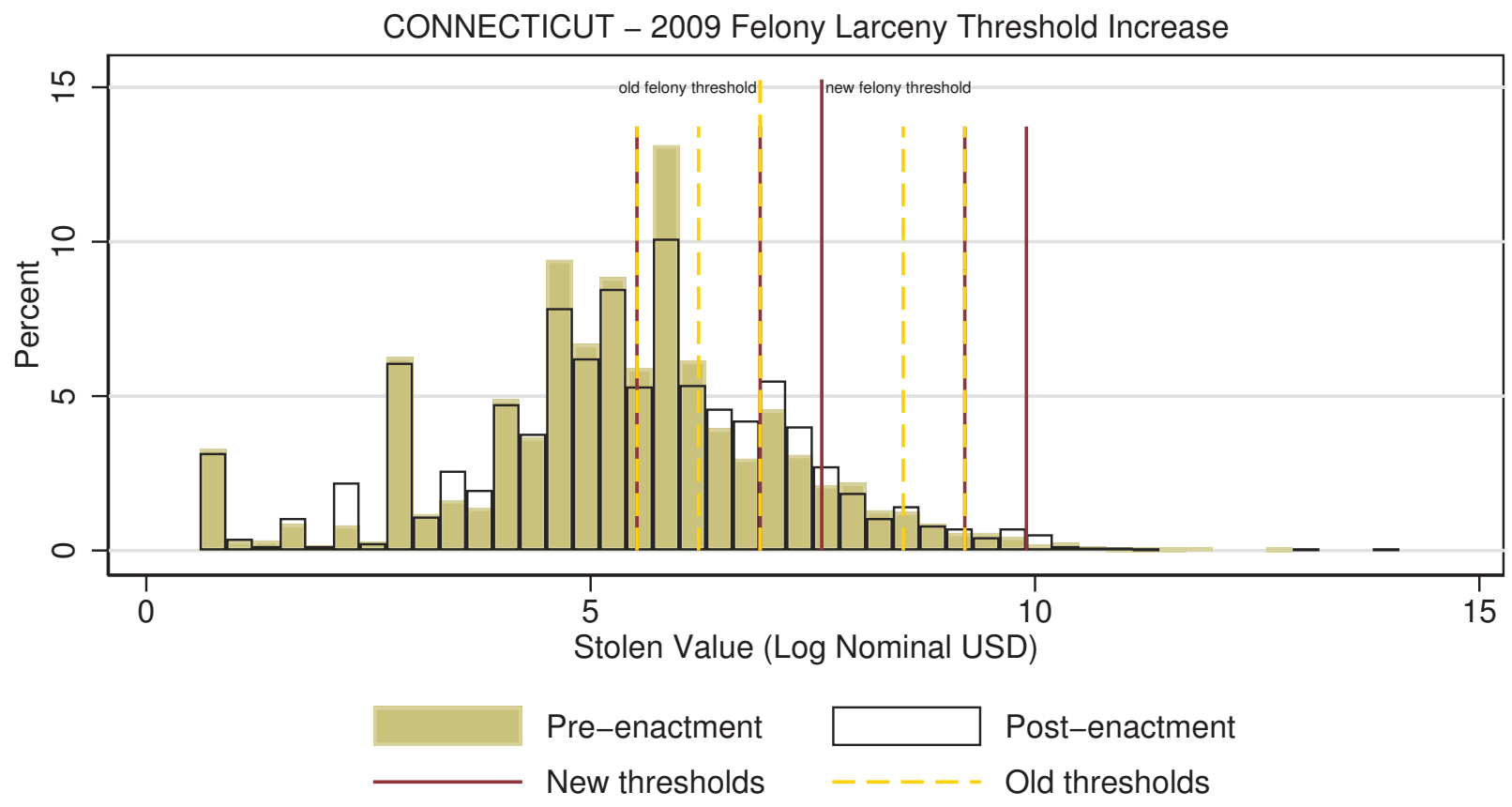

Number of incidents 120 days before enactment: 2,453

Number of incidents 121 days after enactment: 2,089

Total number of incidents: 4,542

Figure 3: Distribution of Stolen Values, Vermont and Connecticut

Source(s): State legislation, National Incident-Based Reporting System data, and author's calculations. 


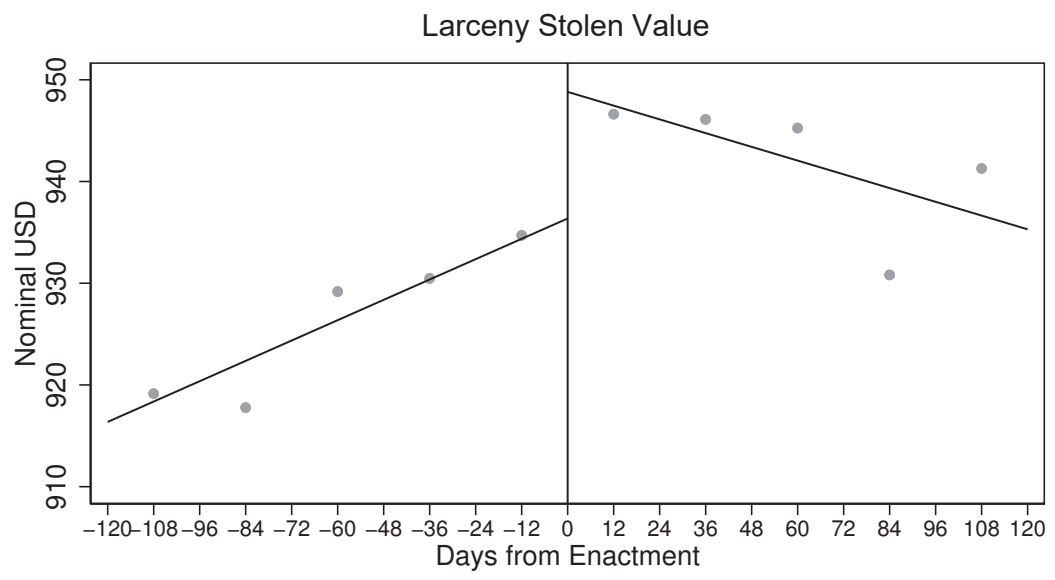

- Sample average within bin $\quad$ Polynomial fit of order 1

Bin width $=24$ days

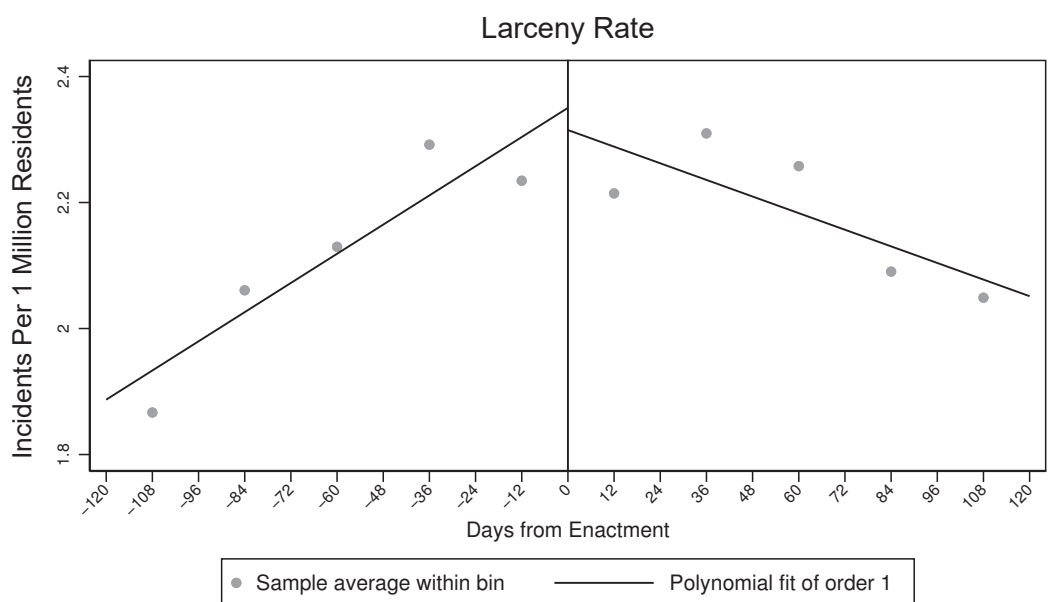

Bin width $=24$ days

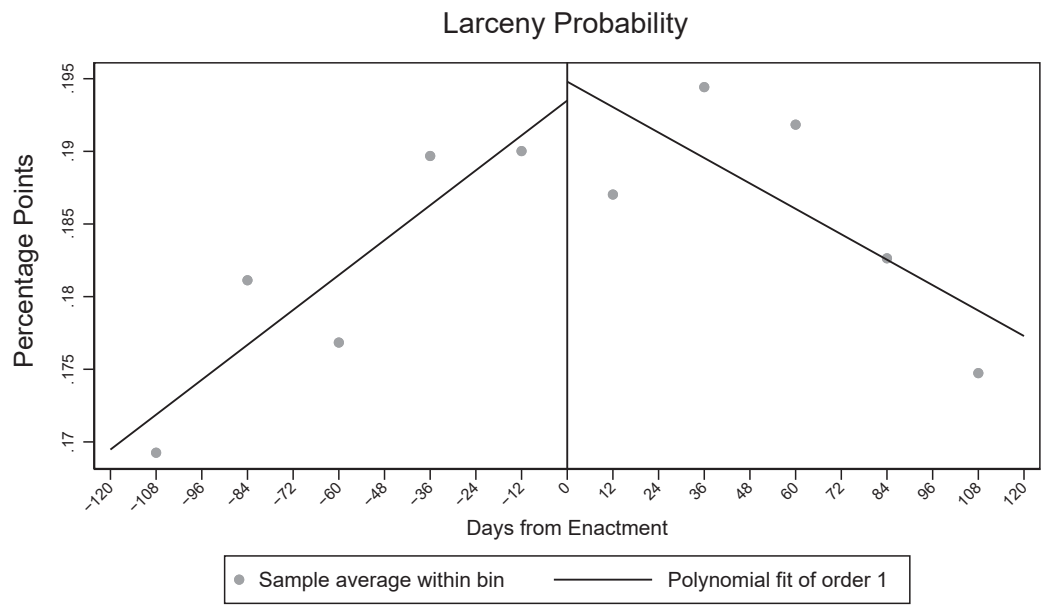

Bin width $=24$ days

Figure 4: RD Plots-Larceny Stolen Value, Rate, and Probability

Source(s): State legislation, National Incident-Based Reporting System data, and author's calculations. 

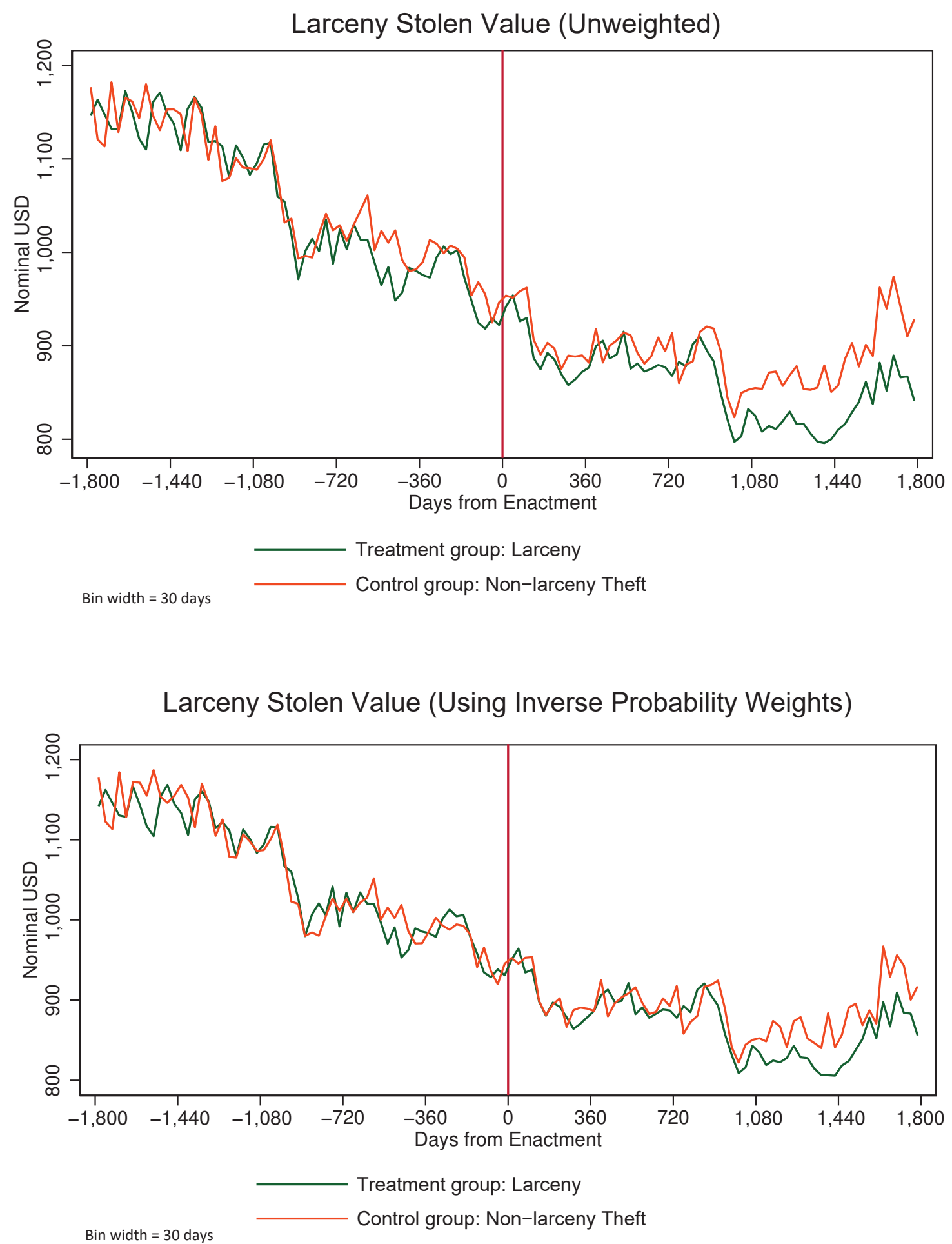

Figure 5: DD Plots - Larceny Stolen Value (Unweighted and IPW)

Source(s): State legislation, National Incident-Based Reporting System data, and author's calculations. 


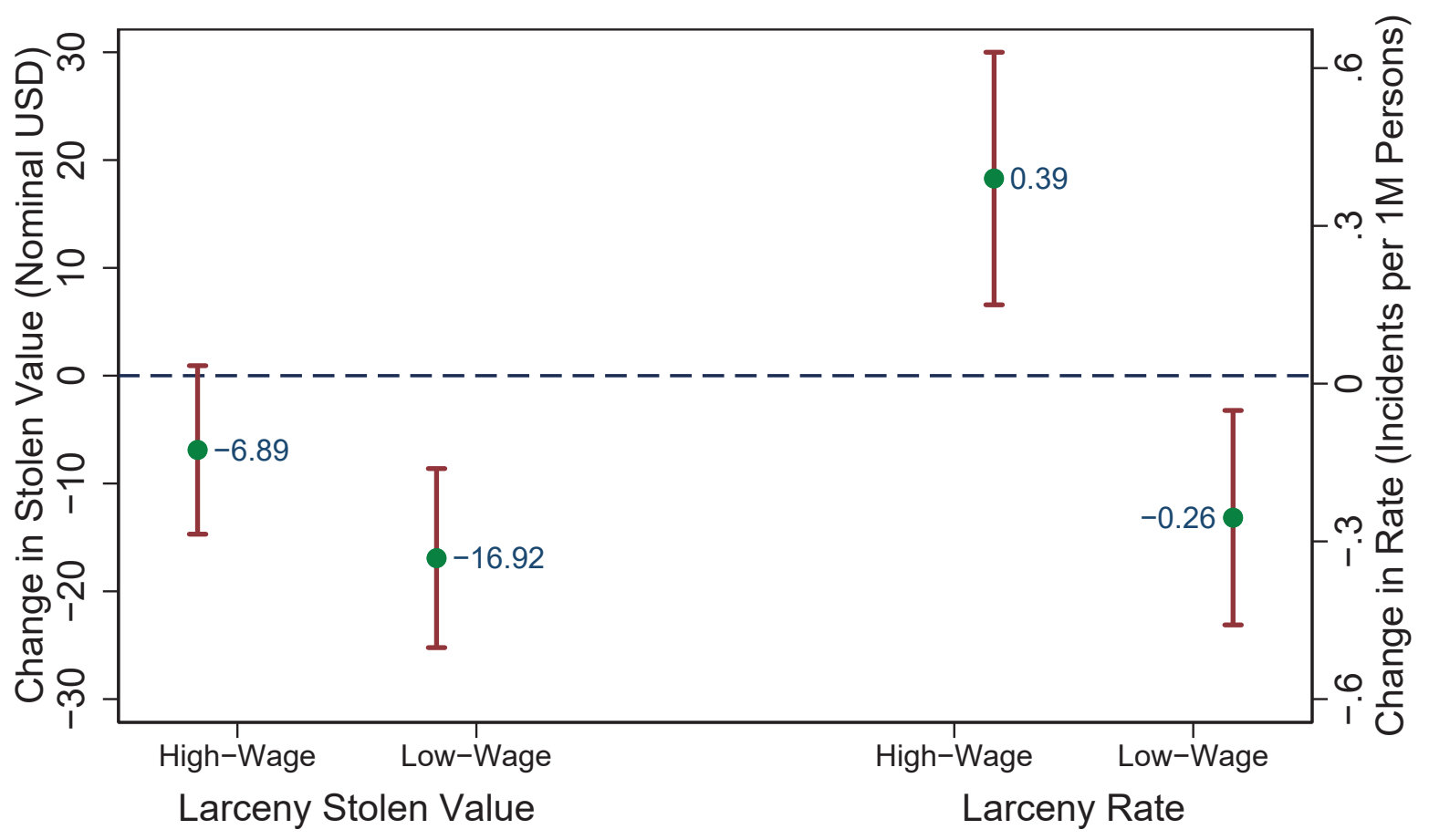

- Estimate $\longmapsto 90 \%$ Confidence Interval

Figure 6: The Long-Run Impact of Felony Larceny Threshold Enactment on Larceny Crime, by Labor Market Wages

Source(s): State legislation, National Incident-Based Reporting System data, Bureau of Labor Statistics wage data (Quarterly Census of Employment and Wages), and author's calculations. 
Table 1: The Short-Run Impact of Larceny Threshold Enactment on Larceny

\begin{tabular}{lcccccc}
\hline & \multicolumn{3}{c}{ Stolen Value } & \multicolumn{2}{c}{ Rate } & \multicolumn{2}{c}{ Probability } \\
\hline Enactment & 13.949 & $20.364^{* *}$ & -0.030 & -0.077 & 0.001 & -0.006 \\
& $(14.619)$ & $(9.857)$ & $(0.068)$ & $(0.079)$ & $(0.005)$ & $(0.006)$ \\
& & & & & & \\
Controls & No & Yes & No & Yes & No & Yes \\
Pre-enactment mean & 930.76 & 930.76 & 2.12 & 2.12 & 0.18 & 0.18 \\
R-sq & 0.00 & 0.76 & 0.00 & 0.05 & 0.00 & 0.45 \\
Observations & 22,556 & 22,556 & 626,321 & 626,321 & 626,321 & 626,321 \\
Jurisdictions & 1,059 & 1,059 & 2,477 & 2,477 & 2,477 & 2,477 \\
\hline
\end{tabular}

* Significant at $10 \%$ level; ${ }^{* *}$ significant at $5 \%$ level; ${ }^{* * *}$ significant at $1 \%$ level.

Source(s): Author's calculations using state legislation and 2000-2015 National Incident-Based Reporting System data.

Note(s): Each column displays an estimate from an OLS regression of some measure of larceny on a binary indicator for felony larceny threshold enactment, as noted. "Stolen Value" is the stolen property value per incident, "Rate" is the number of incidents on a given day per 1 million residents in a jurisdiction, and "Probability" is a binary indicator of at least one incident existing on a given day in a jurisdiction. Observations are incidents for the stolen value outcome, while observations are jurisdiction-days for the rate and probability outcomes, weighted by the annual jurisdiction population relevant to a jurisdiction-day in a given calendar year. The pre-enactment mean of the outcome is shown. All regressions include a running variable for the number of days relative to enactment, as well as the running variable interacted with the enactment indicator. Regressions with controls include indicators for jurisdiction $\times$ year $\times$ quarter, day of week, first of month, major holiday, and a constant. Singleton observations within a given fixed effect indicator are dropped. The regression discontinuity window (bandwidth) for estimation is 120 days surrounding the day of enactment, and the kernel is uniform. Incidents underlying all regressions are limited to the "response region" of the theft value distribution between the old and new larceny thresholds applicable to a given jurisdiction-enactment event, plus a $\$ 1$ buffer. The estimation samples additionally exclude incidents reflecting multiple charges, multiple property types, attempted offenses, the listed date as the report date, and state-specific felony larceny threshold exemptions. Further sample restrictions are detailed in the text. Standard errors clustered by jurisdiction are in parentheses. 
Table 2: The Short-Run Impact of Larceny Threshold Enactment on Larceny Stolen Value, Sensitivity Analysis

\begin{tabular}{lcccccc}
\hline & \multicolumn{3}{c}{ Bandwidth } & \multicolumn{3}{c}{ Response Region Buffer } \\
& 30 days & 60 days & 90 days & $\$ 10$ & $\$ 100$ & Unbounded \\
\hline Enactment & 4.828 & 10.536 & 13.189 & $20.550^{* *}$ & 4.883 & 32.519 \\
& $(10.131)$ & $(11.224)$ & $(9.552)$ & $(9.744)$ & $(9.063)$ & $(72.002)$ \\
& & & & & \\
R-sq & 0.77 & 0.77 & 0.77 & 0.77 & 0.74 & 0.06 \\
Observations & 5,665 & 11,724 & 17,468 & 22,819 & 30,580 & 199,563 \\
Jurisdictions & 597 & 853 & 998 & 1,069 & 1,217 & 1,955 \\
\hline \hline & None & Homog. & Semi-homog. & & \\
& $16.192^{*}$ & $21.724^{* *}$ & $19.483^{*}$ & $15.362^{*}$ & 1.004 & \\
\hline Enactment & $(8.324)$ & $(10.379)$ & $(10.289)$ & $(9.019)$ & $(9.087)$ & \\
& \multicolumn{7}{c}{ Placebo } \\
R-sq & 0.75 & 0.78 & 0.78 & 0.76 & 0.76 & \\
Observations & 29,650 & 16,550 & 16,903 & 30,756 & 20,043 & \\
Jurisdictions & 1,185 & 930 & 943 & 1,250 & 903 & \\
\hline
\end{tabular}

* Significant at $10 \%$ level; ${ }^{* *}$ significant at $5 \%$ level; ${ }^{* * *}$ significant at $1 \%$ level.

Source(s): Author's calculations using state legislation and 2000-2015 National Incident-Based Reporting System data.

Note(s): Each column displays an estimate from an OLS regression of the larceny stolen property value per incident on a binary indicator for felony larceny threshold enactment, as noted. Observations are incidents. When the bandwidth is 30 days surrounding enactment, no running variable is included. All other regressions include a running variable for the number of days relative to enactment, as well as the running variable interacted with the enactment indicator. The "Unbounded" response region buffer reflects incidents underlying regressions that correspond to the full theft value distribution. Regarding exemptions, the "None" sample excludes no incidents as a result of exemptions. The "Homogeneous" sample excludes incidents as a result of exemptions by assuming that an exemption in any state is applicable to all states and the jurisdictions therein. The "Semihomogeneous" sample excludes incidents as a result of exemptions by assuming that exemptions are state-specific, with the exception of the following seven exemptions that are treated homogeneously due to high prevalence across states: (i) firearms; (ii) organized retail theft; (iii) animals/livestock; (iv) theft from an elderly or vulnerable victim; (v) motor vehicles; (vi) drugs; and (vii) theft by juveniles, with state-specific age thresholds. Lastly, unless indicated otherwise, the estimation samples exclude incidents reflecting multiple charges, multiple property types, attempted offenses, the listed date as the report date, and state-specific felony larceny threshold exemptions. However, the "Broad" sensitivity analysis includes incidents corresponding to multiple charges, multiple property types, attempted offenses, and the listed date as the report date. Lastly, for the "Placebo" analysis sample, the placebo RD bandwidth is the actual RD bandwidth shifted 121 days earlier, such that the last day of the placebo RD bandwidth is one day before the true enactment date in a jurisdiction. All regressions also include indicators for jurisdiction $\times$ year $\times$ quarter, day of week, first of month, major holiday, and a constant. Singleton observations within a given fixed effect indicator are dropped. The kernel is uniform. Unless indicated otherwise, the regression discontinuity window (bandwidth) for estimation is 120 days surrounding the day of enactment. Also unless indicated otherwise, incidents underlying regressions are limited to the "response region" of the theft value distribution between the old and new larceny thresholds applicable to a given jurisdiction-enactment event, plus a $\$ 1$ buffer. Further sample restrictions are detailed in the text. Standard errors clustered by jurisdiction are in parentheses. 
Table 3: The Long-Run Impact of Larceny Threshold Enactment on Larceny

\begin{tabular}{lccc}
\hline & Stolen Value & Rate & Probability \\
\hline Enactment $\times$ Larceny & $-8.220^{* *}$ & $0.212^{*}$ & 0.002 \\
& $(3.923)$ & $(0.114)$ & $(0.003)$ \\
& & & \\
P-value: F-test, & & & \\
pre-enact. coeffs $=0$ & 0.254 & 0.224 & 0.019 \\
Pre-enactment mean & $1,042.73$ & 2.02 & 0.21 \\
R-sq & 0.74 & 0.03 & 0.37 \\
Observations & 338,316 & $9,502,358$ & $9,502,358$ \\
Jurisdictions & 783 & 1,559 & 1,559 \\
\hline
\end{tabular}

* Significant at $10 \%$ level; ${ }^{* *}$ significant at $5 \%$ level; ${ }^{* * *}$ significant at $1 \%$ level.

Source(s): Author's calculations using state legislation and 2000-2015 National Incident-Based Reporting System data.

Note(s): Each column displays an estimate from an OLS regression of some measure of larceny on a binary indicator for felony larceny threshold enactment interacted with a binary indicator for larceny outcomes (difference-indifferences $[\mathrm{DD}]$ treatment group) rather than non-larceny theft outcomes (DD control group), as noted. All regressions also include the enactment and larceny indicators individually (not interacted). "Stolen Value" is the stolen property value per incident, "Rate" is the number of incidents on a given day per 1 million residents in a jurisdiction, and "Probability" is a binary indicator of at least one incident existing on a given day in a jurisdiction. Observations are inverse-probability-weighted incidents for the stolen value outcome, while observations are inverse-probability-weighted jurisdiction-days for the rate and probability outcomes (for both larceny and non-larceny theft), further weighted by the annual jurisdiction population relevant to a jurisdiction-day in a given calendar year. The pre-enactment mean of the outcome for the DD treatment group is shown. All regressions include indicators for jurisdiction $\times$ year $\times$ quarter, day of week, first of month, major holiday, and a constant. Singleton observations within a given fixed effect indicator are dropped. All regressions also include inverse probability weights. The DD window for estimation is 1,800 days surrounding the day of enactment. Larceny and non-larceny theft incidents underlying all regressions are limited to the "response region" of the theft value distribution between the old and new larceny thresholds applicable to a given jurisdiction-enactment event, plus a $\$ 1$ buffer. The estimation samples additionally exclude larceny and non-larceny theft incidents reflecting multiple charges, multiple property types, attempted offenses, the listed date as the report date, and state-specific felony larceny threshold exemptions (larceny incidents only). Further sample restrictions are detailed in the text. The reported p-value reflects an F-test of pre-enactment, 360-day period coefficients from a dynamic analog of each DD specification jointly equaling zero (pre-enactment parallel trends). Standard errors clustered by jurisdiction are in parentheses. 


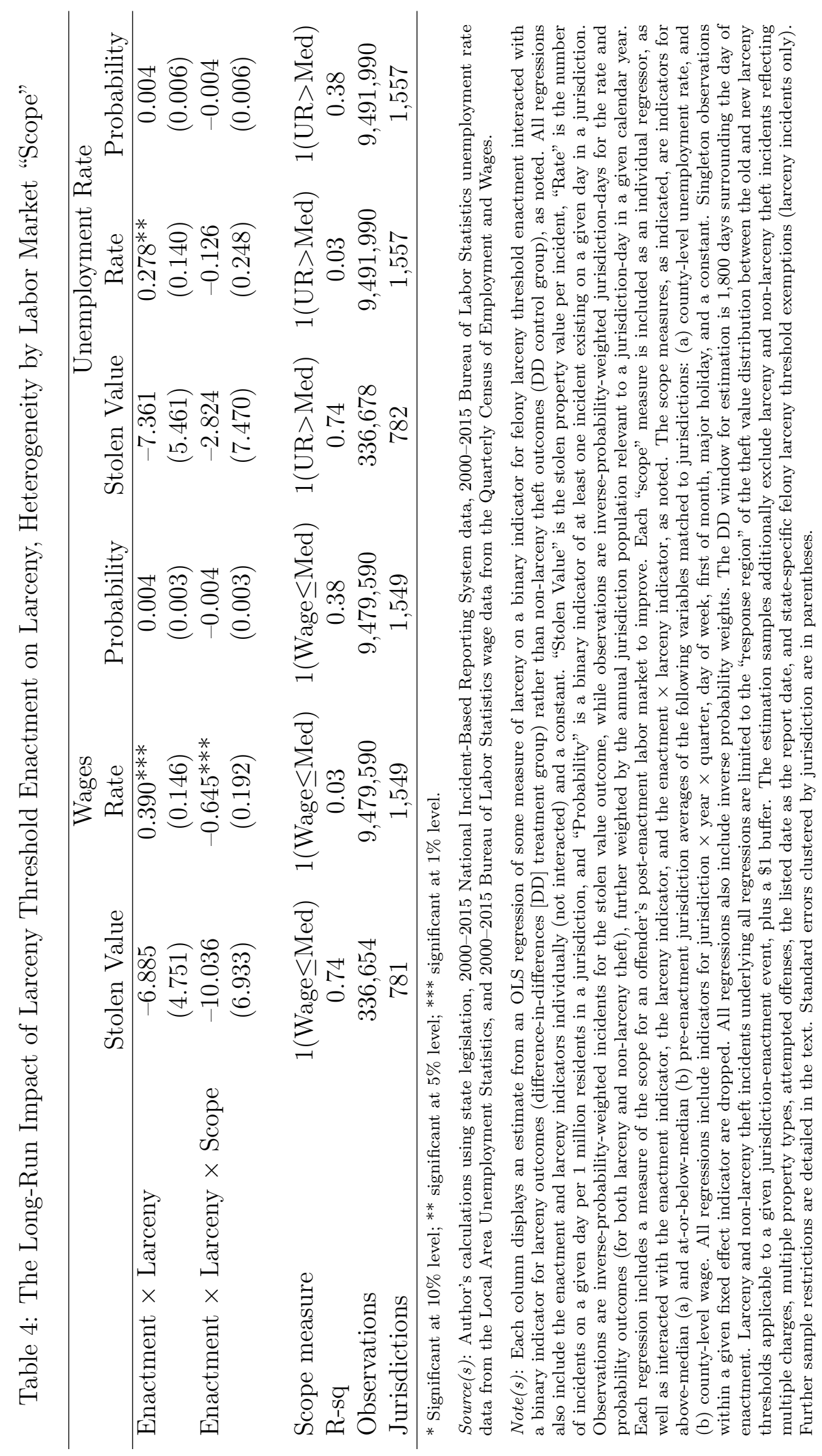




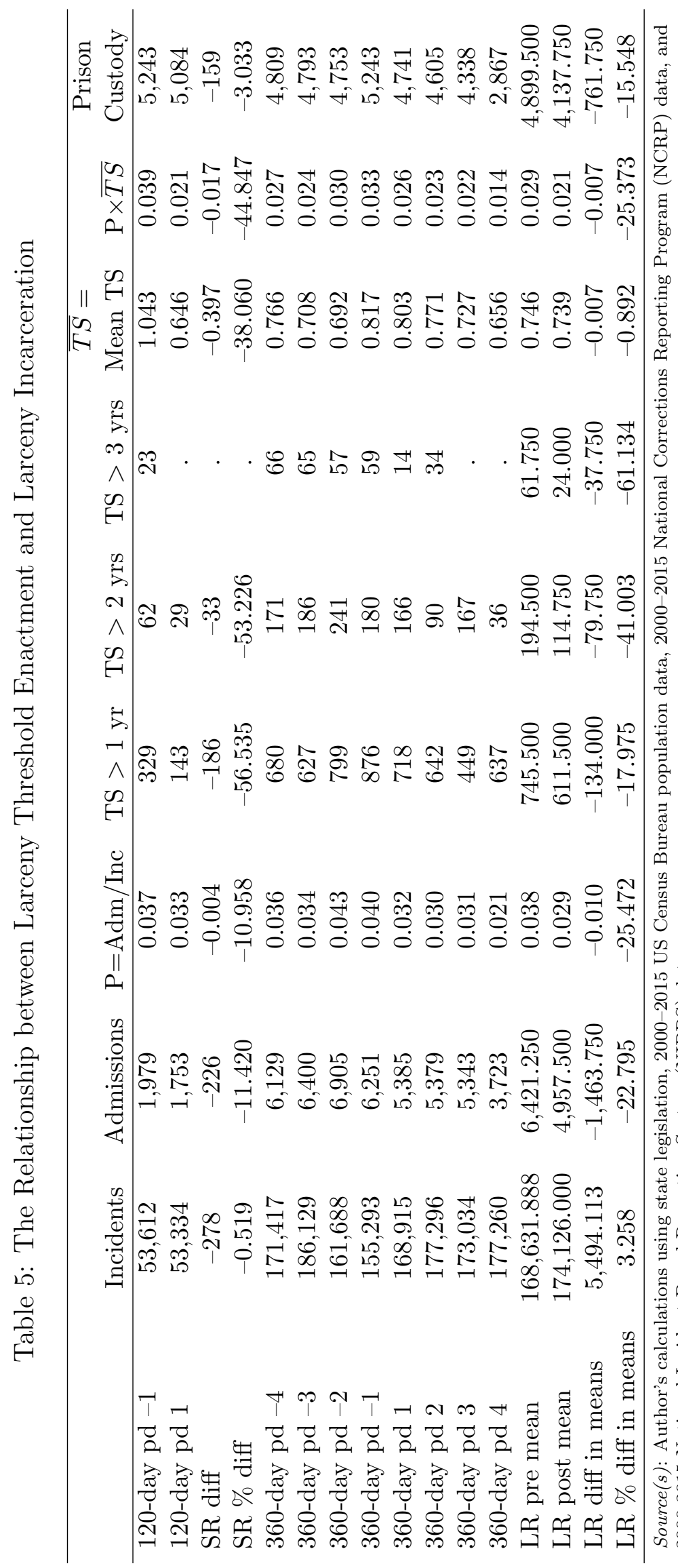

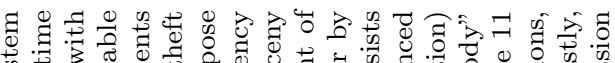

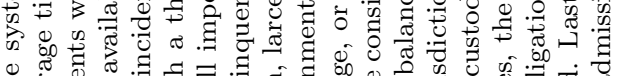

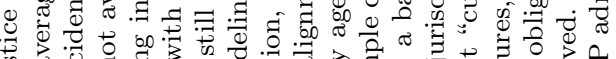

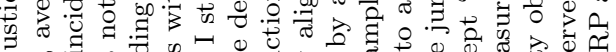

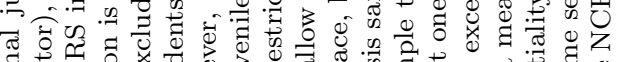

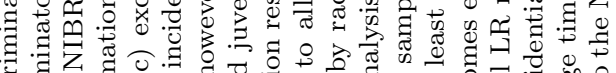

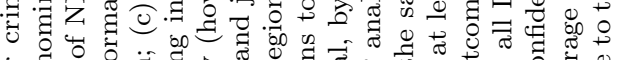

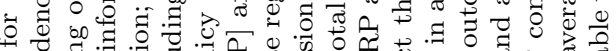

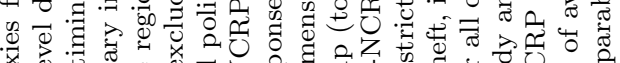

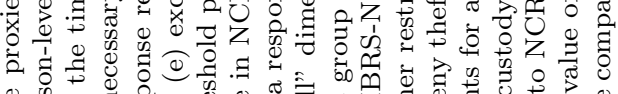
o

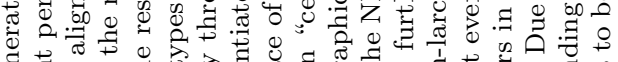

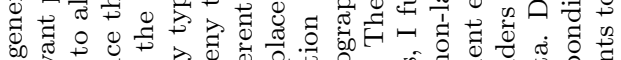

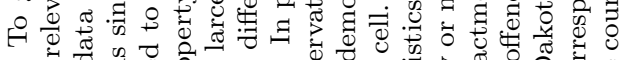

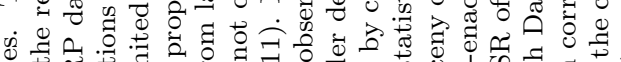
wै

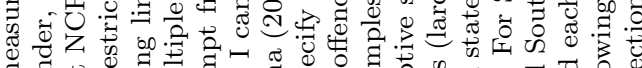

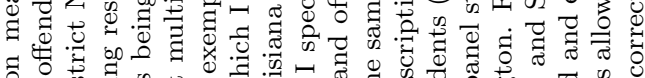

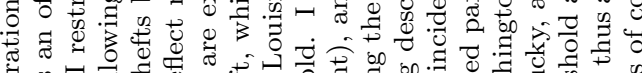
屯ै

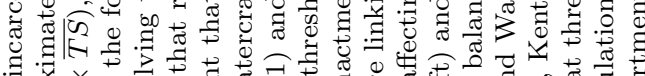

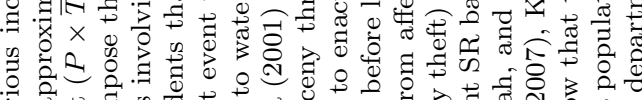

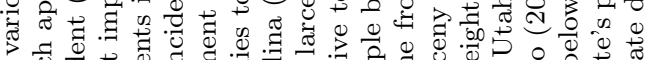

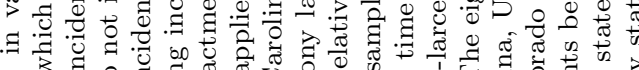
了.

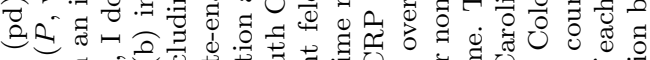

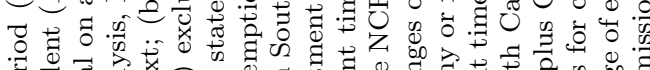

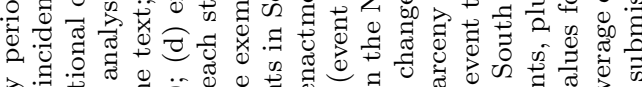

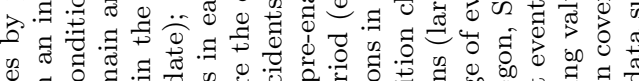
点

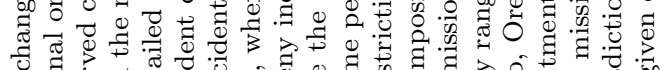

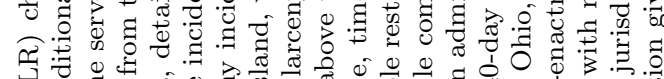

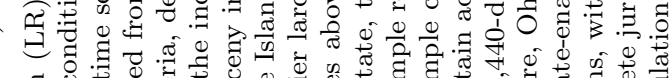

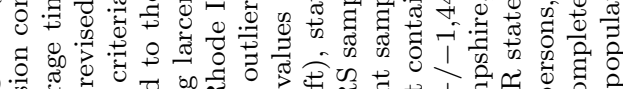
bo.

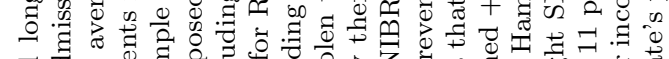

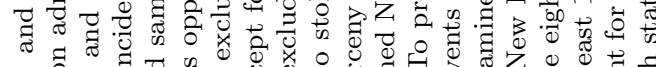

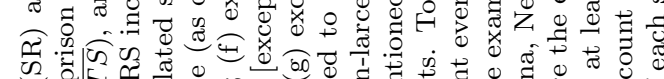

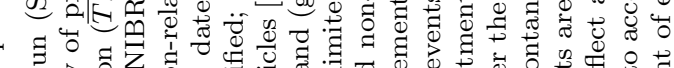

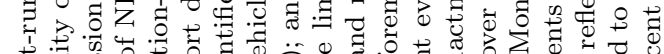

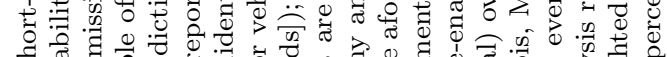
की

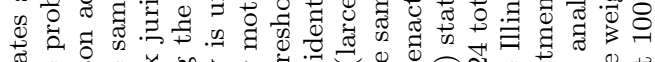

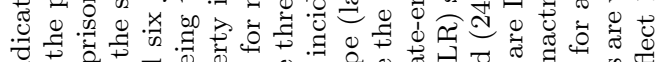

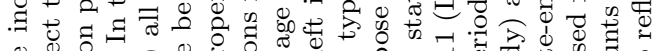
o

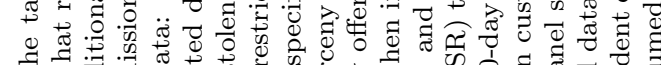

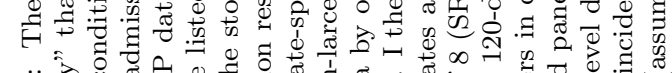

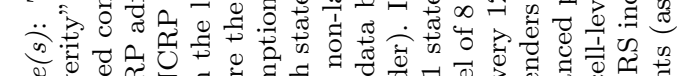

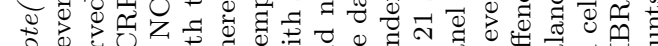




\section{A Appendix}

\section{A.1 Conceptual Framework Details}

I outline details here of a conceptual framework regarding how changes in punishment severity via adjustments to felony larceny thresholds might affect criminal behavior. For crime conducted over a given time horizon, both the expected benefit and the expected cost, currently and in the future, are related to the larceny threshold, $\bar{V}$, as well as to some chosen value of stolen property, $V$. An individual will commit a larceny crime with an optimal stolen value over some time horizon if the expected benefit of such crime is greater than the expected cost.

The expected benefit of crime is a (negative) function of an offender's discount rate, $D$, a (negative) function of the probability of arrest conditional on a crime, $R$, and a (positive) function of offender utility if not arrested. Such offender utility is positively determined in part by leisure consumption, or analogously, the disutility of criminal ("offending") labor supply, $L_{O}$. Offender utility is also a positive function of stolen property value, as such property may be resold or consumed. More specifically, the following expression can be written for $V$ :

$$
V=V\left(P, X_{O}\right)
$$

where

$$
X_{O}=X_{O}\left(L_{O}, Z\right)
$$

and

$$
L_{O}=L_{O}(P, \bar{V})
$$

The per-unit price, $P$, of a composite market good, along with the chosen quantity of units stolen of this composite market good, $X_{O}$, combine and contribute positively to form the chosen stolen property value, where $V=P X_{O}$. The selected quantity of units stolen can in turn be expressed as positively determined by both chosen offender labor supply and offender preferences, $Z$. Lastly, offender labor supply is a positive function of the market good price and a function of the larceny threshold (sign unspecified, allowing for all possible responses). ${ }^{55}$

The expected cost of crime is a (negative) function of an offender's discount rate, a (positive) function of the probability of arrest conditional on a crime, a (positive) function of punishment severity, $S$ (that is, a direct cost) if arrested, as well as a positive function of non-offender utility (the opportunity cost), some of which (in the future) is dependent on (current) arrest. Such non-offender utility is again positively determined in part by leisure consumption, or equivalently, the disutility of legal ("non-offending") labor supply, $L_{N O}$. This utility is also a positive function of the amount of legal market good consumption,

\footnotetext{
${ }^{55}$ The assumption that offender labor supply always positively responds to the market good price eliminates the possibility of backward-bending supply resulting from large income effects at high prices. Also, I focus mainly on the choice of whether to commit larceny crime in order to tie the current conceptual framework to existing literature. However, in a criminal labor supply model, one can explicitly determine the optimal stolen value, $V^{*}$, given the market good price and optimal quantity of the market good, $X_{O}^{*}$, with the latter determined by preferences and by solving for the optimal offender labor supply, $L_{O}^{*}$, given prices and the felony larceny threshold.
} 
$X_{N O}$. For simplicity, resale is now assumed to be inapplicable since the good is not stolen (that is, the good is purchased for consumption, not resale). The following expressions can be written for $S, L_{N O}$, and $X_{N O}$ :

$$
\begin{gathered}
S=S(V, \bar{V}), \\
L_{N O}=L_{N O}\left(P, W_{N O}\right),
\end{gathered}
$$

and

$$
X_{N O}=X_{N O}\left(P, W_{N O}\right),
$$

where

$$
W_{N O}=W_{N O}(S) .
$$

Punishment severity increases with stolen value, which in turn may be affected by the larceny threshold, as indicated in equations (5) through (7). However, punishment severity is also directly and negatively influenced by the larceny threshold. ${ }^{56}$ Both legal labor supply and legal market good consumption are functions of the market good price and the legal wage, $W_{N O}$. The legal wage is assumed to be affected negatively (in the future) by punishment severity, as employers may have diminished labor demand for offenders receiving harsher punishments due to perceptions of lower expected productivity by such individuals. However, the visibility to employers of offender punishment severity (using offender criminal records, for instance) may change over time, with the duration of visibility likely increasing to some degree as severity increases. ${ }^{57}$ Thus, $\frac{\partial W_{N O}}{\partial S}$ may likewise vary depending on the time horizon. For instance, if employers use criminal record availability as a proxy for punishment severity, one possibility is $\frac{\partial W_{N O}}{\partial S}=0$ in the short run following a crime, since criminal records are available for incidents of any severity in this time horizon. However, over a longer time horizon when only criminal records of greater severity are available, $\frac{\partial W_{N O}}{\partial S}<0$, as noted earlier. ${ }^{58}$ Lastly, legal labor supply decreases with the composite good price and increases with the legal wage, as does legal market good consumption. ${ }^{59}$

An increase in the larceny threshold will affect the expected benefit and cost of crime. Regarding the change in the expected benefit of crime, $B$, for notational ease, I can use $\partial V / \partial \bar{V}$ as a shorthand expression for $\frac{\partial L_{O}}{\partial \bar{V}} \times \frac{\partial X_{O}}{\partial L_{O}} \times \frac{\partial V}{\partial X_{O}}$. Then:

$$
\text { Benefit : } \quad \frac{\partial B}{\partial \bar{V}}=\frac{\partial V}{\partial \bar{V}} \times \frac{\partial B}{\partial V} .
$$

The change in the expected cost of crime, $C$, has three possible channels: (a) the direct cost, (b) the opportunity cost of (legal) leisure consumption, and (c) the opportunity cost

\footnotetext{
${ }^{56}$ For example, one could specify $S=g(V)$ if $V<\bar{V}$ and $S=g(V)+a$ if $V \geq \bar{V}$, where $a>0$. In other words, punishment severity discontinuously increases at $\bar{V}$. A larceny threshold increase could thus be represented as $S^{\prime}=g(V)$ if $V<\bar{V}^{\prime}$ and $S^{\prime}=g(V)+a$ if $V \geq \bar{V}^{\prime}$, where $\bar{V}^{\prime}=\bar{V}+h$ and $h>0$.

${ }^{57}$ As previously noted, an example of such a change in the visibility to employers is the "look-back" period for convicted crimes.

${ }^{58}$ Even given some limit to the visibility to employers of offender crimes with greater punishment severity, a detrimental labor market impact of such criminal record availability in the medium run could have lasting effects for offenders.

${ }^{59}$ The assumption that offender labor supply always positively responds to the legal wage eliminates the possibility of backward-bending supply resulting from large income effects at high wages.
} 
of (legal) market good consumption. Specifically:

$$
\begin{aligned}
& \text { Cost (direct) }: \quad\left(\frac{\partial S}{\partial \bar{V}}+\left[\frac{\partial V}{\partial \bar{V}} \times \frac{\partial S}{\partial V}\right]\right) \times \frac{\partial C}{\partial S} \\
& \text { Cost (opp., leisure) : }\left(\frac{\partial S}{\partial \bar{V}}+\left[\frac{\partial V}{\partial \bar{V}} \times \frac{\partial S}{\partial V}\right]\right) \times \frac{\partial W_{N O}}{\partial S} \times \frac{\partial L_{N O}}{\partial W_{N O}} \times \frac{\partial C}{\partial L_{N O}} \\
& \text { Cost (opp.,good) : }\left(\frac{\partial S}{\partial \bar{V}}+\left[\frac{\partial V}{\partial \bar{V}} \times \frac{\partial S}{\partial V}\right]\right) \times \frac{\partial W_{N O}}{\partial S} \times \frac{\partial X_{N O}}{\partial W_{N O}} \times \frac{\partial C}{\partial X_{N O}} .
\end{aligned}
$$

Thus, even without a stolen value response to a higher larceny threshold $(\partial V / \partial \bar{V}=0)$, all three cost mechanisms could still lead to a positive or negative change in whether an offender commits a larceny crime with some fixed stolen value. ${ }^{60}$ Expression (15) shows that a higher opportunity cost of legal consumption when the larceny threshold is raised might sufficiently lower the incentive to commit larceny crime. In other words, over a long time horizon (again, assuming $\frac{\partial W_{N O}}{\partial S}<0$ in the long run but equals 0 in the short run), lower punishment severity could deter crime rather than escalate it.

\footnotetext{
${ }^{60}$ With $\partial V / \partial \bar{V}=0$, expressions (13) and (14) would be negative, while expression (15) would be positive. More generally, one can set some reasonable expectations on the sign and magnitude of $\partial V / \partial \bar{V}$ by examining the direct cost in expression (13). Recall, I can expect $\partial S / \partial \bar{V}<0$ and $\partial S / \partial V>0$. Thus, if $\partial V / \partial \bar{V}$ is positive and sufficiently large, such an increase in stolen value helps to offset the reduction in severity from a higher larceny threshold, resulting in no change in the direct cost of crime. Assuming such an upper bound on $\partial V / \partial \bar{V}$ thus allows expressions (13), (14), and (15) to be signed as weakly negative, weakly negative, and weakly positive, respectively, even while allowing $\partial V / \partial \bar{V}$ to have any sign.
} 


\section{A.2 Legislation and Additional Results}

Table A1: Felony Larceny Threshold Changes in Sample, 2000-2015

\begin{tabular}{lcccc}
\hline State & $\begin{array}{c}\text { Enactment } \\
\text { Date }\end{array}$ & Bill/Act & $\begin{array}{c}\text { New } \\
\text { Threshold }\end{array}$ & $\begin{array}{c}\text { Prior } \\
\text { Threshold }\end{array}$ \\
\hline Arizona & $9 / 21 / 2006$ & HB2581 & $\$ 1,000$ & $\$ 250$ \\
Arkansas & $7 / 27 / 2011$ & SB750 & $\$ 1,000$ & $\$ 500$ \\
Colorado & $7 / 1 / 2007$ & SB260 & $\$ 1,000$ & $\$ 500$ \\
& $6 / 5 / 2013$ & HB1160 & $\$ 2,000$ & $\$ 1,000$ \\
Connecticut & $10 / 1 / 2009$ & HB6576 & $\$ 2,000$ & $\$ 1,000$ \\
Illinois & $1 / 1 / 2011$ & HB3797 & $\$ 500$ & $\$ 300$ \\
Kansas & $7 / 1 / 2004$ & HB2271 & $\$ 1,000$ & $\$ 500$ \\
Kentucky & $6 / 25 / 2009$ & HB369 & $\$ 500$ & $\$ 300$ \\
Louisiana & $8 / 15 / 2010$ & HB555 & $\$ 500$ & $\$ 300$ \\
& $8 / 1 / 2014$ & HB791 & $\$ 750$ & $\$ 500$ \\
Mississippi & $7 / 1 / 2014$ & HB585 & $\$ 1,000$ & $\$ 500$ \\
Montana & $10 / 1 / 2009$ & SB476 & $\$ 1,500$ & $\$ 1,000$ \\
Nebraska & $8 / 30 / 2015$ & LB605 & $\$ 1,500$ & $\$ 500$ \\
New Hampshire & $7 / 1 / 2010$ & SB205 & $\$ 1,000$ & $\$ 500$ \\
North Dakota & $8 / 1 / 2013$ & SB2251 & $\$ 1,000$ & $\$ 500$ \\
Ohio & $9 / 30 / 2011$ & HB86 & $\$ 1,000$ & $\$ 500$ \\
Oregon & $1 / 1 / 2010$ & HB2323 & $\$ 1,000$ & $\$ 750$ \\
Rhode Island & $6 / 8 / 2012$ & H7176 & $\$ 1,500$ & $\$ 500$ \\
South Carolina & $6 / 2 / 2010$ & SB1154 & $\$ 2,000$ & $\$ 1,000$ \\
South Dakota & $7 / 1 / 2005$ & SB43 & $\$ 1,000$ & $\$ 500$ \\
Texas & $9 / 1 / 2015$ & HB1396 & $\$ 2,500$ & $\$ 1,500$ \\
Utah & $11 / 1 / 2010$ & SB10 & $\$ 1,500$ & $\$ 1,000$ \\
Vermont & $7 / 1 / 2006$ & SB265 & $\$ 900$ & $\$ 500$ \\
Washington & $9 / 1 / 2009$ & SB6167 & $\$ 750$ & $\$ 250$ \\
\hline
\end{tabular}

Source(s): State legislation.

Note(s): Inquiries sent to multiple officials in each state to confirm information (response rate: 5 out of 22 states). 


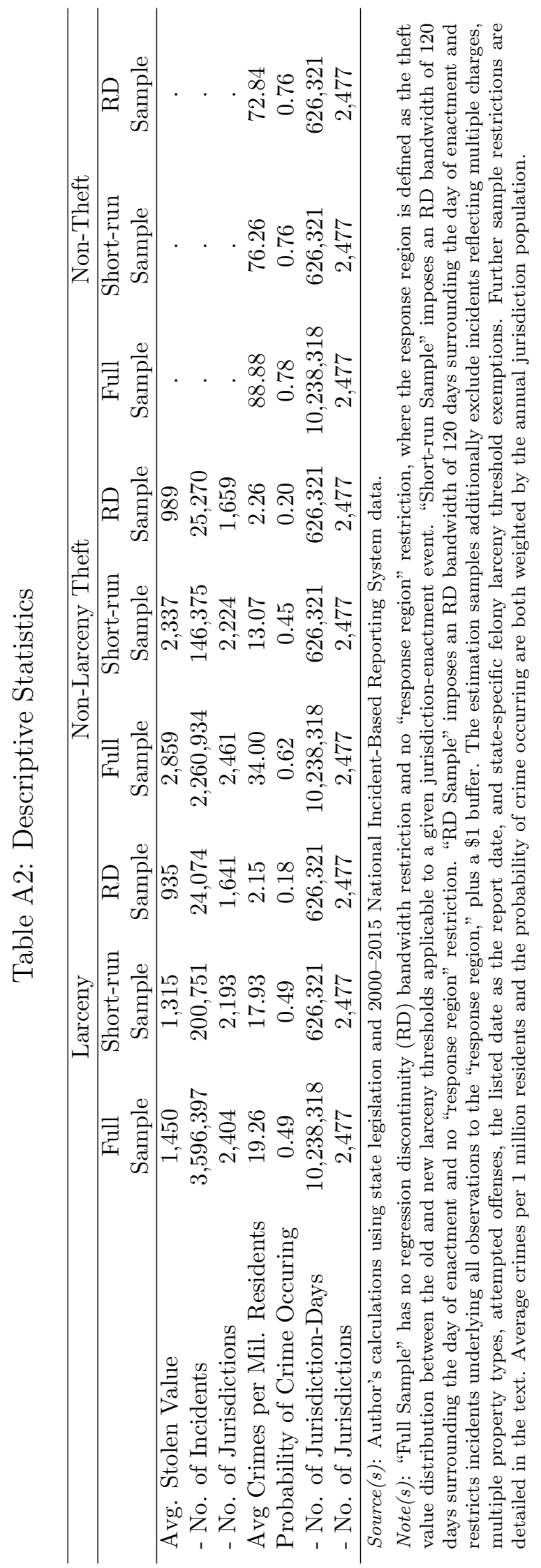


Table A3: The Short-Run Impact of Larceny Threshold Enactment on Non-Larceny Crime

\begin{tabular}{lccccc}
\hline & $\begin{array}{c}\text { NL Theft } \\
\text { Stolen Value }\end{array}$ & $\begin{array}{c}\text { NL Theft } \\
\text { Rate }\end{array}$ & $\begin{array}{c}\text { NL Theft } \\
\text { Probability }\end{array}$ & $\begin{array}{c}\text { Non-Theft } \\
\text { Rate }\end{array}$ & $\begin{array}{c}\text { Non-Theft } \\
\text { Probability }\end{array}$ \\
\hline Enactment & -1.440 & -0.119 & 0.003 & 0.373 & 0.000 \\
& $(7.838)$ & $(0.087)$ & $(0.010)$ & $(0.819)$ & $(0.003)$ \\
Pre-enactment mean & 993.93 & 2.20 & 0.19 & 75.04 & 0.76 \\
R-sq & 0.77 & 0.06 & 0.46 & 0.35 & 0.54 \\
Observations & 23,724 & 626,321 & 626,321 & 626,321 & 626,321 \\
Jurisdictions & 1,053 & 2,477 & 2,477 & 2,477 & 2,477 \\
\hline
\end{tabular}

* Significant at $10 \%$ level; ** significant at $5 \%$ level; *** significant at $1 \%$ level.

Source(s): Author's calculations using state legislation and 2000-2015 National Incident-Based Reporting System data.

Note(s): Each column displays an estimate from an OLS regression of some measure of non-larceny crime (non-larceny $[\mathrm{NL}]$ theft and non-theft) on a binary indicator for felony larceny threshold enactment, as noted. "Stolen Value" is the stolen property value per incident, "Rate" is the number of incidents on a given day per 1 million residents in a jurisdiction, and "Probability" is a binary indicator of at least one incident existing on a given day in a jurisdiction. Observations are incidents for the stolen value outcome, while observations are jurisdiction-days for the rate and probability outcomes, weighted by the annual jurisdiction population relevant to a jurisdiction-day in a given calendar year. The pre-enactment mean of the outcome is shown. All regressions include a running variable for the number of days relative to enactment, as well as the running variable interacted with the enactment indicator. All regressions also include indicators for jurisdiction $\times$ year $\times$ quarter, day of week, first of month, major holiday, and a constant. Singleton observations within a given fixed effect indicator are dropped. The regression discontinuity window (bandwidth) for estimation is 120 days surrounding the day of enactment, and the kernel is uniform. Incidents underlying regressions with theft outcomes are limited to the "response region" of the theft value distribution between the old and new larceny thresholds applicable to a given jurisdiction-enactment event, plus a $\$ 1$ buffer. The estimation samples additionally exclude incidents reflecting multiple charges, multiple property types, attempted offenses, the listed date as the report date, and state-specific felony larceny threshold exemptions. Further sample restrictions are detailed in the text. Standard errors clustered by jurisdiction are in parentheses. 
Table A4: The Short-Run Impact of Larceny Threshold Enactment on Larceny, Placebo Test

\begin{tabular}{lcccccc}
\hline & \multicolumn{3}{c}{ Placebo Sample } & \multicolumn{3}{c}{ Main Sample (Restricted) } \\
& Stolen Value & Rate & Probability & Stolen Value & Rate & Probability \\
\hline Enactment & 1.004 & 0.027 & -0.007 & $20.757^{* *}$ & -0.070 & -0.006 \\
& $(9.087)$ & $(0.057)$ & $(0.007)$ & $(9.973)$ & $(0.079)$ & $(0.006)$ \\
& & & & & & \\
R-sq & 0.76 & 0.05 & 0.45 & 0.76 & 0.05 & 0.45 \\
Observations & 20,043 & 597,697 & 597,697 & 22,059 & 619,934 & 619,934 \\
Jurisdictions & 903 & 2,440 & 2,440 & 903 & 2,440 & 2,440 \\
\hline
\end{tabular}

* Significant at $10 \%$ level; ${ }^{* *}$ significant at $5 \%$ level; ${ }^{* * *}$ significant at $1 \%$ level.

Source(s): Author's calculations using state legislation and 2000-2015 National Incident-Based Reporting System data.

Note(s): Each column displays an estimate from an OLS regression of some measure of larceny on a binary indicator for felony larceny threshold enactment, as noted. For the "Main Sample (Restricted)," the regression discontinuity (RD) window (bandwidth) for estimation is 120 days surrounding the day of enactment, restricted to the same jurisdictions as the "Placebo Sample." For the "Placebo Sample," the placebo RD bandwidth is the actual RD bandwidth shifted earlier by 121 days, such that the last day of the placebo RD bandwidth is one day before the true enactment date in a jurisdiction. The kernel is uniform. "Stolen Value" is the stolen property value per incident, "Rate" is the number of incidents on a given day per 1 million residents in a jurisdiction, and "Probability" is a binary indicator of at least one incident existing on a given day in a jurisdiction. Observations are incidents for the stolen value outcome, while observations are jurisdiction-days for the rate and probability outcomes, weighted by the annual jurisdiction population relevant to a jurisdiction-day in a given calendar year. All regressions include a running variable for the number of days relative to enactment, as well as the running variable interacted with the enactment indicator. All regressions also include indicators for jurisdiction $\times$ year $\times$ quarter, day of week, first of month, major holiday, and a constant. Singleton observations within a given fixed effect indicator are dropped. Incidents underlying all regressions are limited to the "response region" of the theft value distribution between the old and new larceny thresholds applicable to a given jurisdictionenactment event, plus a $\$ 1$ buffer. The estimation samples additionally exclude incidents reflecting multiple charges, multiple property types, attempted offenses, the listed date as the report date, and state-specific felony larceny threshold exemptions. Further sample restrictions are detailed in the text. Standard errors clustered by jurisdiction are in parentheses. 
Table A5: The Short-Run Impact of Larceny Threshold Enactment on Larceny Stolen Value, Stratifying by Proportional Size of Threshold Increase

\begin{tabular}{lccc}
\hline & Increase $<100 \%$ & Increase $=100 \%$ & Increase $>100 \%$ \\
\hline Enactment & 1.201 & $25.470^{*}$ & 24.480 \\
& $(17.049)$ & $(13.746)$ & $(19.759)$ \\
R-sq & 0.92 & & \\
Observations & 3,633 & 16,146 & 0.51 \\
Jurisdictions & 270 & 688 & 2,777 \\
\hline
\end{tabular}

* Significant at $10 \%$ level; ${ }^{* *}$ significant at $5 \%$ level; ${ }^{* * *}$ significant at $1 \%$ level.

Source(s): Author's calculations using state legislation and 2000-2015 National Incident-Based Reporting System data.

Note(s): Each column displays an estimate from an OLS regression of the larceny stolen property value per incident on a binary indicator for felony larceny threshold enactment, as noted. Observations are incidents. All regressions include a running variable for the number of days relative to enactment, as well as the running variable interacted with the enactment indicator. The "Increase $<100 \%$ " sample reflects the following nine state-enactment events with larceny threshold increases less than 100 percent: Illinois, Kentucky, Louisiana (2010 and 2014), Montana, Oregon, Texas, Utah, and Vermont. The "Increase $=100 \%$ " sample reflects the following 11 state-enactment events with larceny threshold increases equal to 100 percent: Arkansas, Colorado (2007 and 2013), Connecticut, Kansas, Mississippi, New Hampshire, North Dakota, Ohio, South Carolina, and South Dakota. The "Increase $>100 \%$ " sample reflects the following four state-enactment events with larceny threshold increases greater than 100 percent: Arizona, Nebraska, Rhode Island, and Washington. The estimation samples exclude incidents reflecting multiple charges, multiple property types, attempted offenses, the listed date as the report date, and state-specific felony larceny threshold exemptions. All regressions also include indicators for jurisdiction $\times$ year $\times$ quarter, day of week, first of month, major holiday, and a constant. Singleton observations within a given fixed effect indicator are dropped. The kernel is uniform. The regression discontinuity bandwidth for estimation is 120 days surrounding the day of enactment. Incidents underlying regressions are limited to the "response region" of the theft value distribution between the old and new larceny thresholds applicable to a given jurisdiction-enactment event, plus a $\$ 1$ buffer. Further sample restrictions are detailed in the text. Standard errors clustered by jurisdiction are in parentheses. 
Table A6: The Short-Run Impact of Larceny Threshold Enactment on Larceny, Differencein-Differences

\begin{tabular}{lccc}
\hline & Stolen Value & Rate & Probability \\
\hline Enactment $\times$ Larceny & 3.073 & 0.116 & -0.000 \\
& $(6.560)$ & $(0.121)$ & $(0.001)$ \\
& & & \\
R-sq & 0.76 & 0.03 & 0.36 \\
Observations & 32,778 & 864,460 & 864,460 \\
Jurisdictions & 744 & 1,706 & 1,706 \\
\hline * Significant at $10 \%$ level $^{* *}$ significant at $5 \%$ & level $* * *$
\end{tabular}

* Significant at $10 \%$ level; ${ }^{* *}$ significant at $5 \%$ level; $* * *$ significant at $1 \%$ level. Source(s): Author's calculations using state legislation and 2000-2015 National Incident-Based Reporting System data.

Note(s): Each column displays an estimate from an OLS regression of some measure of larceny on a binary indicator for felony larceny threshold enactment interacted with a binary indicator for larceny outcomes (difference-indifferences $[\mathrm{DD}]$ treatment group) rather than non-larceny theft outcomes (DD control group), as noted. All regressions also include the enactment and larceny indicators individually (not interacted). "Stolen Value" is the stolen property value per incident, "Rate" is the number of incidents on a given day per 1 million residents in a jurisdiction, and "Probability" is a binary indicator of at least one incident existing on a given day in a jurisdiction. Observations are inverse-probability-weighted incidents for the stolen value outcome, while observations are inverse-probability-weighted jurisdiction-days for the rate and probability outcomes (for both larceny and non-larceny theft), further weighted by the annual jurisdiction population relevant to a jurisdiction-day in a given calendar year. All regressions include indicators for jurisdiction $\times$ year $\times$ quarter, day of week, first of month, major holiday, and a constant. Singleton observations within a given fixed effect indicator are dropped. All regressions also include inverse probability weights. The DD window for estimation is 120 days surrounding the day of enactment. Larceny and non-larceny theft incidents underlying all regressions are limited to the "response region" of the theft value distribution between the old and new larceny thresholds applicable to a given jurisdiction-enactment event, plus a $\$ 1$ buffer. The estimation samples additionally exclude larceny and non-larceny theft incidents reflecting multiple charges, multiple property types, attempted offenses, the listed date as the report date, and state-specific felony larceny threshold exemptions (larceny incidents only). Further sample restrictions are detailed in the text. Standard errors clustered by jurisdiction are in parentheses. Differences in jurisdictions compared with analogous RD analysis result from inverse probability weighting (missing weights, common support restrictions) and subsequent estimation singleton observations. 


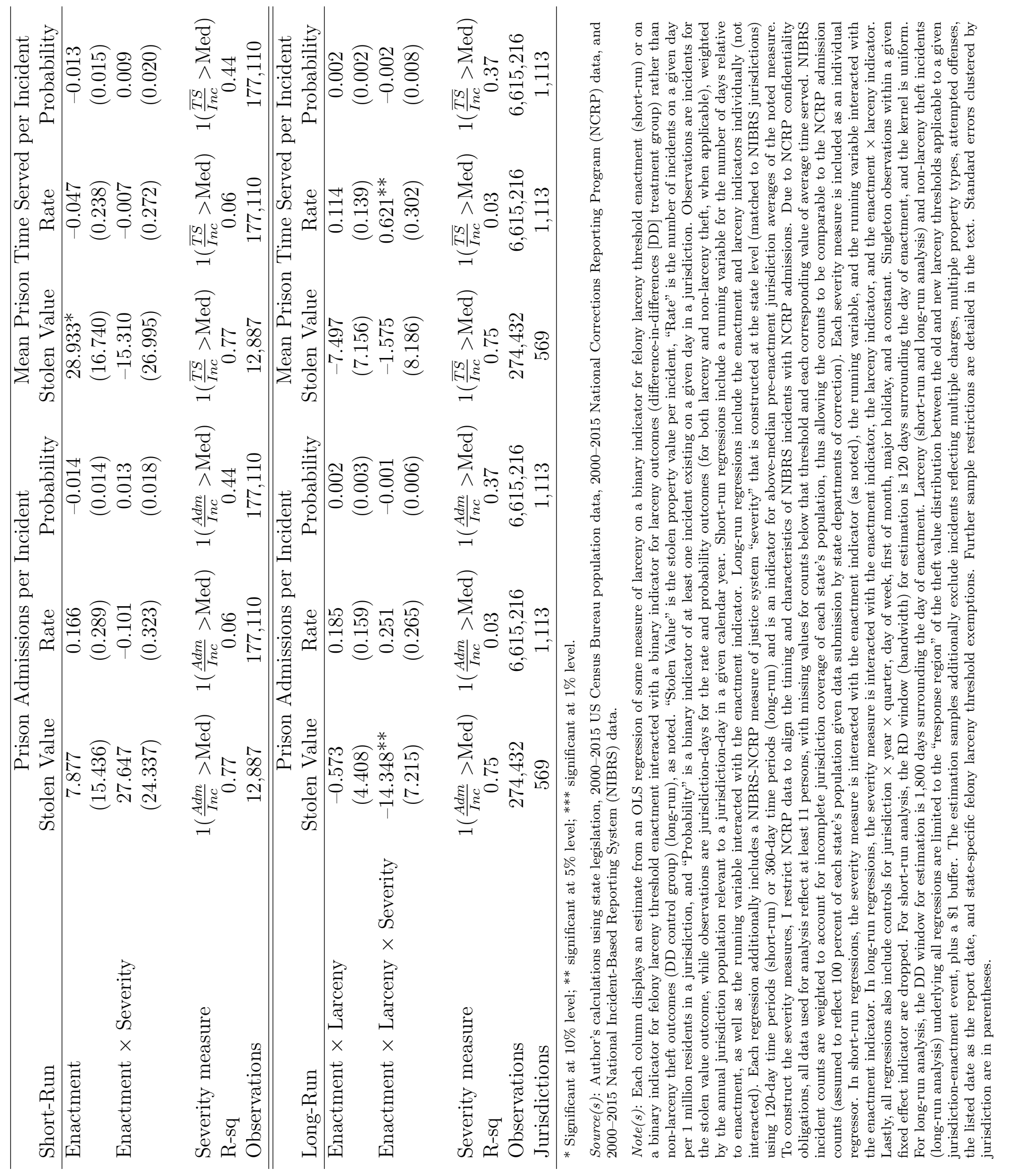




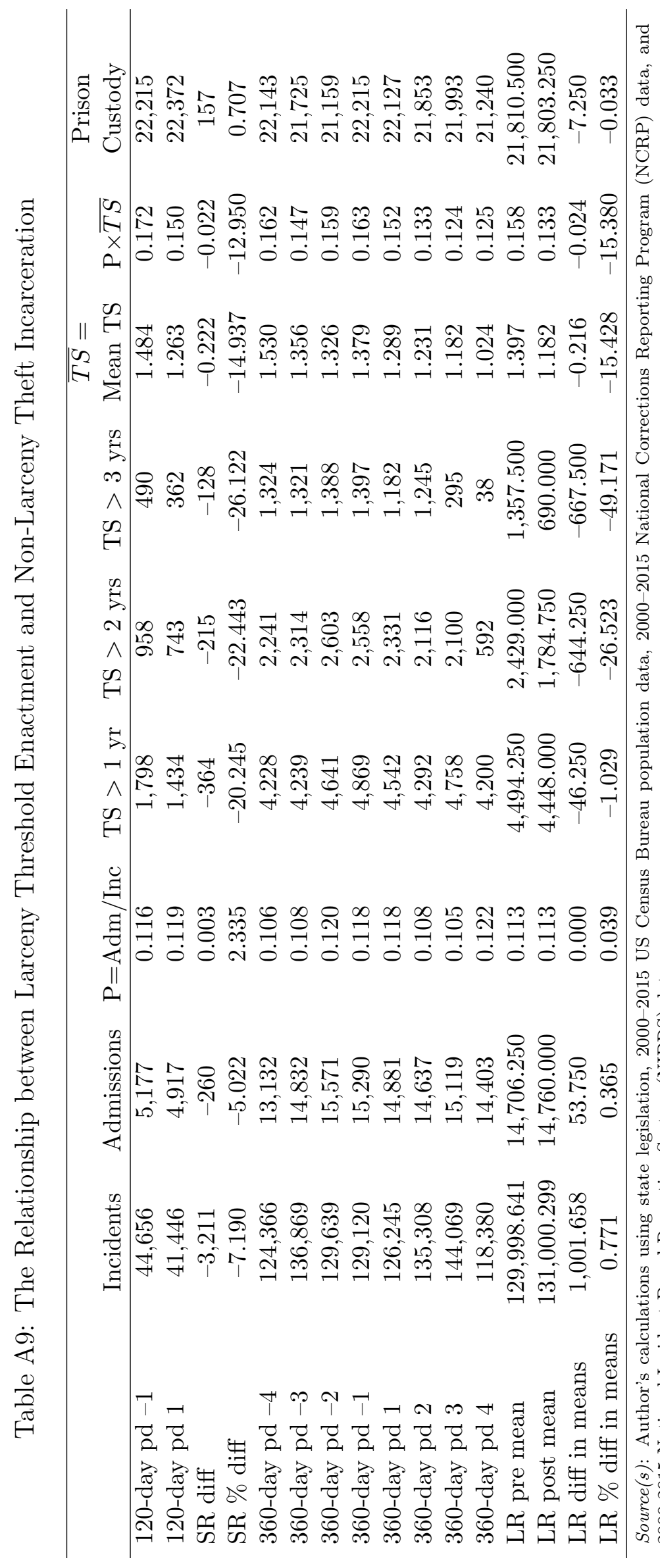

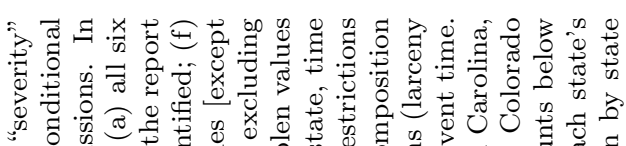

g 0 .

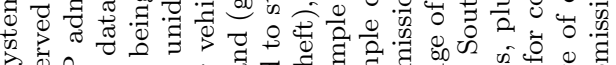

की

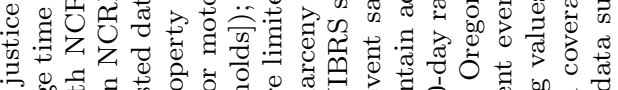

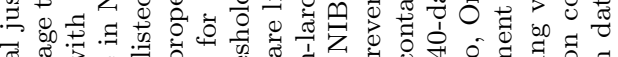

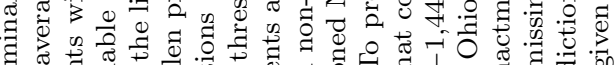

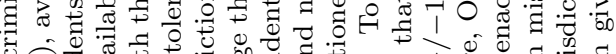

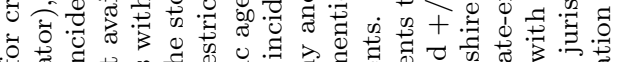

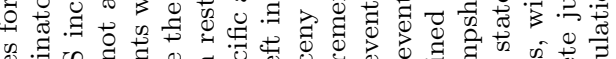

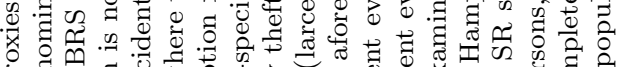

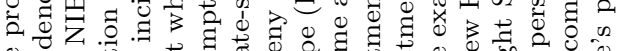

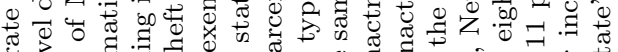

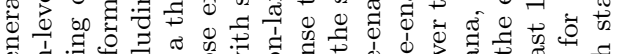

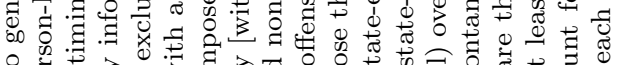

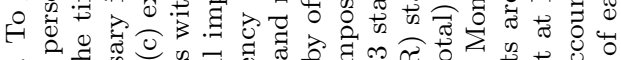

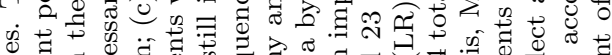

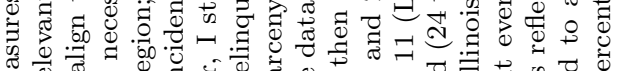

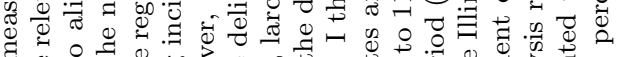

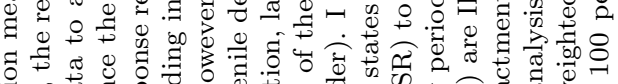

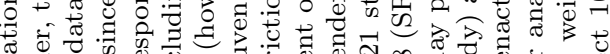

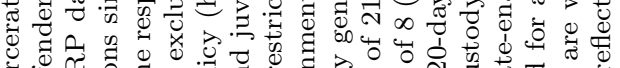

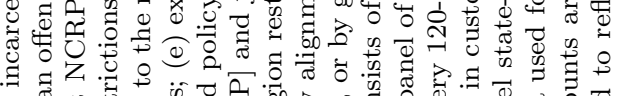

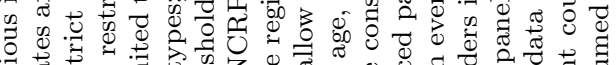

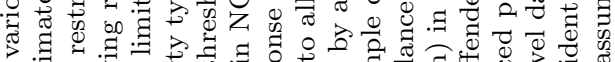
캉 ชิ

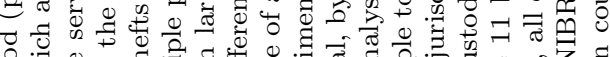

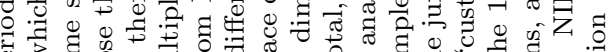

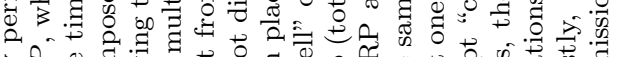

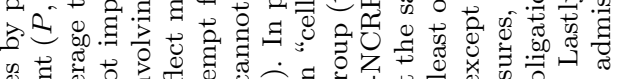
㟧

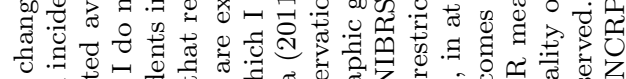

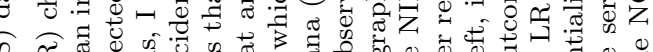

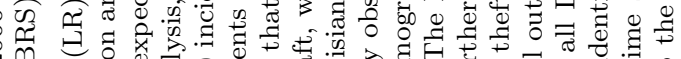

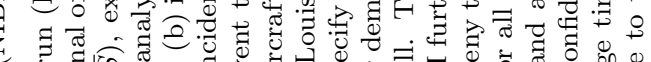
b. 节

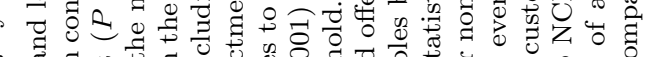

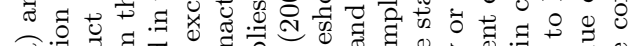

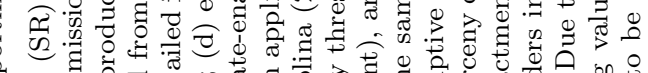

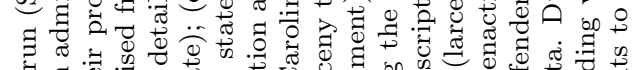

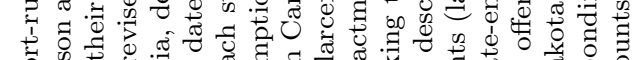
क की

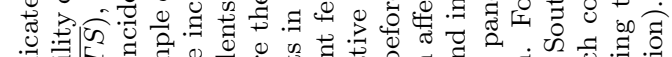

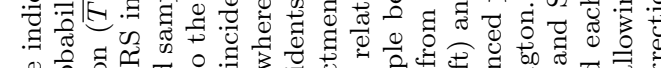
0 응

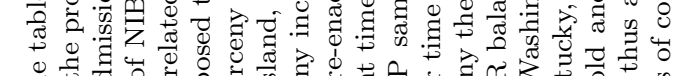
g च

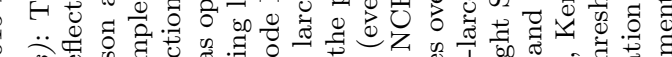
की

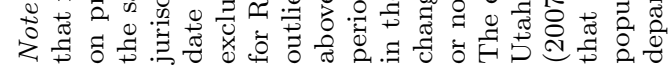




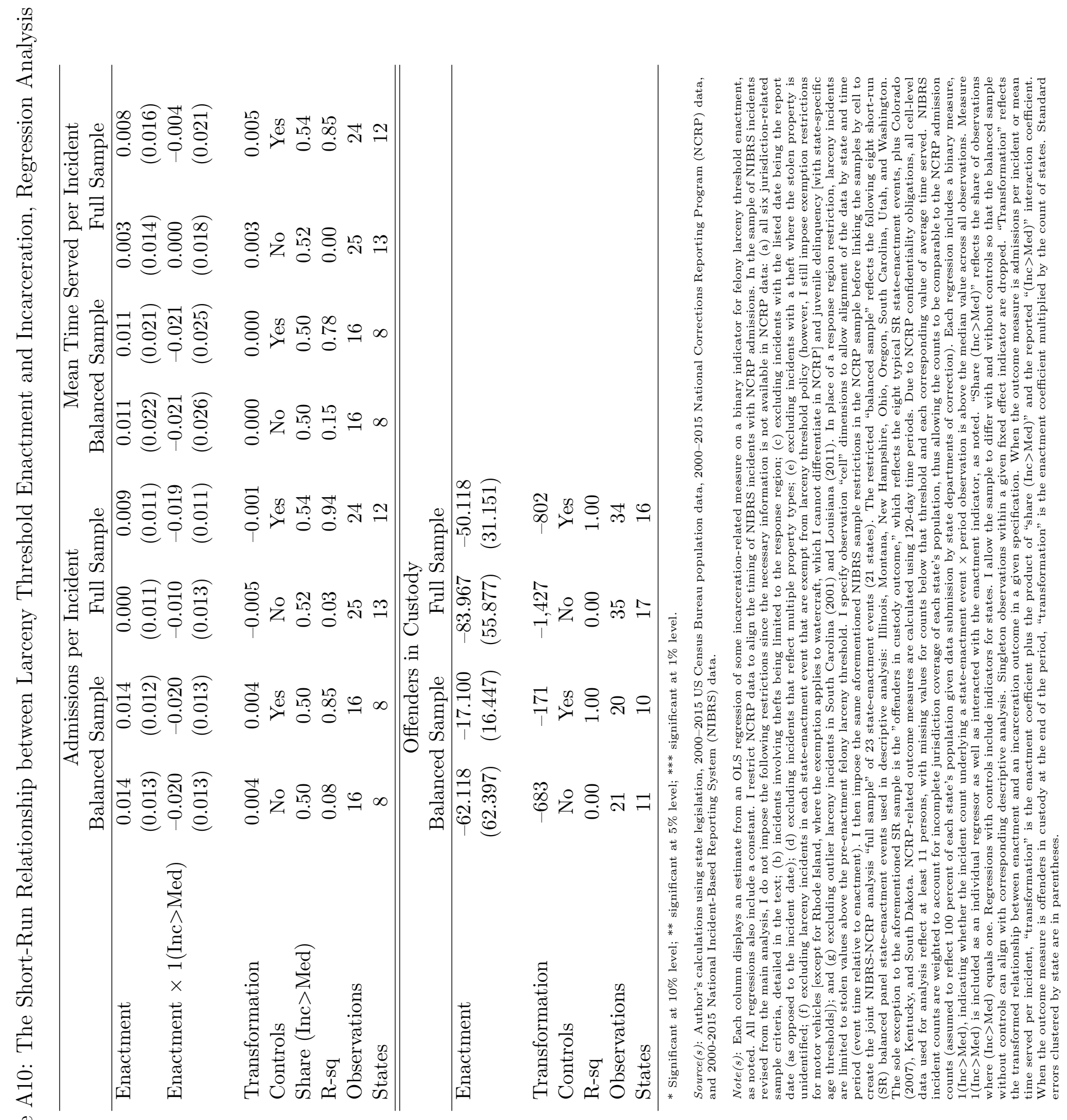




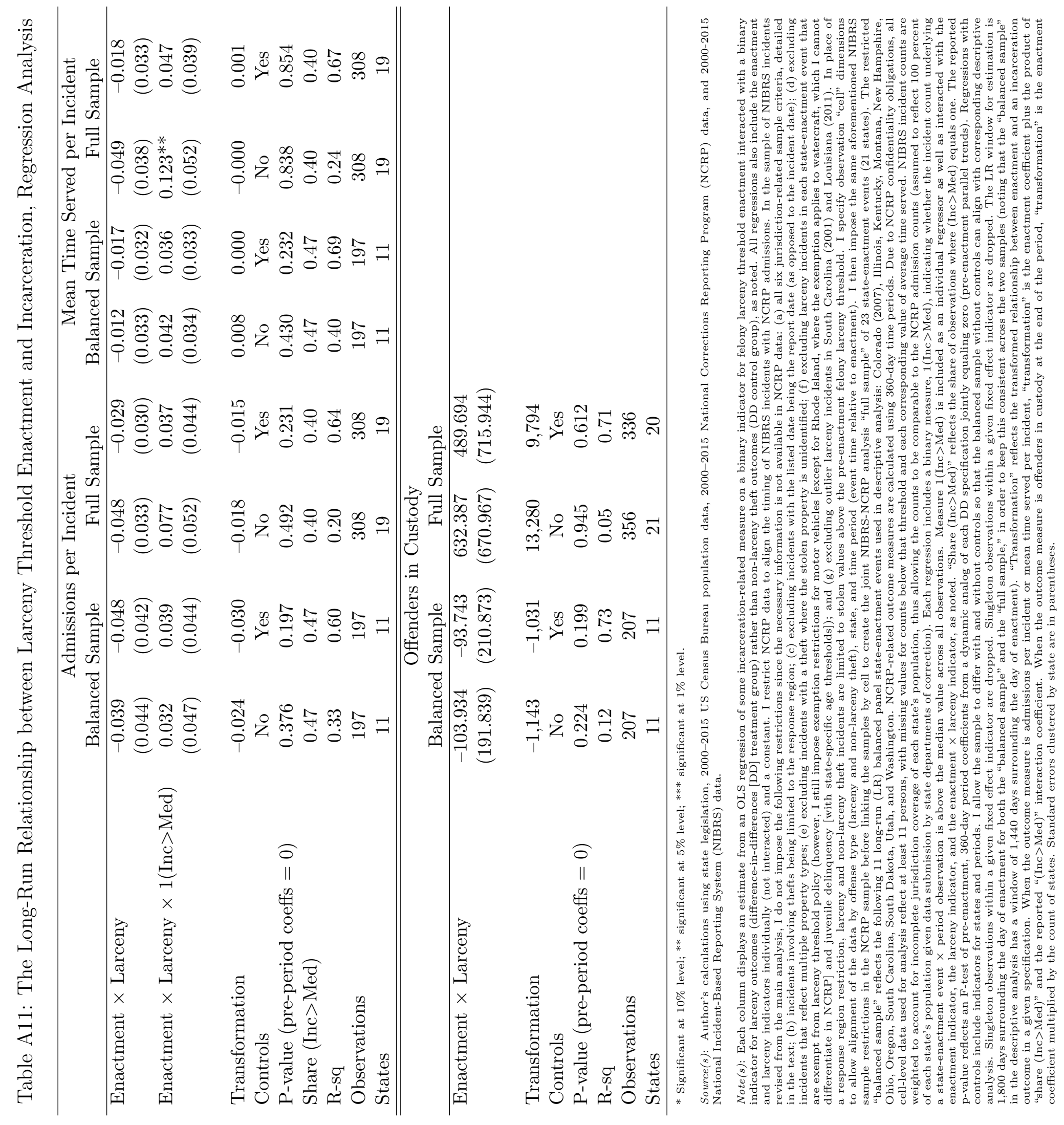




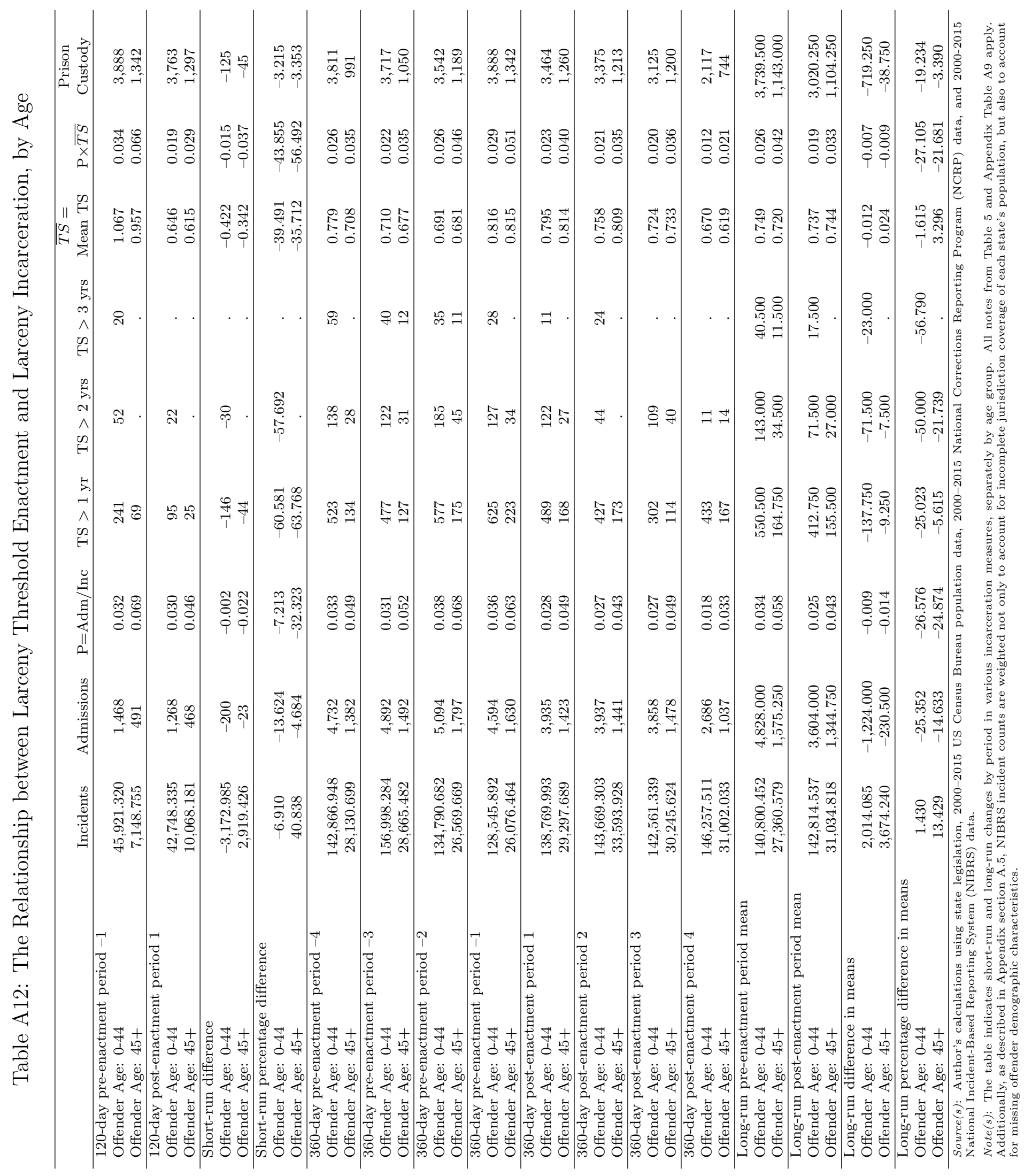




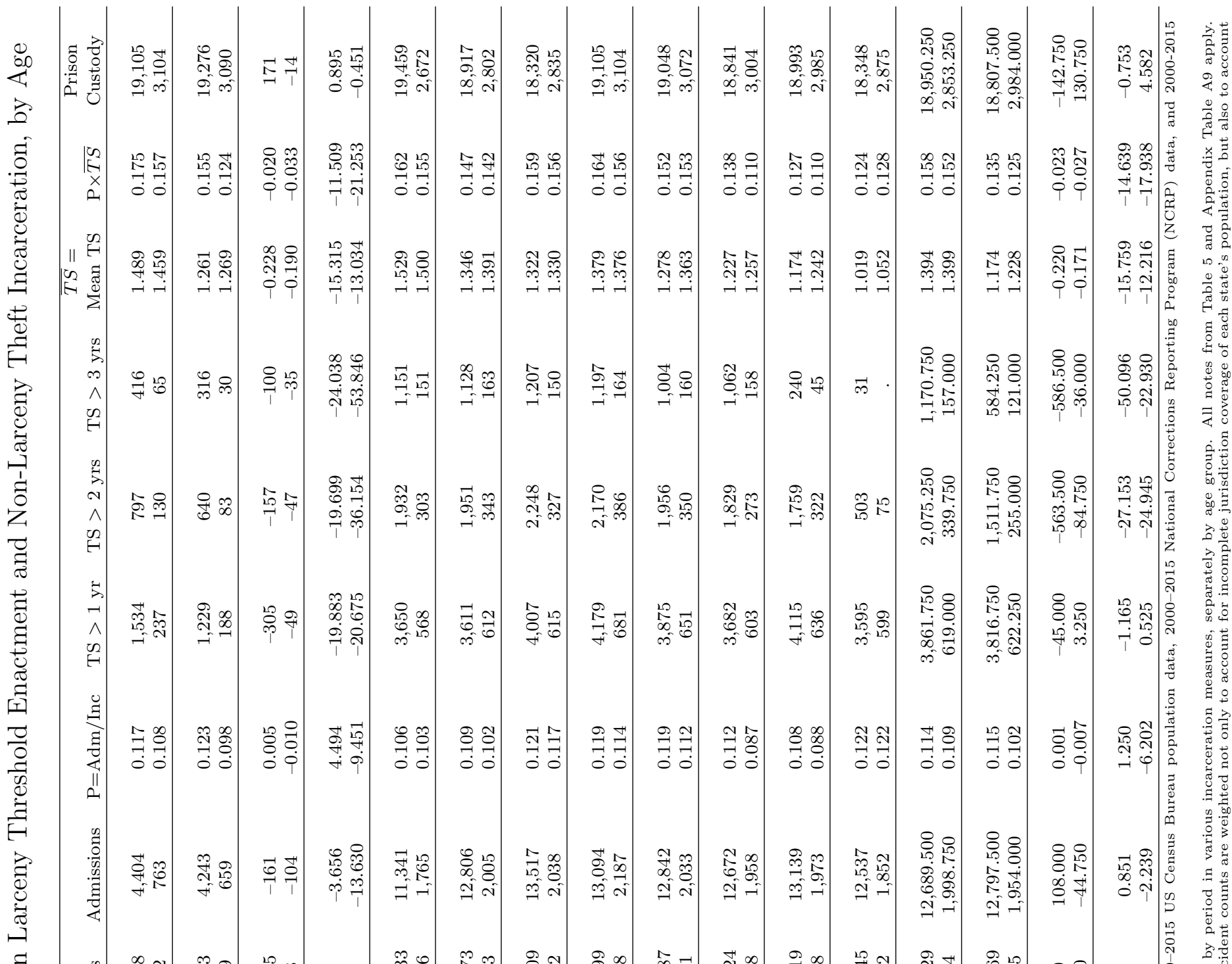

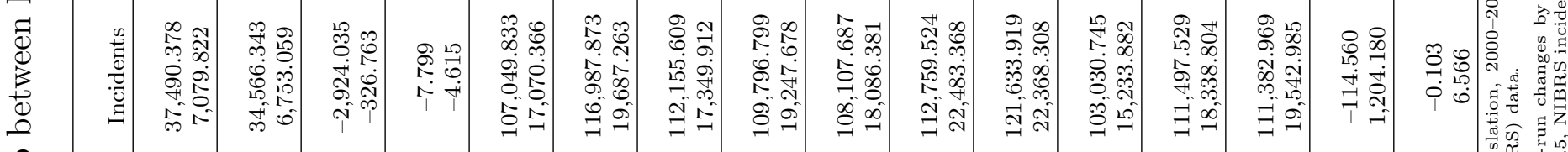

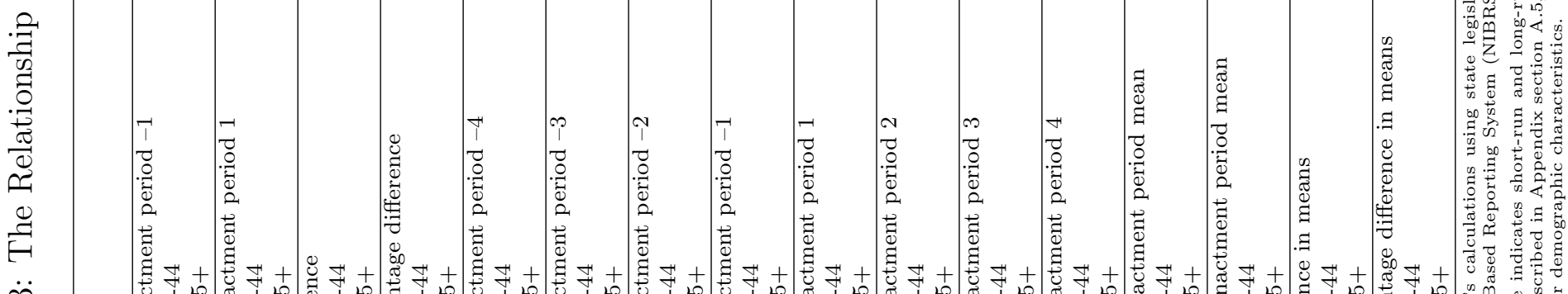

要

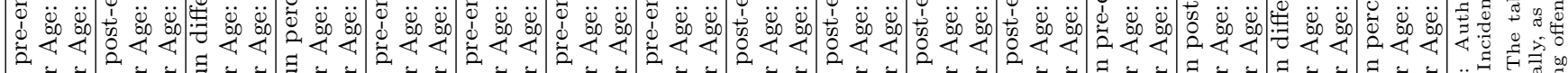

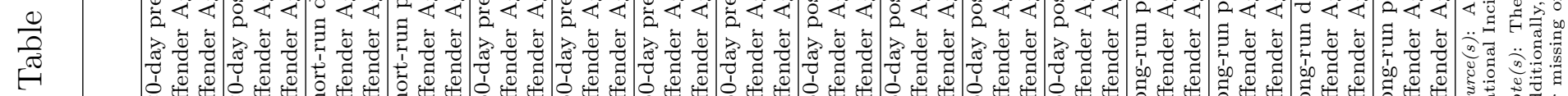

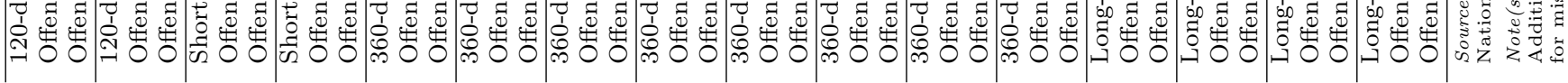




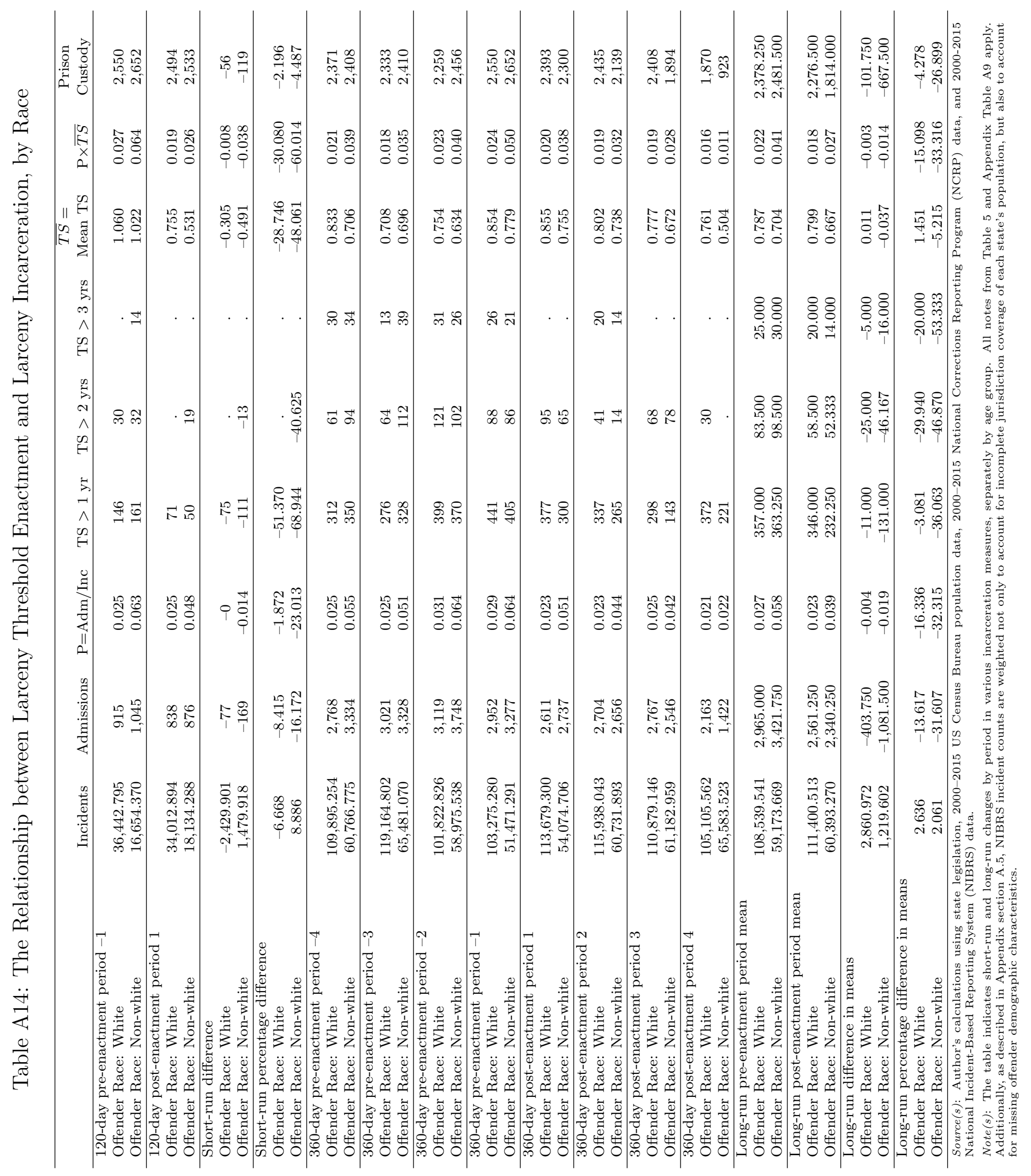




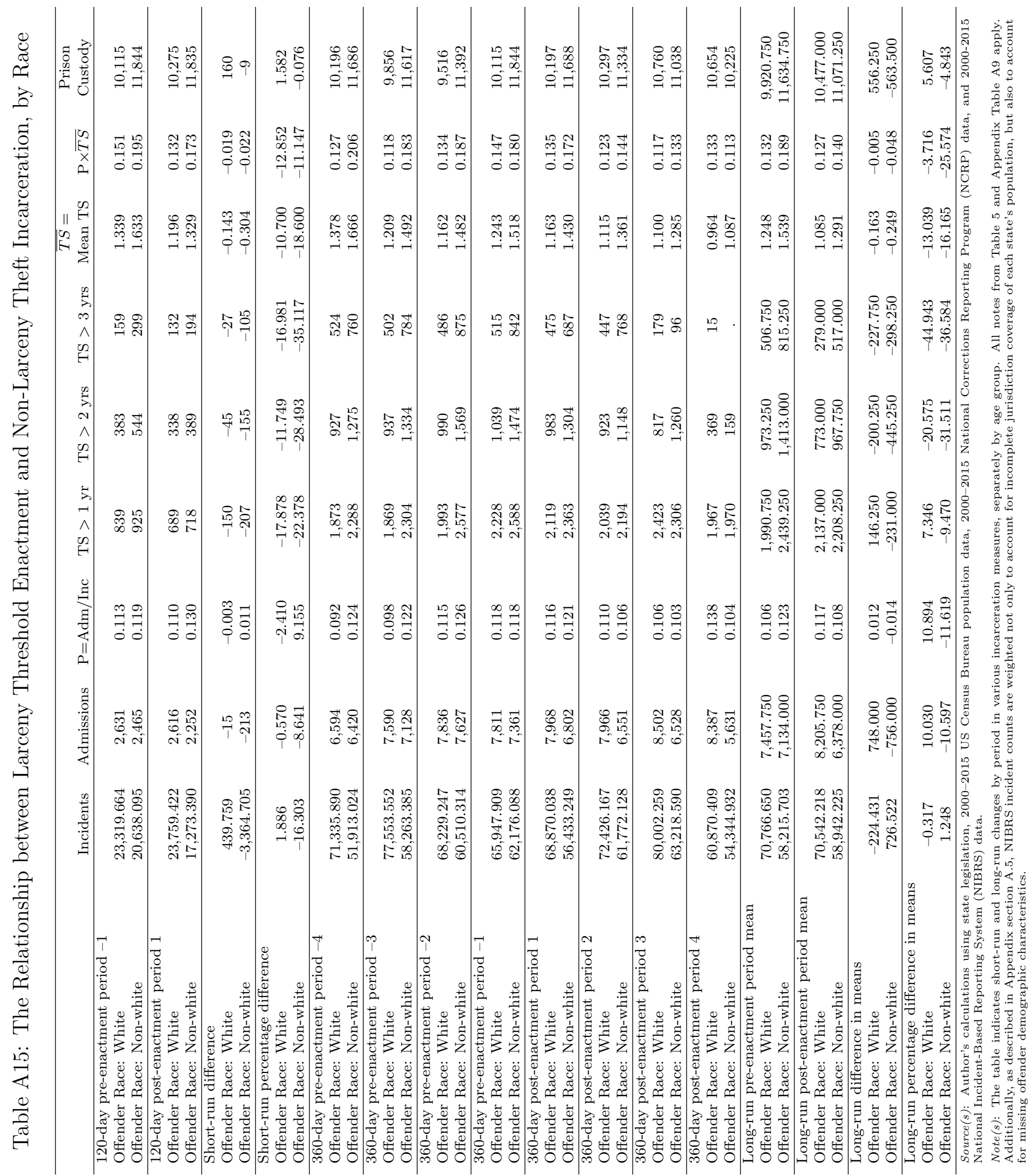




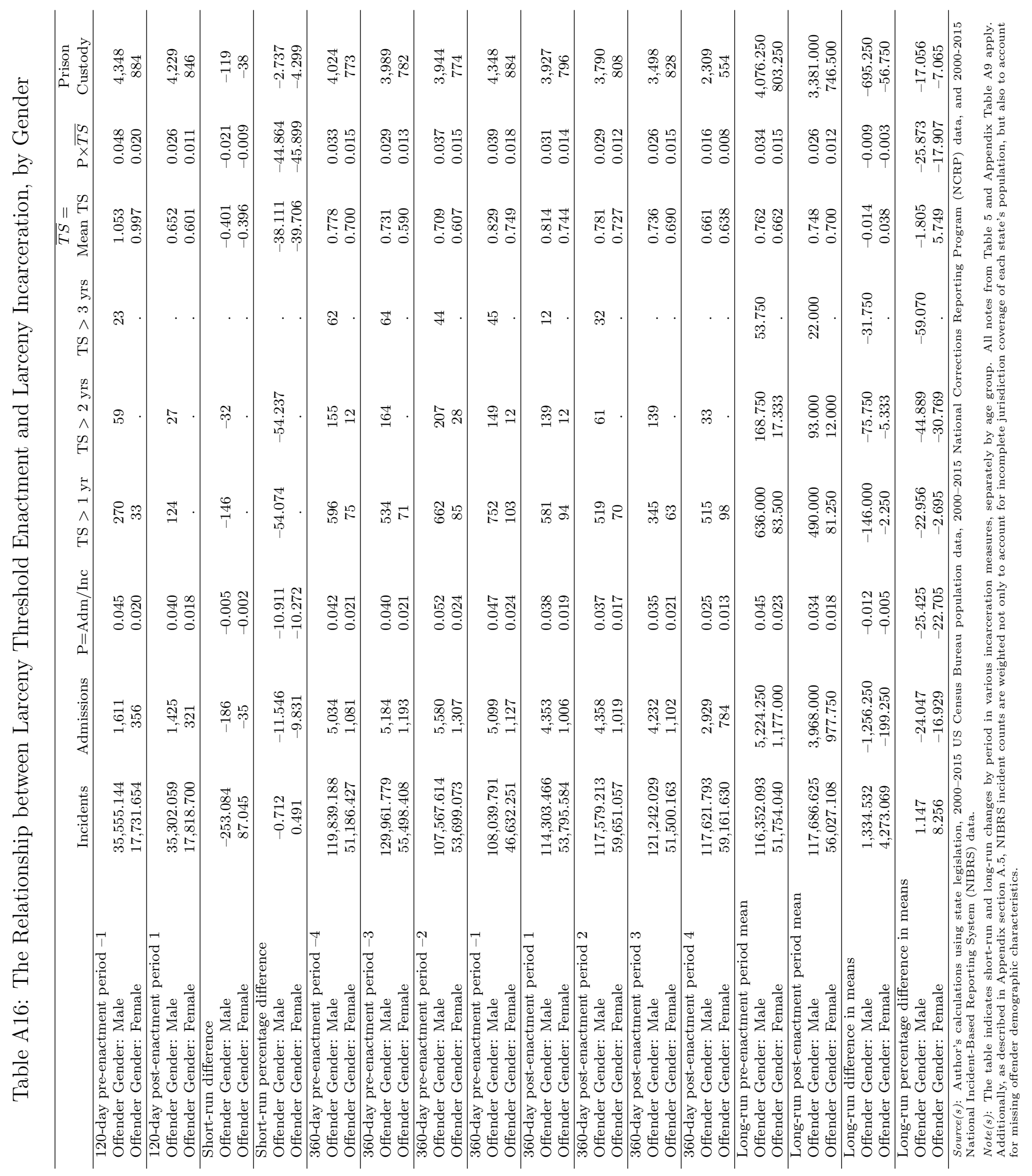




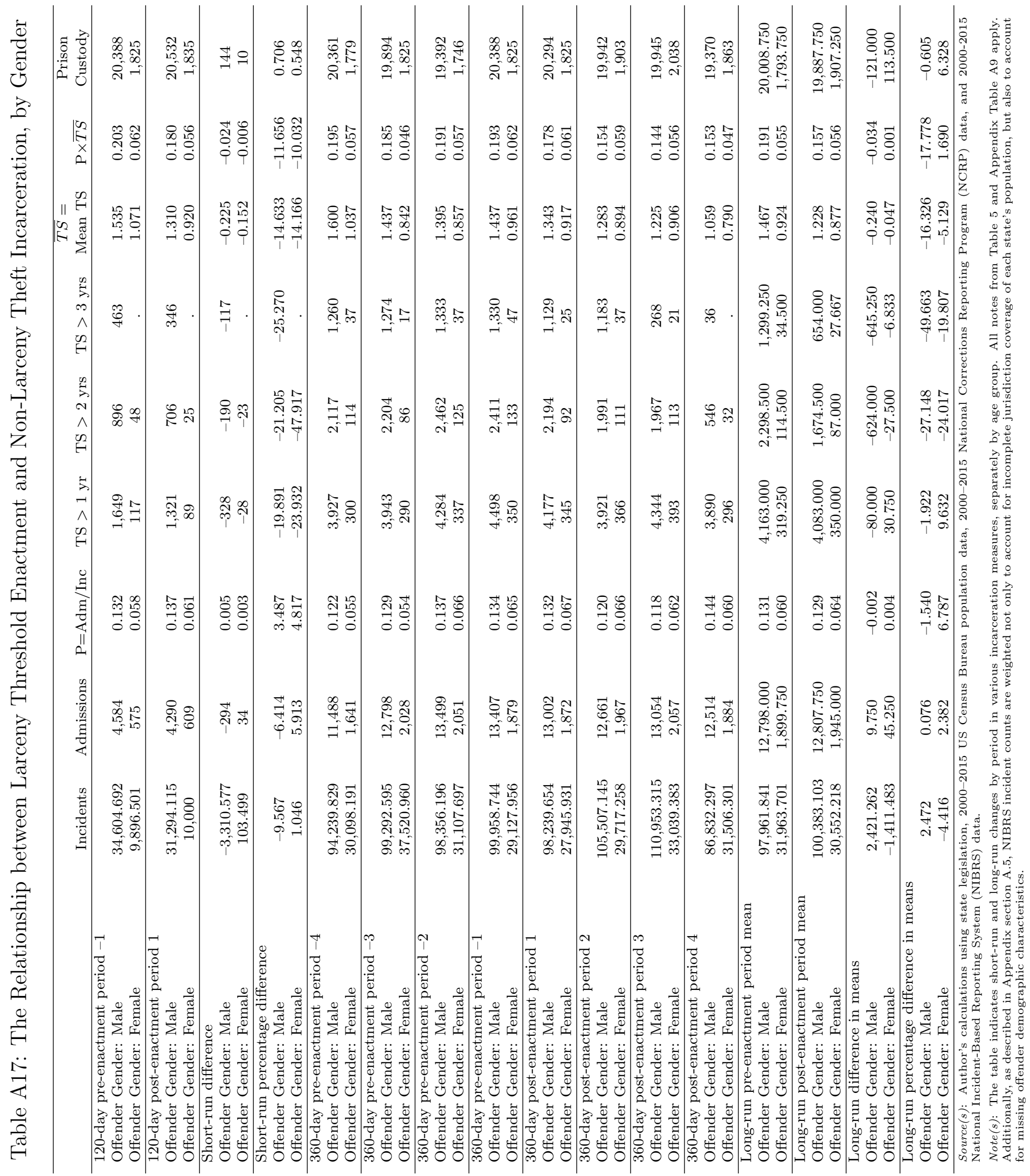




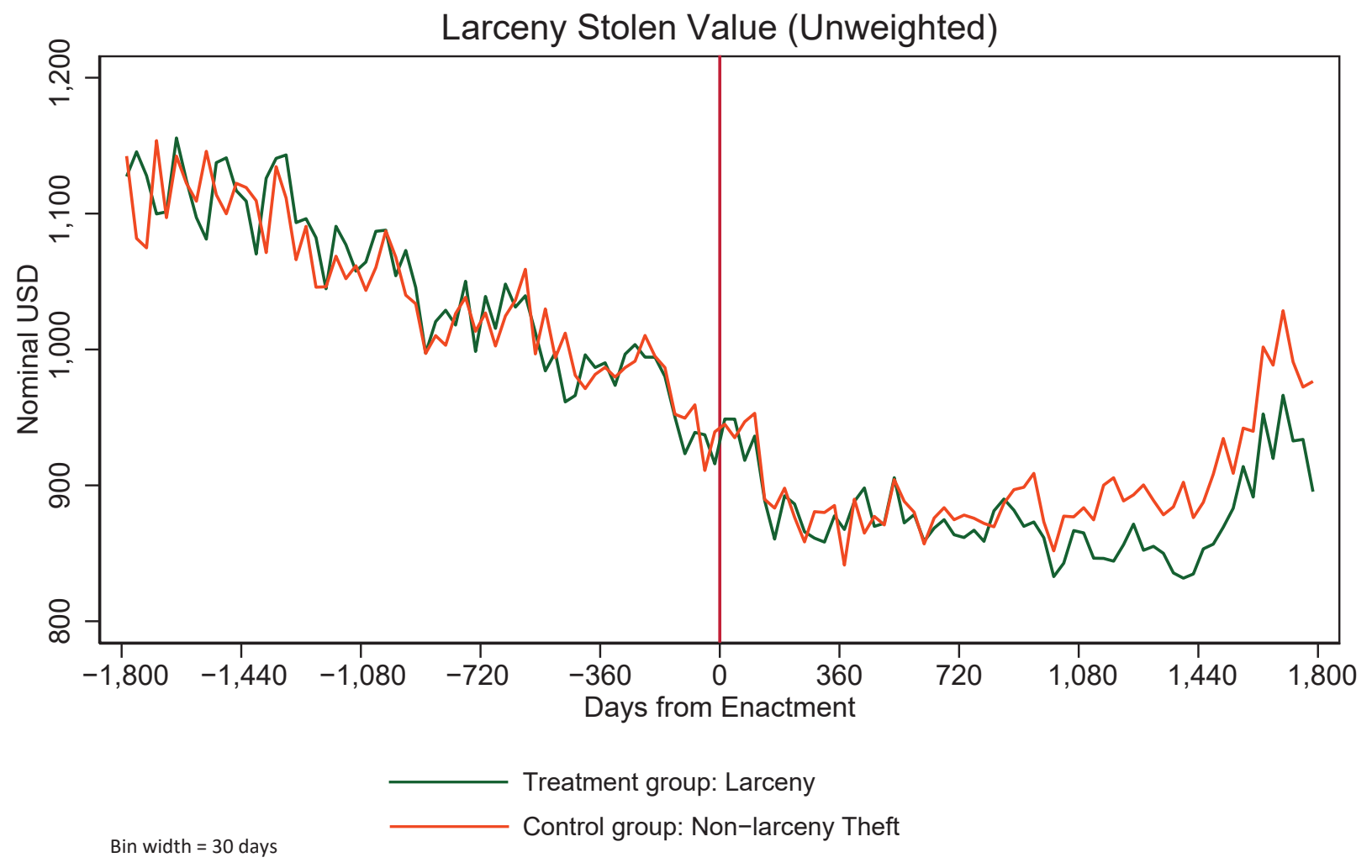

Figure A1: DD Plot-Larceny Stolen Value (Unweighted), excluding CO(2013) and WA Source(s): State legislation, National Incident-Based Reporting System data, and author's calculations. Note(s): Sample of state-enactment events excludes Colorado (2013) and Washington. 


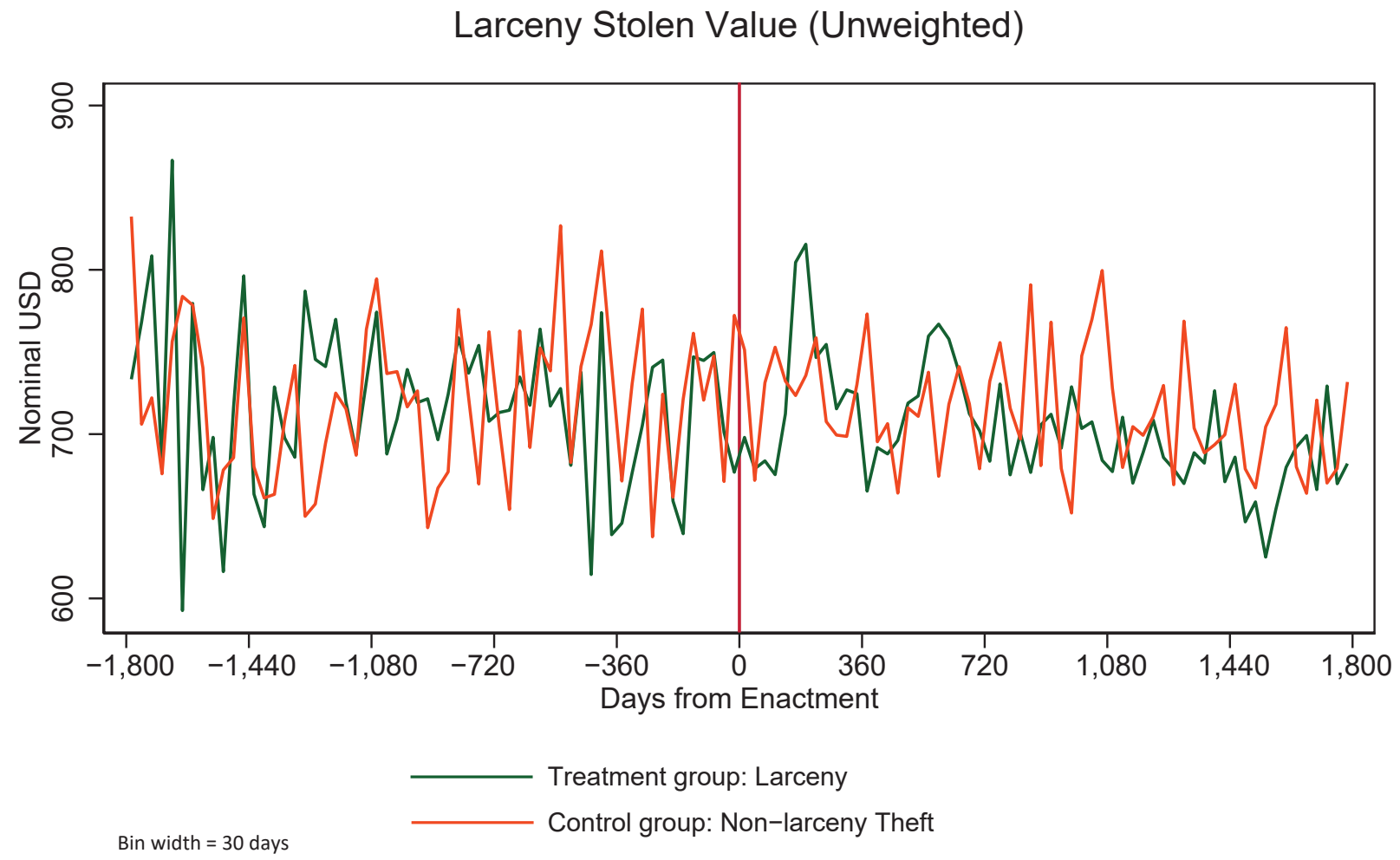

Figure A2: DD Plot-Larceny Stolen Value (Unweighted), New Hampshire Source(s): State legislation, National Incident-Based Reporting System data, and author's calculations. Note(s): Sample of state-enactment events is for New Hampshire only. 


\section{A.3 Regression Discontinuity Analysis}

\section{A.3.1 Assessing Optimal Bandwidth, Polynomial Order, and Bin Width}

Table A18: Optimal Bandwidth by Polynomial Order and Selection Method

\begin{tabular}{lccc}
\hline & MSERD & IK & CV \\
\hline Restrictions + exemptions & & & \\
Order 0 & 16 & 30 & 62 \\
Order 1 & 40 & 49 & 94 \\
Order 2 & 37 & 97 & 102 \\
Order 3 & 52 & 61 & 116 \\
Restrictions + no exemptions & & & \\
Order 0 & 20 & 69 & 72 \\
Order 1 & 39 & 64 & 94 \\
Order 2 & 53 & 73 & 108 \\
Order 3 & 56 & 84 & 112 \\
No restrictions + exemptions & & & \\
Order 0 & 10 & 27 & 62 \\
Order 1 & 29 & 36 & 68 \\
Order 2 & 42 & 71 & 96 \\
Order 3 & 61 & 62 & 110 \\
No restrictions + no exemptions & & & \\
Order 0 & 22 & 39 & 64 \\
Order 1 & 39 & 39 & 80 \\
Order 2 & 52 & 83 & 96 \\
Order 3 & 64 & 72 & 112 \\
\hline
\end{tabular}

Source(s): Author's calculations using state legislation and 2000-2015 National Incident-Based Reporting System data.

Note(s): "MSERD" reflects the mean squared error (MSE)-optimal bandwidth selector that is directly applicable to RD designs proposed by Calonico et al. (2017), rounded to the nearest integer. "IK" is the MSE-optimal bandwidth selector proposed by Imbens and Kalyanaraman (2012). "CV" is the MSEoptimal cross-validation bandwidth selector proposed by Ludwig and Miller (2007). The dependent variable is the larceny stolen property value per incident, the running variable is the number of days relative to enactment, and estimation uses a uniform kernel. Incidents underlying all regressions are limited to the "response region" of the theft value distribution between the old and new larceny thresholds applicable to a given jurisdiction-enactment event, plus a $\$ 1$ buffer. "Restrictions" indicates that the estimation sample additionally excludes incidents reflecting multiple charges, multiple property types, attempted offenses, and the listed date as the report date. "Exemptions" indicates that the sample additionally excludes statespecific felony larceny threshold exemptions. Further sample restrictions are detailed in the main text. The "Restrictions + exemptions" sample is used for primary analysis in the main text. 


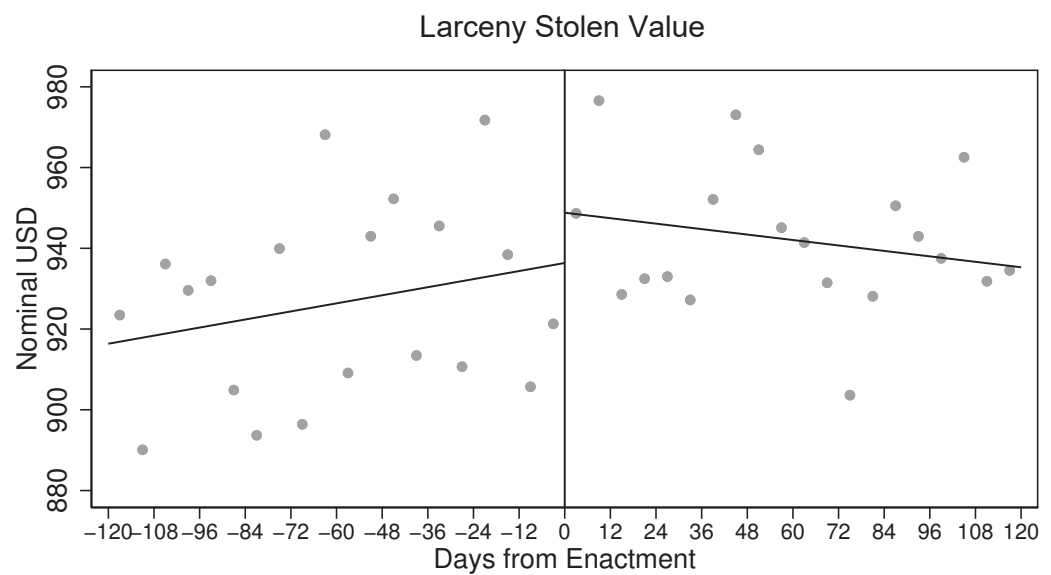

- Sample average within bin _ Polynomial fit of order 1

Bin width $=6$ days
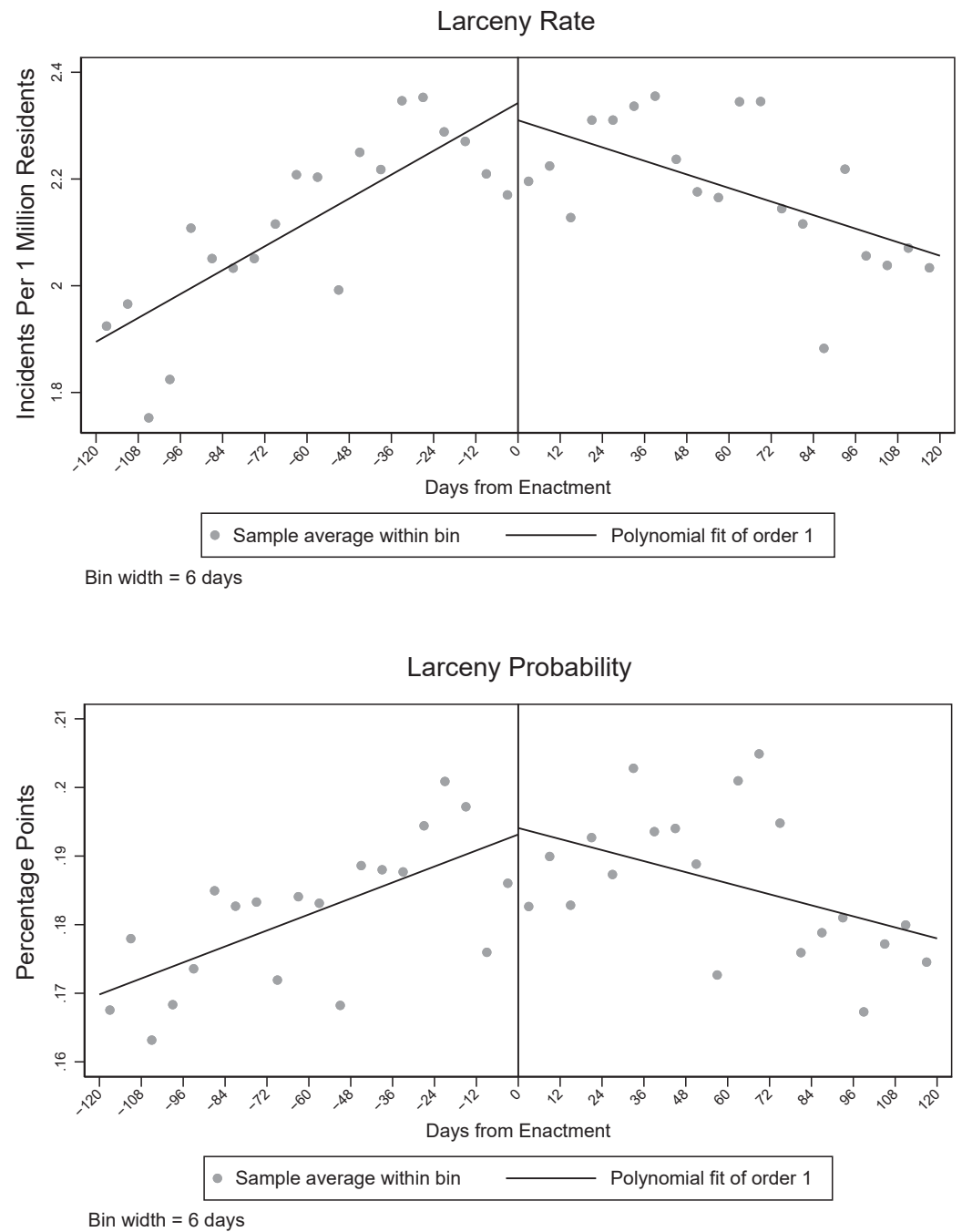

Figure A3: RD Plots - Larceny Stolen Value, Rate, and Probability (Alternative Bin Width) Source(s): State legislation, National Incident-Based Reporting System data, and author's calculations. 


\section{A.3.2 Assessing Validity of Regression Discontinuity Identification}

Table A19: The Short-Run Impact of Larceny Threshold Enactment on Offender Traits

\begin{tabular}{lcccccccc}
\hline & \multicolumn{8}{c}{ Offender Age } \\
& $0-17$ & $18-24$ & $25-34$ & $35-44$ & $45-54$ & $55-64$ & $65+$ & Missing \\
\hline Enactment & $0.003^{*}$ & -0.006 & 0.010 & -0.003 & 0.008 & $-0.008^{* *}$ & -0.002 & -0.002 \\
& $(0.002)$ & $(0.008)$ & $(0.009)$ & $(0.007)$ & $(0.008)$ & $(0.004)$ & $(0.002)$ & $(0.016)$ \\
R-sq & 0.07 & 0.15 & 0.13 & 0.12 & 0.14 & 0.11 & 0.11 & 0.18 \\
Observations & 22,556 & 22,556 & 22,556 & 22,556 & 22,556 & 22,556 & 22,556 & 22,556 \\
\hline \hline \multirow{8}{*}{ Offender Race } & \multicolumn{7}{c}{ Offender Gender } \\
& White & Black & Other & Missing & Female & Male & Missing \\
\hline Enactment & 0.014 & $-0.012^{*}$ & 0.003 & -0.005 & 0.004 & 0.001 & -0.005 \\
& $(0.015)$ & $(0.007)$ & $(0.003)$ & $(0.016)$ & $(0.010)$ & $(0.013)$ & $(0.015)$ & \\
R-sq & & & & & & & & \\
Observations & 22,556 & 22,556 & 22,556 & 22,556 & 22,556 & 22,556 & 22,556 & \\
\hline
\end{tabular}

* Significant at $10 \%$ level; ${ }^{* *}$ significant at $5 \%$ level; ${ }^{* * *}$ significant at $1 \%$ level.

Source(s): Author's calculations using state legislation and 2000-2015 National Incident-Based Reporting System data.

Note(s): Each column displays an estimate from an OLS regression of a binary indicator for an offender characteristic on a binary indicator for felony larceny threshold enactment, as noted. Observations are incidents. The offender characteristics examined refer to the first (and often only) offender associated with an incident. All regressions include a running variable for the number of days relative to enactment, as well as the running variable interacted with the enactment indicator. The estimation samples exclude incidents reflecting multiple charges, multiple property types, attempted offenses, the listed date as the report date, and state-specific felony larceny threshold exemptions. All regressions also include indicators for jurisdiction $\times$ year $\times$ quarter, day of week, first of month, major holiday, and a constant. Singleton observations within a given fixed effect indicator are dropped. The kernel is uniform. The regression discontinuity bandwidth for estimation is 120 days surrounding the day of enactment. Incidents underlying regressions are limited to the "response region" of the theft value distribution between the old and new larceny thresholds applicable to a given jurisdiction-enactment event, plus a $\$ 1$ buffer. Further sample restrictions are detailed in the text. Standard errors clustered by jurisdiction are in parentheses. 


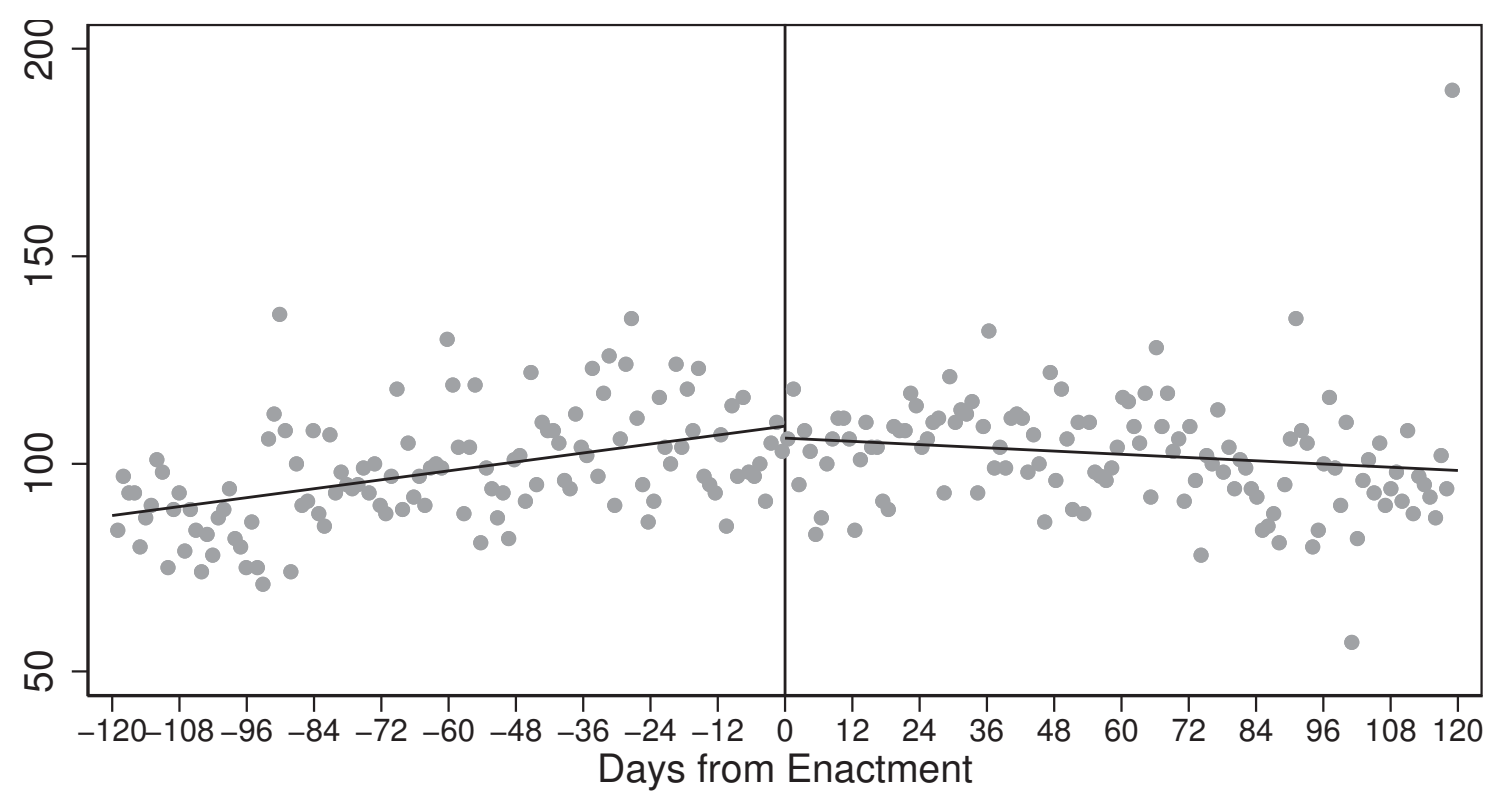

- Sample average within bin $\quad$ Polynomial fit of order 1

Bin width = 1 day

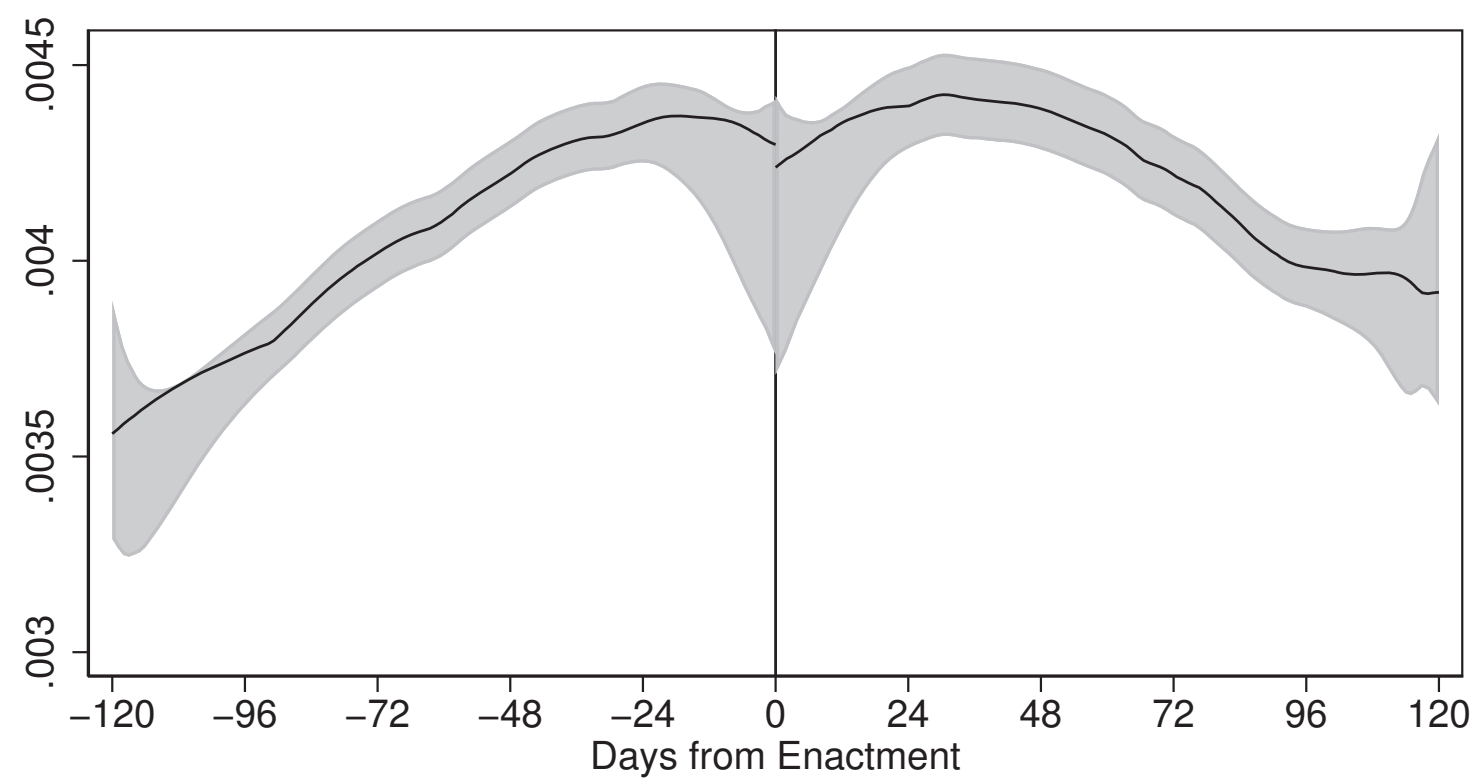

Bin width $=1$ day

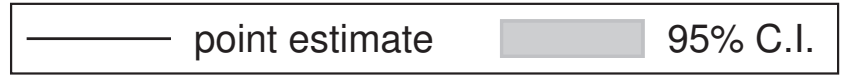

$p$-value for bias-corrected density test $=0.879$

Figure A4: RD Density of Incidents Around Enactment (Ocular and CJM Tests) Source(s): State legislation, National Incident-Based Reporting System data, and author's calculations. Note(s): Lower plot reflects Cattaneo, Jansson, and Ma (2018) density test. 


\section{A.4 Difference-in-Differences Analysis}

\section{A.4.1 Inverse Probability Weighting}

In difference-in-differences estimation, I use inverse probability weights to help adjust for nonrandom selection into treatment (that is, being a larceny rather than a non-larceny theft) based on observable characteristics. To generate these inverse probability weights, I first run a linear probability model (LPM) at the incident level on a pre-enactment sample of incidents with the full set of restrictions discussed in the main text (including restricting stolen values to the response region plus a $\$ 1$ buffer). The dependent variable is an indicator for a larceny incident, as opposed to a non-larceny theft incident. The independent variables are first-of-month indicators, major holiday indicators, day-of-week indicators, and jurisdiction indicators. These variables correspond directly to the covariates in estimation, but are now time-invariant in the case of jurisdiction indicators (rather than jurisdiction-year-quarter indicators).

Following LPM estimation, I drop from the sample any jurisdictions that were excluded from estimation as a result of being singletons in estimation. I then generate predicted probabilities. These are the propensity scores, $p$, which are predicted out of sample for the post-enactment period. ${ }^{61}$ To help ensure comparability of larceny and non-larceny theft incidents, I compare the distribution of $p$ for the treatment and control groups. I then impose common support restrictions using a "min-max" criteria - that is, I drop $p$ if it is at or above the smaller upper bound of the two DD groups (0.950) or if $p$ is at or below the higher lower bound of the two DD groups (0.250).

With the resulting sample, I generate inverse probability weights, $w$, which take on distinct values for the treatment group, $T$, and the control group, $C: w_{T}=1 / p$ and $w_{C}=1 /(1-p)$. If a larceny incident in the treatment group has observable characteristics similar to those of a typical non-larceny theft incident in the control group, this larceny incident will likely receive a lower propensity score, $p$, and thus a higher inverse probability weight, $w_{T}$. Likewise, if a non-larceny incident in the control group has observable characteristics similar to those of a larceny incident in the treatment group, the non-larceny theft incident will tend to receive a higher propensity score, $p$, and thus a higher inverse probability weight, $w_{C}$. Thus, treatment and control group observations that appear observably similar to observations in the other DD group receive a higher inverse probability weight, and observations that appear observably dissimilar receive a lower inverse probability weight.

Weighting incidents by these generated inverse probability weights yields estimates of the average treatment effect (ATE), which is the desired parameter for DD estimates, since the RD design yields estimates of the local average treatment effect (LATE), where "local" refers to the enactment cutoff. Thus, I would like DD estimates to reflect the ATE so that when the pre-enactment and post-enactment periods are constrained, DD may similarly capture

\footnotetext{
${ }^{61}$ I examine sensitivity of the baseline model to different combinations of the regressors. Most of the variation in the baseline model's propensity scores is driven by the jurisdiction indicators. Alternative LPM estimation with only jurisdiction indicators yields propensity scores that have an extremely high correlation of 0.99 with those of the baseline model, and both models have R-squared values of 0.04. Similarly, an LPM model with a full set of interaction terms between each pair of regressors has an R-squared value of 0.07, and generates propensity scores that have a fairly high correlation of 0.65 with propensity scores from the baseline model.
} 
an ATE that is local to the enactment cutoff, thereby enabling a direct comparison with the RD LATE estimate and serving as an informal assessment of the validity of the DD approach (see Appendix Table A6).

To generate inverse-probability-weighted crime rate and probability measures at the jurisdiction-day level (separately for larceny and non-larceny theft), I first start with the set of incidents underlying the RD rate and probability estimation and redo the steps above. Such repetition is necessary, because the jurisdictions dropped due to estimation singletons in the RD stolen value analysis differ from those dropped in the RD rate and probability analysis. The common support restrictions here, once again using a "min-max" criteria, result in dropping $p$ if it is at or above the smaller upper bound of the two DD groups (0.975), or if $p$ is at or below the higher lower bound of the two DD groups (0.125). With the rate and probability-specific inverse probability weights now generated, I aggregate up to crime rate and probability outcomes.

For the crime rate, rather than aggregating raw incident counts within a jurisdiction-day as an unweighted sum, I aggregate incidents as a weighted sum using the inverse probability weights to rescale incidents. This adjusted count forms the numerator of the "inverseprobability-weighted crime rate." This variable can be interpreted as a re-weighted count of incidents that places greater weight on "marginal" incidents that, based on observables, would not be predicted to belong to their observed DD group (larceny or non-larceny theft). The rate denominator (annual jurisdiction population) and weighting of the rate in estimation (using annual jurisdiction population) proceed as usual.

For the crime probability, rather than generating a binary indicator of crime occurrence within a jurisdiction-day, I take the maximum of the inverse probability weight. This maximum equals 0 on jurisdiction-days with no incidents. Because this measure is not bounded between 0 and 1, I then rescale each jurisdiction-day value of this variable by the maximum value of the variable across all jurisdiction-days for the given crime type. This "inverse-probability-weighted crime probability" measure can be interpreted as a re-weighted probability of incidents, normalized to the jurisdiction-day with the maximum value of that measure, and with greater weight placed on "marginal" incidents once again. This measure is then weighted in estimation as usual using the annual jurisdiction population. 


\section{A.4.2 Assessing Validity of Difference-in-Differences Identification}

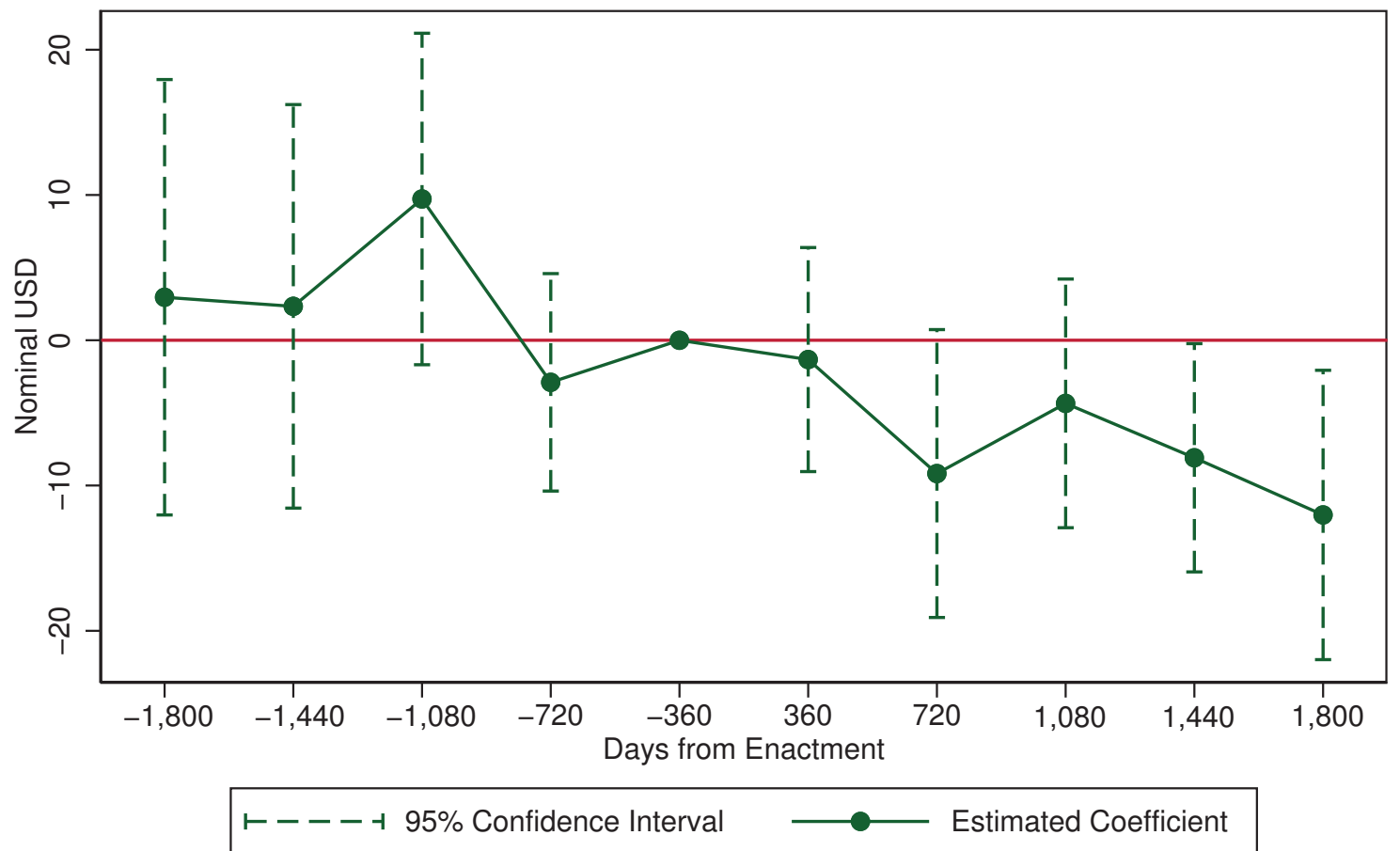

Figure A5: Testing DD Pre-Period Parallel Trends (Larceny Stolen Value, IPW)

Source(s): State legislation, National Incident-Based Reporting System data, and author's calculations. 


\section{A.5 NCRP-Related Analysis}

\section{A.5.1 Creating the Joint NIBRS-NCRP Data Sample}

As noted in the main text, for NIBRS-NCRP analysis, I also determine updated NIBRS sample restrictions that are feasible to impose in the NCRP data given available information, and I specify observation "cell" dimensions to allow for alignment of the NIBRS and NCRP data by offense type, area, time period, and offender demographic group.

Regarding updated NIBRS sample restrictions, I do not impose the following conditions used in the NIBRS primary analysis: (a) all six jurisdiction-related criteria, described earlier; (b) incidents involving thefts being limited to the response region; (c) excluding incidents with the listed date being the report date (as opposed to the incident date); (d) excluding incidents that reflect multiple property types; (e) excluding incidents with a theft where the stolen property is unidentified; (f) excluding larceny incidents in each state-enactment event that are exempt from larceny threshold policy (however, I still impose exemption restrictions for motor vehicles [except for Rhode Island, since this exemption applies to watercraft and I cannot differentiate such vehicles in the NCRP data] and juvenile delinquency with statespecific age thresholds); and (g) excluding outlier larceny incidents in South Carolina (2001) and Louisiana (2011).

Regarding observation cell dimensions, for offense type, I focus on larceny and non-larceny theft. For area, there is a mapping between the jurisdiction where an incident occurs and the locations of subsequent stages of the criminal justice system, including prison location. However, given some uncertainty regarding this mapping, as well as missing NCRP data values at sub-state geographies, I rely on states as areas and use multiple NCRP variables to determine the applicable state designation. ${ }^{62}$ For time period, I would ideally inform this choice with information regarding the distribution of timing in the criminal justice system between incidents and prison admission. Absent such information, a BJS felony sentencing report in the baseline year, 2000, notes that the median time between arrest and sentencing for persons convicted of a larceny felony in state courts is 134 days, with 88 percent of persons sentenced within one year (Durose and Langan 2003). Thus, I focus on periods relative to enactment that are 120 days and 360 days, presuming roughly 50 percent and 88 percent alignment, respectively, of NIBRS incidents and NCRP admissions. Lastly, for offender demographic groups, I focus on binary categories for race (white and non-white), age (between 0 and 44 years old and 45 years old and over), and gender (male and female), as well as all persons.

\section{A.5.2 Reweighting NIBRS Data}

While the NCRP data reflect statewide corrections information each year, the NIBRS data do not correspond to statewide data since reporting jurisdictions reflect incomplete coverage of the state population. To rescale NIBRS incident counts, I first take the state-specific sum of the covered population across included jurisdictions in a given time period (120-day or 360-day). The relevant population is the unweighted average across all calendar years in

\footnotetext{
${ }^{62}$ In order of priority, to fill in missing values as needed, I use (a) the state corresponding to the county where the court imposing the current sentence is located, (b) the state with the legal authority to enforce the prison sentence, and (c) the state that provided data to NCRP.
} 
which the jurisdiction has incident data for a given period. ${ }^{63}$ This value is the population weight numerator. I then use the total state population in the year 2000 (the baseline year of the 2000-2015 sample period) from the US Census as the population weight denominator. Thus, the population weight is the share of each state's total baseline population that is covered by jurisdictions for which there are incident data in a given state-period. I then divide every incident count in a state-period by its corresponding population weight. Such weighted incident counts by state-period are used to form the justice system severity proxies in Table 4. For Table 5, I further aggregate these weighted state-period incident counts across states to obtain weighted "national" counts in each period for the sample of state-enactment events in the NIBRS-NCRP balanced panel.

For the demographic subgroup analogs of Table 5 discussed in the main text and Appendix Tables A12 through A17, I additionally weight the NIBRS incident data to account for missing offender demographic characteristics in both the NIBRS and NCRP data. For every demographic subgroup, time period, and incident type, let $m$ be the weight to adjust for missing demographic information. The numerator of $m$ is the incident count by demographic subgroup, period, and incident type, divided by the incident count by period and incident type. The denominator of $m$ is the admissions count by demographic subgroup, period, and incident type, divided by the admissions count by period and incident type. Thus, weight $m$ takes into account the prevalence of missing demographic information in both NIBRS and NCRP data in order to rescale NIBRS incidents to values that correspond to NCRP admissions. This approach is logistically easier than adjusting both NIBRS and NCRP data while still achieving the same outcome. By construction, after weighting, calculations of aggregated (across demographic subgroup values) admissions per incident values in Appendix Tables A12 through A17 match the corresponding admissions per incident values in Table 5.

\section{A.5.3 NIBRS-NCRP Regression Analysis}

I also run regression analogs of the descriptive analysis in section 7 that examines how incarceration-related outcomes change across enactment. Such regressions allow for the inclusion of area (state) fixed effects for short-run (SR) and long-run (LR) analysis, and for LR analysis, time (period) fixed effects as well. Accordingly, given these controls, the regression $\mathrm{SR}$ and $\mathrm{LR}$ samples of state-enactment events can be permitted to be larger than the balanced SR and LR samples in the Table 5 descriptive analysis (but no larger than the main NIBRS causal analysis sample in the paper), thus allowing for a broader interpretation of the results. However, compared with the main NIBRS causal analysis, such NIBRS-NCRP regression analysis has more limited controls and restricted variation in outcomes due to aggregation to state $\times$ period $\times$ offense type observations. Thus, while the resulting analysis of conditional means has value, conservatively, I do not interpret such estimates as definitively causal and therefore opt for the basic descriptive analysis in section 7 as preferred.

\footnotetext{
${ }^{63}$ Thus, when event time is wholly contained within one calendar year or spans two calendar years but with incident data in only one calendar year, the resulting population reflects only one calendar year. But when event time spans two calendar years with incident data in both years, the resulting population is the unweighted average jurisdiction population across the two calendar years.
} 
Regarding SR analysis, for state $s$ and 120-day period $p$, I can estimate via OLS the reduced form relationship between larceny threshold enactment and incarceration-related outcomes $Y$ :

$$
Y_{s p}=\alpha+\pi E N A C T_{s p}+\theta_{s}+\mu_{s p},
$$

where the examined time range for every state-enactment event is 120 days, or one period, surrounding enactment. ENACT is a binary indicator equal to 1 for the 120-day period in a state on or after enactment, $\theta$ reflects state fixed effects, and I cluster standard errors at the state level. The parameter of interest is $\pi$, which indicates the relationship between raising the area larceny threshold and justice system severity or incarceration within 120 days of enactment. Given the absence of higher-frequency variation in the incarceration-related outcomes, it is not feasible to include a running variable in estimation as in NIBRS causal RD analysis. Thus, while equation (16) reflects short-run analysis, it is not an RD design.

Regarding LR analysis using a DD approach, for state $s$ and 360-day period $t$, I can once again estimate via OLS the reduced form relationship between larceny threshold enactment and incarceration-related outcomes $Y$ :

$$
Y_{s t}=\zeta+\eta E N A C T_{s t}+\lambda L A R C E N Y_{s t}+\pi\left(E N A C T_{s t} \times L A R C E N Y_{s t}\right)+\omega_{s}+\psi_{t}+\nu_{s t},
$$

where $E N A C T$ is a binary indicator equal to 1 for the 360-day period in a state on or after enactment, $L A R C E N Y$ is a binary indicator equal to 1 for observations reflecting larceny outcomes (the DD treatment group) rather than non-larceny theft outcomes (the DD control group), $\omega$ reflects state fixed effects, $\psi$ captures period fixed effects, and once again, I cluster standard errors at the state level. ${ }^{64}$ I am unable to incorporate inverse probability weighting as in the NIBRS causal DD analysis given limited variation in the incarceration-related outcomes. However, in an F test, I cannot reject pre-period parallel trends for unweighted average outcomes, thus mitigating the need for inverse probability weighting.

Unlike NIBRS causal analysis and guided by Solon, Haider, and Wooldridge (2015), I do not weight analysis by area population - for instance, average annual state population during the estimation period — as such weighted estimation tends to yield qualitatively similar estimates but often worsens precision. However, Solon, Haider, and Wooldridge (2015) suggest an alternative form of weighting in this context that is motivated by a factor other than potential heteroskedasticity. Because the descriptive analysis in Table 5 reflects values aggregated across several states at a given point in time, the resulting reported statistics, when they are ratios, are implicitly weighted by denominator values. Such reasoning therefore applies to the justice system severity proxies, admissions per incident, and mean time served per incident. Thus, if there is any heterogeneity in the relationship between enactment and justice system severity along this incident denominator dimension, regression analysis that does not incorporate such heterogeneity will fail to match the Table 5 results quantitatively and perhaps even qualitatively.

Solon, Haider, and Wooldridge (2015), in discussing how to identify average partial effects, provide guidance for incorporating the aforementioned incident-driven heterogeneity in order to align justice system severity patterns in Table 5 with analogous regression anal-

\footnotetext{
${ }^{64}$ Because Colorado and Louisiana each have two enactment dates during the estimation period, I define the pre-period and post-period in each case as in the NIBRS causal DD analysis.
} 
ysis. First, for each justice system severity regression specification, I calculate a state $\times$ period $\times$ offense type (larceny or non-larceny theft) measure, $X$, reflecting the number of incidents underlying the observation. Next, for each offense type across all state $\times$ period observations, I calculate the median value, $M$, of each measure, $X$. I then generate a dummy variable, $D$, indicating whether a given state $\times$ period $\times$ offense type measure, $X$, is greater than the applicable median, $M$. I include $D$ as an additional regressor in the NIBRS-NCRP regression analysis and examine heterogeneity by $D$ using a similar approach as in the NIBRS causal analysis. If $\beta$ reflects the coefficient of the enactment relationship regressor(s) (that is, ENACT in SR analysis and ENACT $\times L A R C E N Y$ in LR analysis) interacted with the incident indicator, $D$, and $S$ reflects the share of state $\times$ period $\times$ offense type observations in a given specification where $D=1$, then the transformed justice system severity relationship of interest in such specifications is $\tau=\pi+S \beta$. In justice system severity regression specifications, $\tau$ should more closely align with corresponding statistics in Table 5. Meanwhile, for the offenders in custody outcome measure, if $N$ reflects the number of states in each specification, then the transformed offenders in custody relationship of interest in such specifications is $\tau=N \pi{ }^{65}$

Appendix Tables A10 and A11 display the results from SR and LR NIBRS-NCRP regression analysis, respectively. The tables show that, conditional on restricting the regression sample to align with the analogous descriptive analysis balanced sample and focusing on the transformed regression relationships, I mostly obtain the same qualitative patterns. Specifically, the signs of the SR and LR transformed regression associations, as well as relative SR versus LR magnitudes, often match the descriptive analysis. ${ }^{66}$

From this starting point, I then examine the impact on the results of including limited controls and expanding the sample of state-enactment events. Appendix Tables A10 and A11 show that with such adjustments, the signs and relative magnitudes of the SR and LR transformed regression associations sometimes match the descriptive analysis patterns but not always. Examining specifications that include controls or use the full sample of states but not both, I find that the differing regression results tend to be driven by the change in the sample of states and related heterogeneity along that dimension, rather than explained by the inclusion of controls.

\footnotetext{
${ }^{65}$ Such a transformation helps align regression analysis for this outcome with descriptive analysis, since in each period, the latter aggregates offenders in custody across the states in the balanced panel sample.

${ }^{66}$ Obtaining the exact same qualitative and quantitative patterns in the regression analysis as the descriptive analysis would require capturing the relevant underlying heterogeneity exactly, as opposed to approximating such heterogeneity, as I currently do using the variables $D, S$, and $N$.
} 